Universidad de Lima

Facultad de Ingeniería y Arquitectura

Carrera de Ingeniería Industrial

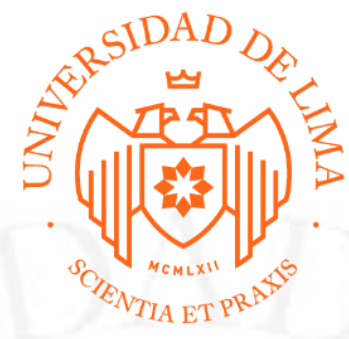

\title{
MEJORA EN GESTIÓN DE LA SEGURIDAD OPERACIONAL EN LA LÍNEA 1 DEL METRO DE LIMA
}

Trabajo de suficiencia profesional para optar el Título Profesional de Ingeniero Industrial

\section{David Jean Maticorena Cabrera}

Código 19981135

\section{Asesor}

Carlos Medardo Urbina Rivera

$$
\text { Lima - Perú }
$$

Setiembre de 2019 


\section{IMPROVEMENT IN OPERATIONAL SAFETY MANAGEMENT IN LÍNEA 1 IN METRO DE \\ LIMA}




\section{TABLA DE CONTENIDOS}

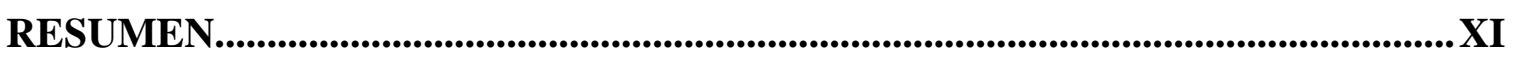

ABSTRACT ..............................................................................................................XII

CAPÍTULO I: ANTECEDENTES DE LA EMPRESA .................................................1

1.1. Breve descripción de la Línea 1 del Metro de Lima......................................... 1

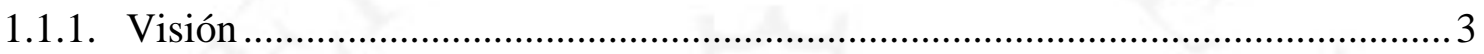

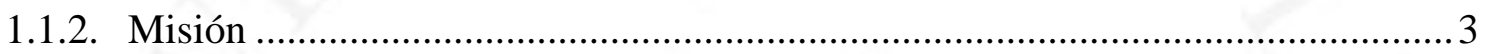

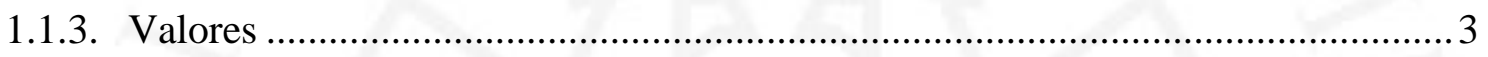

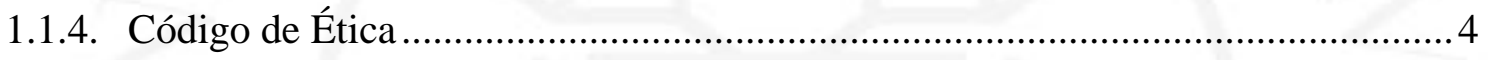

1.2. Descripción de la empresa operadora de la Línea 1 ........................................ 4

1.3. Análisis del sector, modelo de las cinco fuerzas competitivas. ............................5

1.4. Matriz de Evaluación de Factores Externos MEFE.......................................... 9

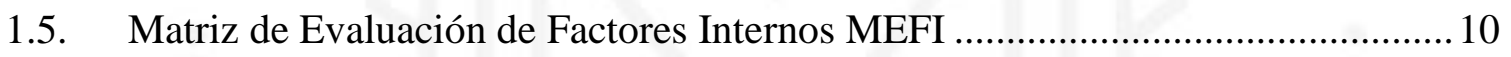

1.6. Matriz Fortalezas Oportunidades Debilidades Amenazas (FODA)...................... 11

1.7. Descripción del problemática actual …....................................................... 12

CAPÍTULO II: OBJETIVOS Y ALCANCE DE LA INVESTIGACIÓN .................. 16

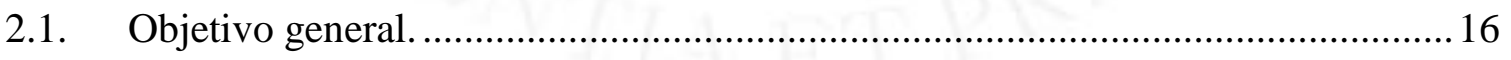

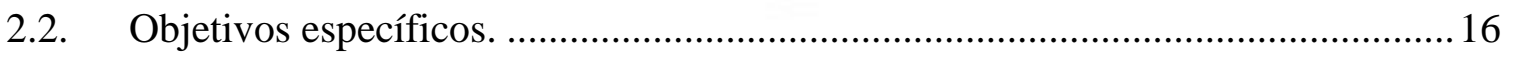

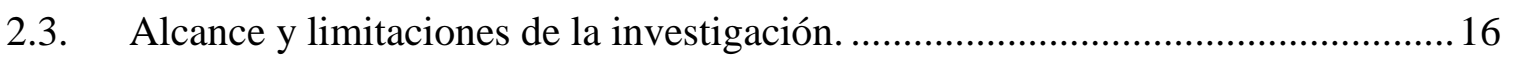

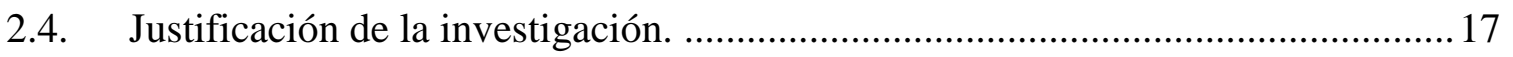

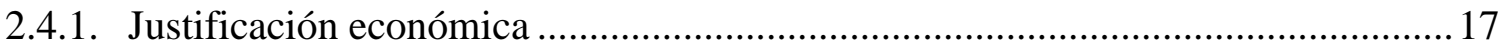

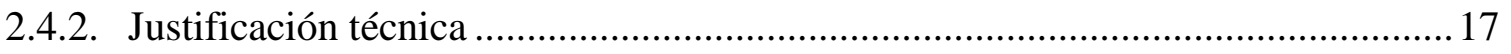




\section{CAPÍTULO III: DIAGNÓSTICO DEL SISTEMA O PROCESO OBJETO DE} ESTUDIO

3.1. Análisis del sistema o proceso objeto de estudio ............................................... 18

3.1.1. Descripción detallada del sistema o proceso objeto de estudio. ........................... 18

3.1.2. Análisis de los indicadores específicos de desempeño del sistema o proceso.......39

3.2. Determinación de las causas raíz de los problemas hallados ............................... 42

CAPÍTULO IV: DETERMINACIÓN DE LA PROPUESTA DE SOLUCIÓN ........47

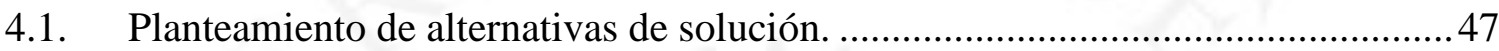

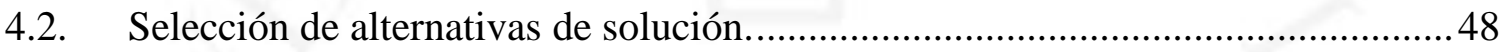

4.2.1. Determinación y ponderación de criterios evaluación de las alternativas. ............48

4.2.2. Evaluación cualitativa y/o cuantitativa de alternativas de solución......................49

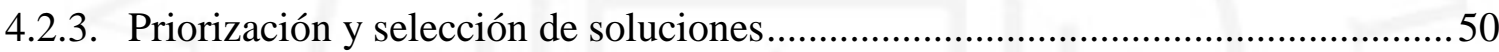

\section{CAPÍTULO V: DESARROLLO, PLANIFICACIÓN Y RESULTADOS}

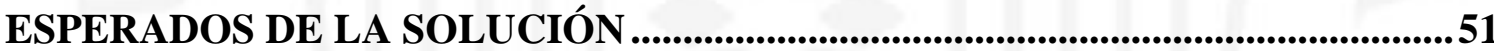

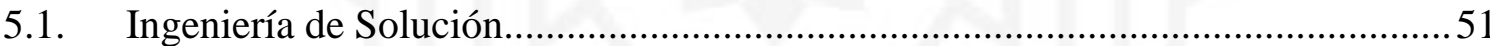

5.1.1. Implementación de un sistema de gestión de seguridad operacional en base a normas internacionales

5.1.2. Optimización de los tiempos de respuesta del servicio de Primeros Auxilios Avanzados .52

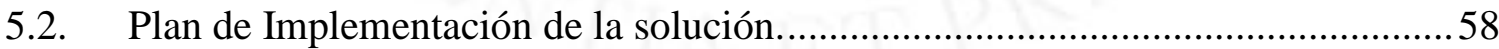

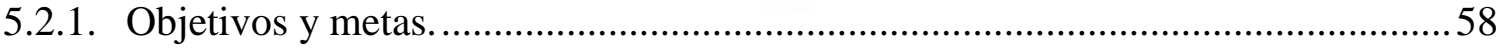

5.2.2. Elaboración del presupuesto requerido para la ejecución de la solución...............58

5.2.3. Actividades y cronograma de implementación de la solución............................... 60

5.3. Evaluación de la solución y análisis costo beneficio ..........................................63

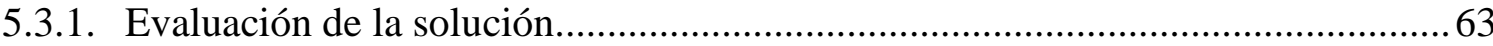


CONCLUSIONES............................................................................................................................68

RECOMENDACIONES .......................................................................................................69

REFERENCIAS ...................................................................................................

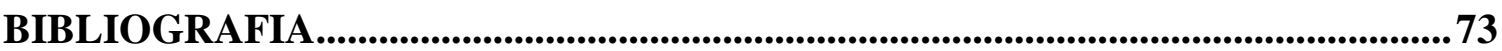

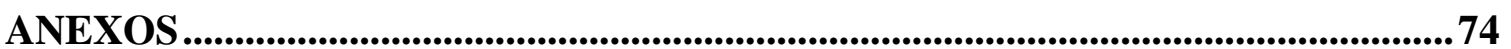




\section{ÍNDICE DE TABLAS}

Tabla 1.1 Matriz de Evaluación de Factores Externos (MEFE) ........................................... 1

Tabla 1.2 Matriz de Evaluación de Factores Internos (MEFI) ......................................... 11

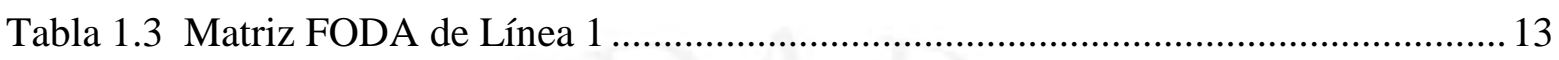

Tabla 3.1 Ubicación actual del personal de salud ........................................................28

Tabla 3.2 Matriz de actividades por puesto de trabajo .................................................... 30

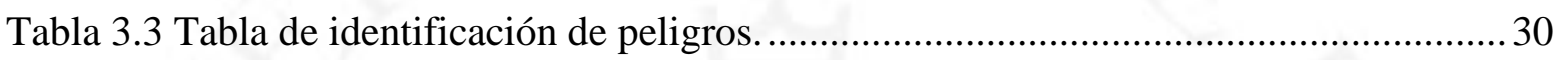

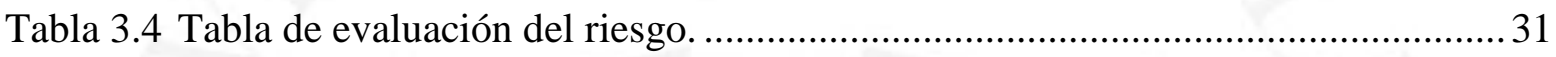

Tabla 3.5 Tabla de valoración de los riesgos. ............................................................... 32

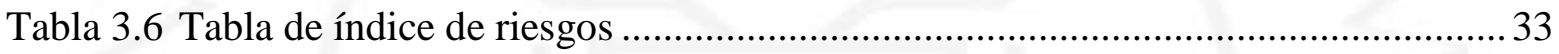

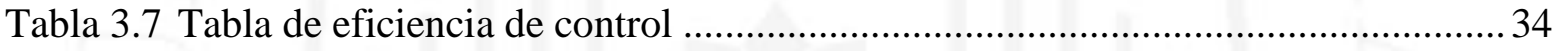

Tabla 3.8 Tabla de efectividad del nivel de control ......................................................... 35

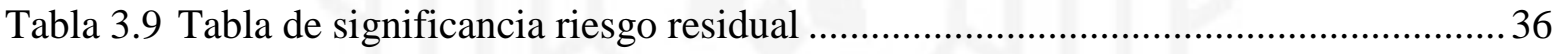

Tabla 3.10Tabla de decisión para la implementación de medidas de control. ....................... 37

Tabla 3.11 Matriz de identificación de peligros y evaluación de riesgos para la atención de

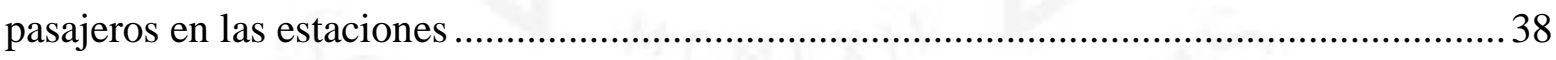

Tabla 3.12 Estadística de incidentes con usuarios durante el año 2018. ............................ 40

Tabla 3.13 Indicadores de accidentabilidad por millón de pasajeros transportados durante el

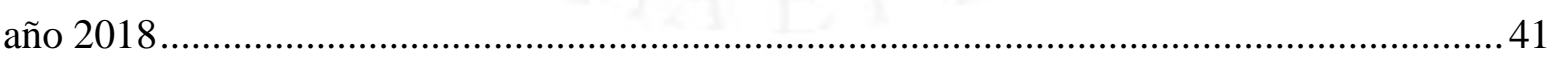

Tabla 3.14 Tabla de puntaje para el diagrama de Pareto ................................................. 45

Tabla 4.1. Matriz Causa - Solución ........................................................................... 47

Tabla 4.2. Matriz de enfrentamiento para determinar los pesos...................................... 48

Tabla 4.3. Ranking de factores para la selección de las propuestas .....................................50

Tabla 5.1 Número de Eventos mes de diciembre 2018 por estación.....................................54 
Tabla 5.2 Número de Eventos por horario de lunes a viernes por estación

Tabla 5.3 Número de eventos por estación por sábado y domingo .......................................56

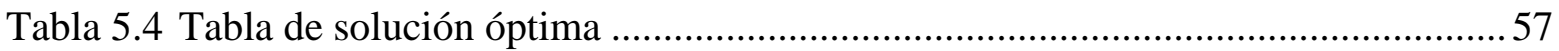

Tabla 5.5 Costos asociados a la optimización del servicio de primeros auxilios avanzados 59

Tabla 5.6 Diagrama de Gantt optimización de los tiempos de respuesta del servicio de

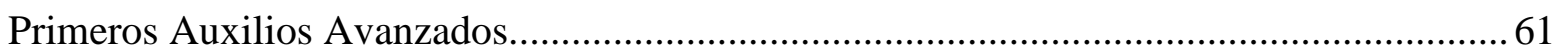

Tabla 5.7 Diagrama de Gantt implementación del SMS en Línea 1 ..................................... 64

Tabla 5.8 Valor de noticias negativas por accidentes año 2019 ...................................... 65

Tabla 5.9 Estadística de incidentes con usuarios durante el año 2019................................66

Tabla 5.10 Implementación de Propuestas de solución ........................................................ 67

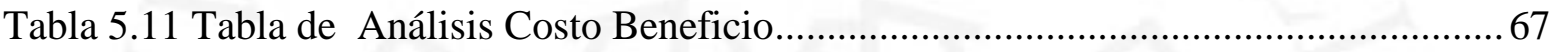




\section{ÍNDICE DE FIGURAS}

Figura 1.1 Red básica del Metro de Lima.................................................................... 1

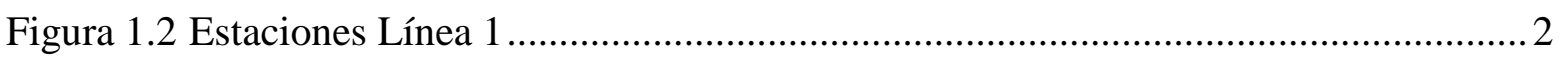

Figura 3.1. Flujograma de atención de accidentes en Línea 1 ..........................................2

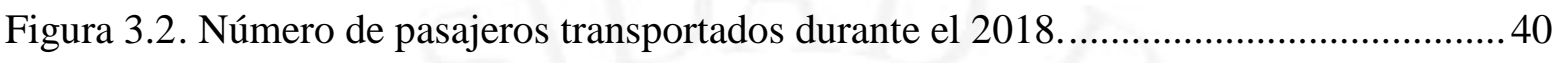

Figura 3.3. Tiempo de respuesta para la atención de incidentes médicos Línea 1, 2018..... 41

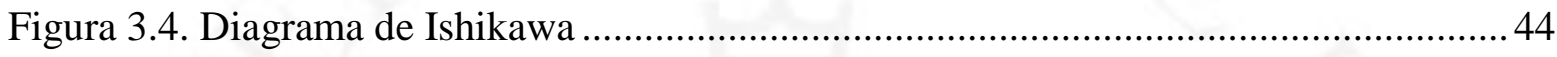

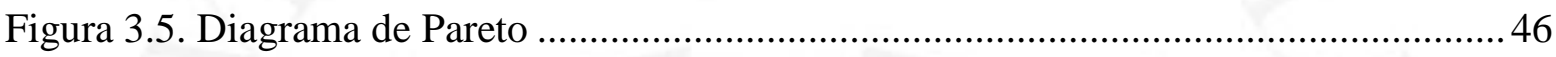

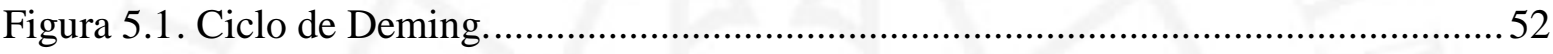

Figura 5.2. Tiempo de respuesta promedio en minutos del SPAA ...................................... 65 


\section{ÍNDICE DE ANEXOS}

Anexo 1: Tiempo promedio en minitos de traslado entre estaciones ................................ 78

Anexo 2: Tablas de optimizacion de tiempos según franja horaria ................................... 79 


\section{RESUMEN}

La Línea 1 del Metro de Lima es un sistema de transporte urbano de pasajeros que conecta 11 distritos de la capital y transporta en la actualidad a más de medio millón de personas al día. Todos los días ocurren incidentes y accidentes que pueden afectar la seguridad de las personas que utilizan el sistema, el objetivo principal del presente trabajo es plantear una propuesta de solución que permita la reducción de accidentes de pasajeros transportados así como la reducción del valor de las noticias negativas que generan estos accidentes en los medios de comunicación que cada año generan noticias negativas por un valor de más de 6 millones de soles, afectando principalmente la imagen de la organización. La manera en que se logrará esta mejora es mediante el diagnóstico del procedimiento de identificación de peligros y evaluación de riesgos operacionales así como la revisión y diagnóstico del procedimiento de atención de primeros auxilios avanzados hacia los usuarios. Una vez encontrada las causas raíces, se tendrán claros los puntos a mejorar y se plantearán alternativas de soluciones orientadas a implementar un sistema de gestión de seguridad operacional o $S M S$ y a optimizar el tiempo de respuesta del servicio de primeros auxilios avanzados. Al culminar la implementación de las propuestas de solución, se realizará un análisis costo beneficio en donde se demostrará que las soluciones implementadas generarán un beneficio para la organización. Durante todo este proceso se han utilizado diferentes herramientas aprendidas en los cursos de la carrera de ingeniería industrial con resultados positivos.

Palabras clave: Línea 1, Seguridad, SMS, Sistemas de Gestión, Primeros Auxilios. 


\begin{abstract}
Line 1 of the Lima Metro is an urban passenger transport system that connects 11 districts of the capital and currently transports more than half a million people a day. Every day there are incidents and accidents that can affect the safety of people who use the system, the main objective of the present work is to propose a solution proposal that allows the reduction of accidents of passengers transported as well as the reduction of the value of the news negatives generated by these accidents in the media that each year generate negative news worth more than 6 million soles, mainly affecting the image of the organization. The way in which this improvement will be achieved is through the diagnosis of the hazard identification procedure and the evaluation of operational risks as well as the review and diagnosis of the advanced first aid care procedure for users. Once the root causes have been found, the points to be improved will be clear and alternative solutions will be proposed to implement a safety management system or SMS and optimize the response time of the advanced first aid service. Upon completion of the implementation of the solution proposals, a cost-benefit analysis will be conducted where it will be demonstrated that the implemented solutions will generate a benefit for the organization. Throughout this process, different tools learned in the courses of the industrial engineering career have been used with positive results.
\end{abstract}

Keywords: Line 1, Security, SMS, Management Systems, First Aid. 


\section{CAPÍTULO I: ANTECEDENTES DE LA EMPRESA}

\subsection{Breve descripción de la Línea 1 del Metro de Lima.}

La Línea 1 del metro de Lima es la primera línea de metro de la ciudad, este sistema de transporte tiene planificado 06 líneas de metro que cruzan diversos distritos de Lima y Callao. Ver Figura 1.1. (Autoridad Autónoma del Tren Eléctrico, 2019)

\section{Figura 1.1}

Red básica del Metro de Lima.

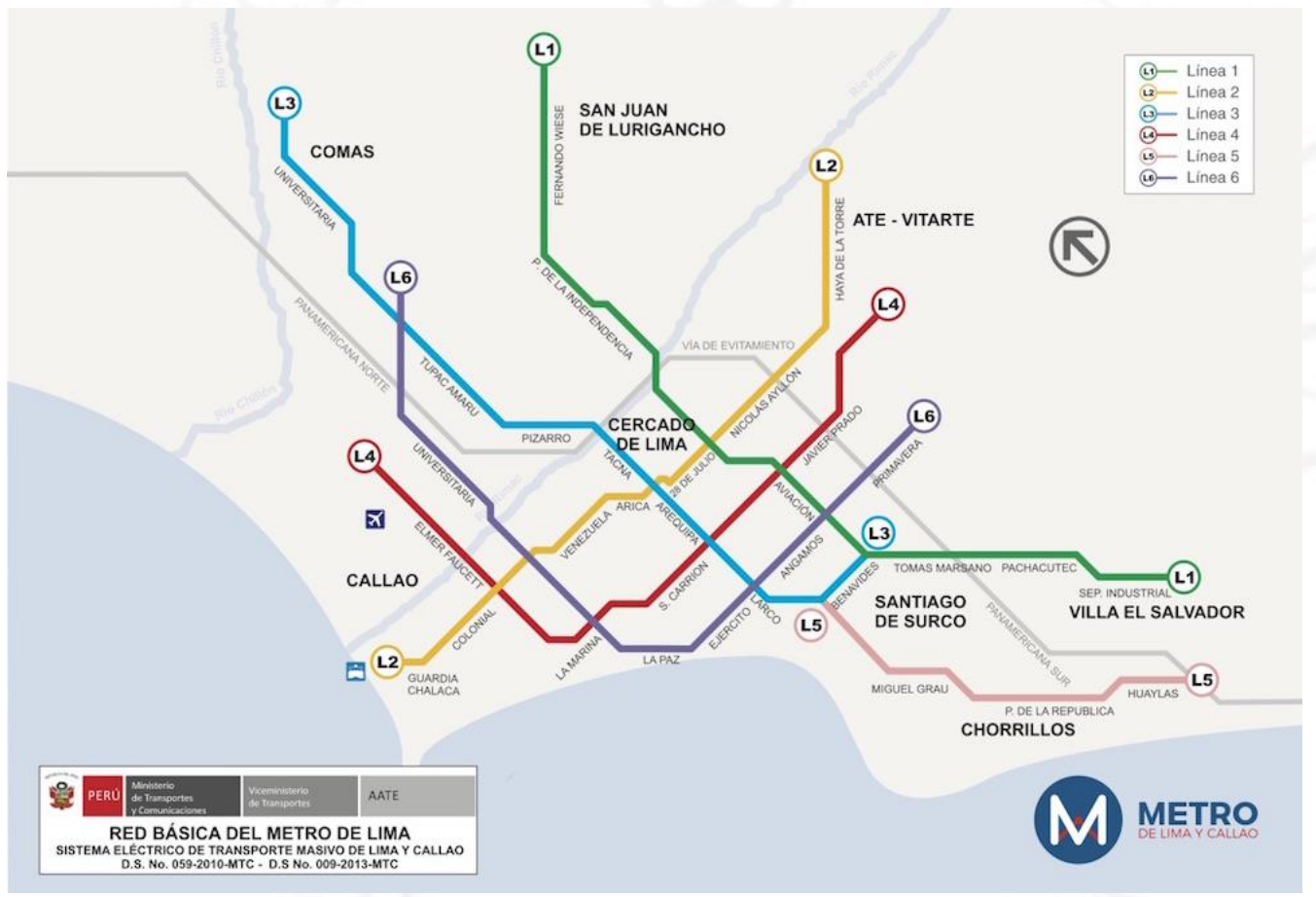

Fuente: Autoridad Autónoma del Tren Eléctrico (2019)

La infraestructura del Metro de Lima o también llamado Tren Eléctrico le pertenece al Estado Peruano y es administrado por la Autoridad Autónoma del Tren Eléctrico (AATE) que es una entidad adscrita al Ministerio de Transporte y Comunicaciones (MTC). La operación y el mantenimiento de la Línea 1 se encuentra a cargo de la concesionaria GyM Ferrovías, entidad privada y consorciada entre las empresa Graña y Montero y Ferrovias Argentina. 
La Línea 1 cuenta con 26 estaciones a lo largo de 34 km, 06 de estas estaciones se encuentran en viaducto a nivel del suelo y 20 se encuentran en un viaducto elevado. La Línea 1 recorre 11 distritos y el tiempo de viaje es de aproximadamente 54 minutos desde la estación Villa el Salvador en el distrito del mismo nombre hasta la estación Bayovar en el distrito de San Juan de Lurigancho. Ver Figura 1.2. (Autoridad Autónoma del Tren Eléctrico, 2019)

Figura 1.2

\section{Estaciones Línea 1}

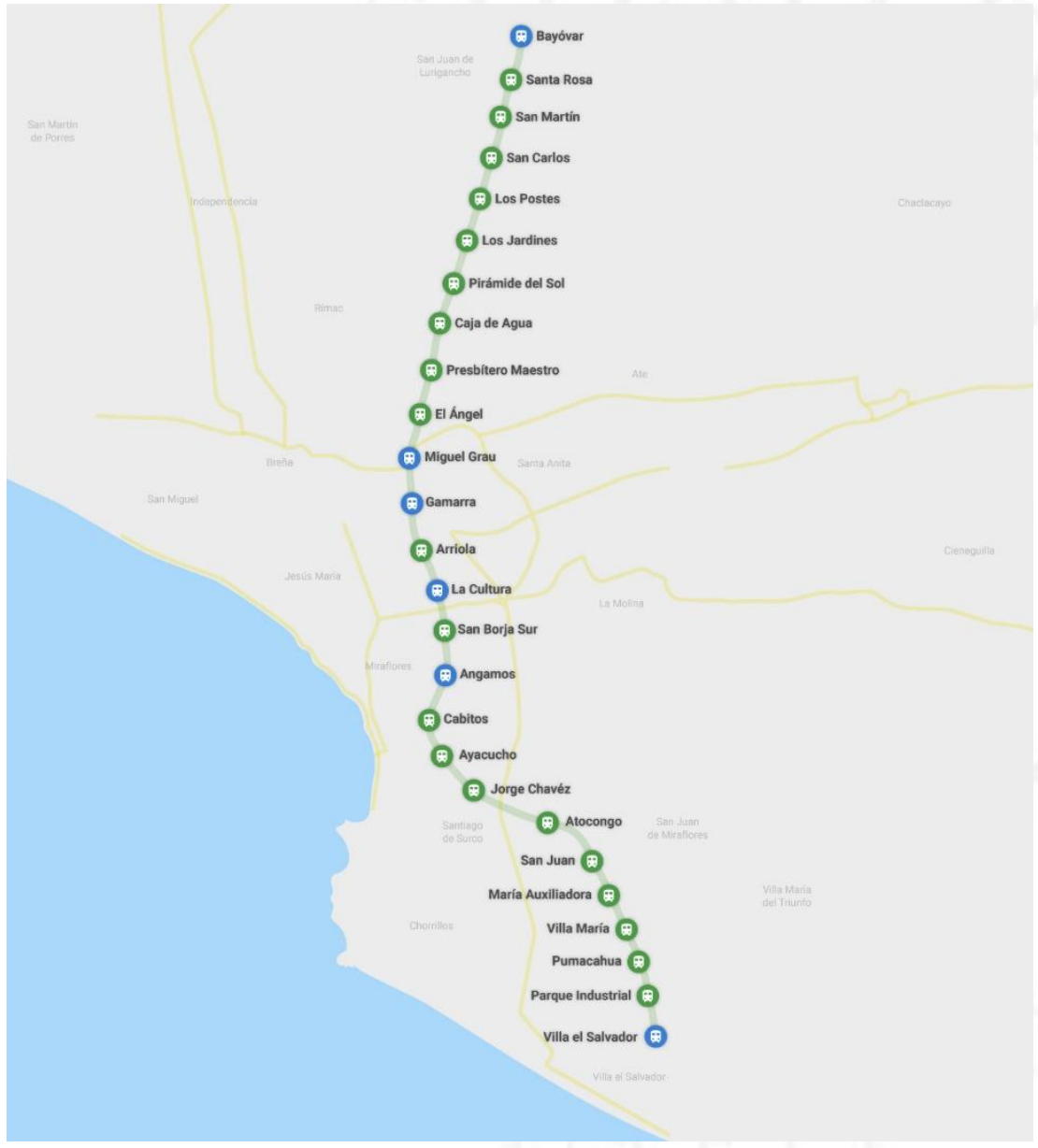

Fuente: GyM Ferrovías (2019)

La colocación de la primera piedra el inicio de la construcción se dio en el año 1986 durante el primer periodo del Expresidente Alan García Pérez, en dicho periodo se construyeron 05 estaciones, retomándose la construcción luego de más de 20 años con la construcción de 09 estaciones como parte del tramo 1. 
Línea 1 empezó a construirse en el año 1986 con una larga interrupción de más de dos décadas, retomándose luego el proceso de construcción a inicios del año 2010. Durante la primera etapa se construyó los primeros $9.85 \mathrm{~km}$ que va desde las estaciones de Villa El Salvador hasta Atocongo, siendo un trazado de vía doble desarrollado principalmente a nivel del suelo (aproximadamente $7 \mathrm{~km}$ ) que, luego, continúa en viaducto elevado. Desde esa fecha hasta inicios del 2010, la obra ha estado paralizada, realizándose únicamente labores de mantenimiento de la infraestructura existente. En la segunda etapa se continuó con la construcción de la estación Atocongo hasta la estación Grau, culminando así el Tramo 1, e iniciando la construcción del Tramo II, en viaducto elevado, que va desde la estación Grau hasta la estación Bayóvar en San Juan de Lurigancho. En esta etapa se realizaron diversas actividades de reparación, rehabilitación y mantenimiento de la infraestructura y material rodante existente para garantizar la operatividad del proyecto

\subsubsection{Visión}

La visión definida actualmente por Línea 1, es: "Ser reconocidos como EL OPERADOR DE TRANSPORTE MÁS CONFIABLE, MODERNO Y SEGURO, generador de desarrollo sostenible y cultura ciudadana, orgullo del Perú.” (Línea 1, 2019).

\subsubsection{Misión}

La misión planteada por Línea 1 es: Ser una organización con un equipo humano competente y comprometido, dedicada a la operación de LÍNEA 1 del Metro de Lima, que brinda un SERVICIO INTEGRAL DE TRANSPORTE PARA MEJORAR LA CALIDAD DE VIDA DE NUESTROS CLIENTES y contribuir al desarrollo de la ciudad. (Línea 1, 2019)

\subsubsection{Valores}

Son los valores los que guían a una organización. Los valores definidos por Línea 1 son los siguientes:

- Seriedad

- Calidad 
- Cumplimiento

- Eficiencia

- $\quad$ Seguridad

- $\quad$ Responsabilidad. (Línea 1, 2019)

\subsubsection{Código de Ética}

Según (D’Alessio, 2015), en el código de ética se establecen las conductas que debe seguir la organización, también debe reflejar los valores y principios de la organización generando un conceso sobre lo que es ético y lo que no lo es. El código de conducta, es un marco de referencia para el accionar de los colaboradores de una organización.

El Código de Conducta de Negocios del Grupo Graña y Montero esra desarrollado para hacer respetar los valores definidos por la organización y sirven como un marco referencia para el actuar de los colaboradores. El contenido del código prevalece frente a cualquier conflicto con otras políticas y procedimientos del grupo Graña y Montero. Dicho documento reemplaza a la Carta Ética (1995) y al Código de Conducta (2012). Violaciones de ese Código y de las políticas y procedimientos del Grupo Graña y Montero generarían medidas disciplinarias a sus colaboradores (Código de Conducta del Grupo Graña y Montero, 2018)

\subsection{Descripción de la empresa operadora de la Línea 1}

CONCAR S.A. es una empresa que tiene más de 22 años en el mercado, que brinda mantenimiento de infraestructura vial y ferroviaria, además, y opera concesiones viales y la infraestructura de la Línea 1 del Metro de Lima.

En 1994 CONCAR obtiene su primera concesión vial en los tramos Arequipa Matarani con una longitud de 110km. En el 2003 se le adjudica la concesión vial Norvial por un plazo de 25 años. En el 2007 se le adjudica la concesión vial de Survial por un plazo de 25 años. En el 2011 se adjudica el mantenimiento y operación de la Línea1 del Metro de lima con 26 estaciones, 02 patios talleres y 33 kilómetros de vía férrea por un plazo de 30 años. En el 2012 certifica por primera vez la norma ISO 9001:2008 e inicia operaciones en su planta de emulsión asfáltica. En el 2016 se adjuntica las concesiones de Chinchaypujio y Chuquibambilla en Apurimac y Cuzco con un plazo de 8 y 5 años respectivamente. (CONCAR, 2019) 
Concar cuenta con 03 unidades de negocios:

\section{Unidad vial}

Esta unidad brinda soluciones de ingeniería, conservación y gestión vial de las principales carreteras del Perú. Dentro de los servicios ofrecidos cuenta con la administración de peajes y de pesajes, cuenta con una planta de emulsión asfáltica, y gestiona una central de emergencia para sus usuarios.

\section{Unidad ferroviaria}

Esta unidad se encarga de la operación y el mantenimiento de la Línea 1, se basa en una excelente gestión operativa y de mantenimiento, a cargo de personal altamente especializado que aseguran el transporte de pasajeros a los largo de toda la vía férrea.

\section{Unidad de Gestión de Infraestructura.}

Esta unidad se especializa en brindar soluciones relacionadas al mantenimiento de infraestructura, equipos contra incendios, limpieza industrial, operación de plantas de tratamiento de aguas, mantenimiento menor, entro otros servicios relacionados al mantenimiento de edificios.

\subsection{Análisis del sector, modelo de las cinco fuerzas competitivas.}

Para el presente trabajo, se realizó un análisis del sector en donde se ubica la Línea 1 del Metro de Lima, basándose en el modelo de las 5 fuerzas competitivas (Porter, 2010) en donde se evaluarán los siguientes factores: (a) amenaza de competidores, (b) ingreso de nuevos competidores, (c) amenaza de productos sustitutos, (d) poder de negociación de los consumidores y (e) poder de negociación de los proveedores.

\section{Poder de negociación de los proveedores (alto)}

Para evaluar el poder de negociación de los proveedores se evaluaron las siguientes características:

- Numero de grandes proveedores: Existen pocos proveedores especializados en proveer suministros y repuestos en el sector ferroviario. 
- Concentración de proveedores: Los proveedores se encuentran concentrados ya que el sector es muy especializado.

- Volumen de ventas de los proveedores respecto a las compras del sector: los volúmenes de ventas respecto a las compras del sector son altos ya que los repuestos deben ser de los mismos fabricantes para efectos de mantener la garantía.

- Sustitubilidad del producto proveído: los insumos y repuestos no son de fácil sustitución ya que la tecnología es desarrollada por el mismo fabricante, siendo el mismo quien vende sus repuestos.

- Información de los proveedores respecto del sector: Los proveedores son especializados y cuentan con mucha información sobre el sector.

- Amenaza de integración hacia delante por parte de los proveedores: No existe amenaza de integración hacia delante.

El poder de negociación de los principales proveedores es alto, ya que en Línea 1 los insumos, materiales y equipos son únicos en el mercado y se fabrican a pedido según la configuración de los sistemas ferroviarios.

\section{Poder de negociación de los compradores (alto)}

En este caso se ha considerado que Línea 1 tiene 1 solo cliente que sería el Estado Peruano, en función a ello se han evaluado las siguientes características:

- Numero de grandes compradores: cuenta con un solo comprador que sería el Estado Peruano.

- Concentración de compradores: muy alta concentración ya que se trata de un solo cliente.

- Volumen de compras de los clientes respecto a las ventas del sector: El Estado a través del MTC cuenta con una cartera de proyectos de inversión que consta de una red de 7 líneas de Metro a nivel de Lima y Callao. Por lo que el volumen de compra o adquisiciones es alto.

- Diferenciación del producto: Alta diferenciación ya que Línea 1 es la primera Línea de metro de la ciudad.

- Identificación de marca: Alta identificación de marca ya que los usuarios identifican a diario al concesionario del servicio. 
- Información de los compradores respecto del sector: El estado tiene mucha información a través de las entidades estatales especializadas y a través del Ministerio de Transportes.

Según lo analizado concluimos que el poder de negociación de los consumidores es alto.

\section{Amenaza de los sustitutos (medio)}

Si bien el concesionario tiene un solo cliente, los consumidores del servicio serían los pasajeros que usan el servicio de transporte público en general, entonces se determina que el servicio de transporte privado y público es una alternativa de los pasajeros para utilizar como sustituto al servicio de metro. Los servicios enmarcados al transporte privado y público en la ciudad de lima son: uso de vehículos propios, uso de aplicaciones de taxis, uso de taxis formales e informales y transporte público formal e informal. Se han analizado las siguientes características

- Posibilidad de sustitutos cercanos: existe alta posibilidad de que los usuarios del transporte metro, utilicen sistema de transporte terrestre público, sobre todo cuando el servicio de metro de encuentre saturado.

- Costo de cambio del usuario: El costo de cambio es alto, ya que pasar de usar un servicio de metro a un servicio privado necesariamente involucra un costo financiero y en el caso del servicio público el cambio del costo sería gastar más tiempo en el viaje hacia su destino.

- Agresividad del producto sustituto: las empresas de servicio privado están implementando estrategias agresivas para captar más clientes, utilizando medios como aplicaciones en celulares, colectivos informales, red de buses articulados, etc.

- Propensión de los consumidores a cambiar de productos: la propensión a utilizar otros medios que puedan facilitar el transporte de manera rápida es alta sobre todo cuando existe un sobredemanda del servicio de metro

- Relación valor del producto sustituto / precio del producto sustituto: la relación es baja ya los productos sustitutos carecen de variables importantes para los clientes como son la seguridad, confiabilidad, y rapidez. 


\section{Amenaza de los entrantes (bajo)}

Las barreras de ingreso para ganar un contrato de concesión son muy altas, cada concesión debe pasar por un proceso de licitación riguroso a cargo de la Agencia de Promoción de la Inversión Privada (PROINVERSION). Para determinar la amenaza de los entrantes se han analizado las siguientes características:

- Diferenciación del servicio: El servicio ofrecido es muy diferenciado ya que se trata de un servicio de transporte de pasajeros en vías férreas exclusivas en un radio urbano.

- Identificación de marca: La identificación de la marca es alta ya que al ser un servicio de transporte masivo existe alta exposición de los usuarios sobre el servicio utilizado.

- Costos de cambio: Los costos de cambiar son muy altos, ya que al ingresar se realizan inversiones muy fuertes.

- Requisito de capital: para poder ingresar al mercado de operación y mantenimiento de sistemas ferroviarios se requiere una inversión considerable.

- Imitación del proceso: El proceso es difícil de imitar, ya que requiere una infraestructura similar para realizar el mismo servicio.

- Regulación gubernamental restrictiva: Existe mucha regulación por parte de las entidades del estado debido a que se trata de un servicio básico para la población.

- Acceso privilegiado a materias primas. La materia prima insumos, y materiales utilizados son muy especializados por lo que se tiene acceso privilegiado.

- Efecto de experiencia: Para mantener el éxito en el mercado es necesario contar con experiencia previa en el sector y forma parte de los requisitos para tener la concesión.

- Expectativas de reacción: Las expectativas de reacción son muy altas ya que el servicio es muy visible para la población con efectos mediático en caso de emergencias y contingencias.

- Tecnología de fabricación: La tecnología de los sistemas ferroviarios es muy especializada. 


\section{Rivalidad de los competidores (bajo)}

Para analizar la rivalidad de los competidores en el sector se realizó el análisis de las siguientes características:

- Crecimiento del sector: La necesidad de crear nuevas líneas de metros y sistemas de transporte público eficiente es latente.

- Sobre oferta existente: Existe una sobre oferta de usuarios que requieren un servicio de rápido, seguro y confiable.

- Diferenciación del producto: Existe una gran diferenciación del servicio brindado ya que se trata de movilización de pasajeros a través de sistema ferroviario urbano, único en el país.

- Costos de cambio: Los costos de cambiar son muy altos, ya que al ingresar se realizan inversiones muy fuertes.

- Número de competidores: Actualmente se cuenta con una sola línea de metro, y un sistema de buses troncalizado con sus alimentadores llamado Metropolitano y un sistema de buses ubicados en corredores viales a cargo de la Municipalidad de Lima, por lo que el número de competidores es muy bajo.

- Barreras de salida: las barreras de salidas son altas ya que las concesiones se basan en contratos a largo plazo.

- Costos fijos: existen grandes costos fijos asociados a mantener el servicio en las estaciones y trenes.

- Estacionalidad: no existe estacionalidad ya que el servicio es necesario en igual magnitud en todas las épocas del año, es un servicio considerado como básico.

\subsection{Matriz de Evaluación de Factores Externos MEFE.}

La Matriz de Evaluación de Factores Externos (MEFE) se realiza en función al análisis externo y considera factores políticos, económicos, sociales, tecnológicos y medio ambientales, de esta manera, se identificaron las principales oportunidades y amenazas que tiene la Línea 1. En la Tabla 1.1 se puede observar que se obtiene un valor de 2.57 , muy cerca al promedio que es 2.5 , con estos valores la organización debería aprovechar al máximo las oportunidades y actuar frente a las amenazas. 


\section{Tabla 1.1}

Matriz de Evaluación de Factores Externos (MEFE)

\begin{tabular}{|c|c|c|c|}
\hline Factores determinantes de éxito & Peso & Valor & $\begin{array}{l}\text { Puntaje } \\
\text { ponderado }\end{array}$ \\
\hline \multicolumn{4}{|l|}{ Oportunidades } \\
\hline $\begin{array}{l}\text { Sinergias en los sistemas de transporte por la creación } \\
\text { de la Autoridad del Transporte Urbano (ATU) }\end{array}$ & 0.13 & 3 & 0.39 \\
\hline $\begin{array}{l}2 \text { Programa de inversión en infraestructura ferroviaria a } \\
\text { nivel nacional }\end{array}$ & 0.12 & 4 & 0.48 \\
\hline $\begin{array}{l}3 \text { Posibilidad de establecer estándares nacionales al ser la } \\
\text { primera operación de metros del país }\end{array}$ & 0.11 & 4 & 0.44 \\
\hline $\begin{array}{l}4 \text { Tendencia en el uso de sistemas de transporte que } \\
\text { ayuden al medio ambiente }\end{array}$ & 0.07 & 4 & 0.28 \\
\hline $5 \quad$ Estabilidad macroeconómica & 0.10 & 2 & 0.20 \\
\hline Subtotal de oportunidades & 0.53 & & 1.79 \\
\hline \multicolumn{4}{|l|}{ Amenazas } \\
\hline $\begin{array}{l}\text { Exposición mediática de los incidentes ocurridos en la } \\
\text { operación de Línea } 1\end{array}$ & 0.13 & 2 & 0.26 \\
\hline $\begin{array}{l}\text { Problemas de corrupción, caso "ODEBRECHT" y caso } \\
\text { "Club de la Construcción" }\end{array}$ & 0.15 & 1 & 0.15 \\
\hline $\begin{array}{l}\text { Inicio de operación de la Línea2 del Metro de Lima, } \\
\text { mayor afluencia en los puntos de conexión }\end{array}$ & 0.05 & 3 & 0.15 \\
\hline $\begin{array}{l}4 \text { Inseguridad por el incremento de organizaciones para } \\
\text { la reventa de pasajes }\end{array}$ & 0.08 & 2 & 0.16 \\
\hline $\begin{array}{l}5 \text { Problemas operativos por el exceso de demanda en las } \\
\text { horas de mayor afluencia. }\end{array}$ & 0.06 & 1 & 0.06 \\
\hline Subtotal de amenazas & 0.47 & & 0.78 \\
\hline Total & 1.00 & & 2.57 \\
\hline
\end{tabular}

Elaboración propia

\subsection{Matriz de Evaluación de Factores Internos MEFI}

Para la elaboración de la matriz de factores internos se acudió a la opinión de la línea de mando de Línea 1, a través de ellos se pudo obtener la relación de las fortalezas y debilidades de la organización, así como los pesos y puntajes que se muestran en la Tabla 1.2. El valor obtenido fue de 2.80 el cual supera el valor promedio, lo que significa que Linea 1 tiene una brecha por mejorar para hacer frente a las fortalezas y debilidades de la organización. 
Tabla 1.2

Matriz de Evaluación de Factores Internos (MEFI)

\begin{tabular}{|c|c|c|c|}
\hline Factores determinantes de éxito & Peso & Valor & $\begin{array}{c}\text { Puntaje } \\
\text { ponderado }\end{array}$ \\
\hline \multicolumn{4}{|l|}{ Fortalezas } \\
\hline $\begin{array}{l}\text { La seguridad es un valor reconocido por todos los } \\
1 \text { miembros de la organización. Apoyo de la alta } \\
\text { dirección para implementar mejoras en el sistema. }\end{array}$ & 0.10 & 4 & 0.40 \\
\hline $\begin{array}{l}2 \text { Excelencia operacional, superando los niveles de } \\
\text { servicio acordados con el Estado. }\end{array}$ & 0.09 & 4 & 0.36 \\
\hline $\begin{array}{l}\text { Exitosos programas de generación de Cultura Metro } \\
\text { e inclusión social }\end{array}$ & 0.09 & 4 & 0.36 \\
\hline $\begin{array}{l}4 \text { Alto nivel de calidad de servicio, que es reconocida } \\
\text { por los usuarios del sistema }\end{array}$ & 0.10 & 4 & 0.40 \\
\hline $\begin{array}{l}\text { Se cuenta con el mejor talento de la industria } \\
5 \text { ferroviaria. Evaluación de colaboradores } 180 \\
\text { grados. }\end{array}$ & 0.07 & 3 & 0.21 \\
\hline $\begin{array}{l}\text { Expertos en prevención de riesgos laborales. Cero } \\
\text { accidentes mortales. }\end{array}$ & 0.07 & 4 & 0.28 \\
\hline $\begin{array}{l}7 \text { Flota de trenes de última generación, uso de } \\
\text { tecnología de punta. }\end{array}$ & 0.08 & 4 & 0.32 \\
\hline Subtotal de fortalezas & 0.60 & & 2.33 \\
\hline \multicolumn{4}{|l|}{ Debilidades } \\
\hline $\begin{array}{l}\text { Plan de contingencia cuenta con instrucciones } \\
\text { generales }\end{array}$ & 0.09 & 1 & 0.09 \\
\hline $\begin{array}{l}2 \text { Alta rotación del personal de operaciones, } \\
\text { incremento de la curva de aprendizaje. }\end{array}$ & 0.08 & 1 & 0.08 \\
\hline $\begin{array}{l}\text { Implementación deficiente en el sistema de Gestión } \\
\text { de Seguridad Operacional }\end{array}$ & 0.07 & 2 & 0.14 \\
\hline 4 Incremento de accidentes y suicidios en el sistema. & 0.06 & 1 & 0.06 \\
\hline $\begin{array}{l}\text { Poca sinergia entre personal de seguridad, limpieza } \\
\text { y operaciones en las estaciones. }\end{array}$ & 0.10 & 1 & 0.10 \\
\hline Subtotal de debilidades & 0.40 & & 0.47 \\
\hline Total & 1.00 & & 2.80 \\
\hline
\end{tabular}

Nota: 1 debilidad mayor, 2 debilidad menor, 3 fortaleza menor y 4 fortaleza mayor.

Elaboración propia.

\subsection{Matriz Fortalezas Oportunidades Debilidades Amenazas (FODA).}

Para elaborar la matriz FODA se utilizaron como insumos de las matrices EFI y EFE, luego de este emparejamiento se generaron las siguientes estrategias:

- Estrategia 1 (E1): Implementar un programa de intercambio de experiencias entre las diversas entidades de transporte público.

- Estrategia 2 (E2): Proponer al estado nueva legislación (Estándar) en materia de seguridad operacional. 
- Estrategia 3 (E3): Elaborar instructivos operacionales que complementen al Plan de contingencias en incluyan actividades para personal de seguridad y limpieza

- Estrategia 4 (E4): Optimizar el tiempo de respuesta de los sistemas de atención de primeros auxilios para los usuarios

- Estrategia 5 (E5): Diseñar e implementar el sistema de gestión en seguridad operacional.

- Estrategia 6 (E6): Adquirir o desarrollar un software para la gestión de eventos en Línea 1

- Estrategia 7 (E7): Desarrollar una guía de mensajes hacia los usuarios durante situaciones de contingencias.

- Estrategia 7 (E8): Preparar un plan de acción con los medios de comunicación frente a eventos que generen impacto a los usuarios del sistema

- Estrategia 7 (E9): Informar y solicitar al Estado acciones frente al incremento de revendedores en los exteriores de la Línea 1

- Estrategia 7 (10): Mitigar el impacto de los incidentes a través de la implementación de equipamiento de respuesta a emergencias en las estaciones

\subsection{Descripción del problemática actual}

A fines del 2018, la Línea 1 del Metro de Lima transportó 420 mil usuarios al día aproximadamente, a lo largo de sus 26 estaciones. Debido a que el servicio de Metro de Lima es un servicio de transporte masivo, diariamente se atienden emergencias médicas por accidentes y por problemas relacionados a la salud de los pasajeros, estas emergencias pueden atenderse con la aplicación de los primeros auxilios básicos brindados por los agentes de estación, sin embargo, muchas de las atenciones requieren de la aplicación de primeros auxilios avanzados por parte de personal de salud especializado, y algunos de estos casos requieren la derivación de emergencia a un centro de salud cercano a través de una ambulancia. 


\section{Tabla 1.3}

\section{Matriz FODA de Línea 1}

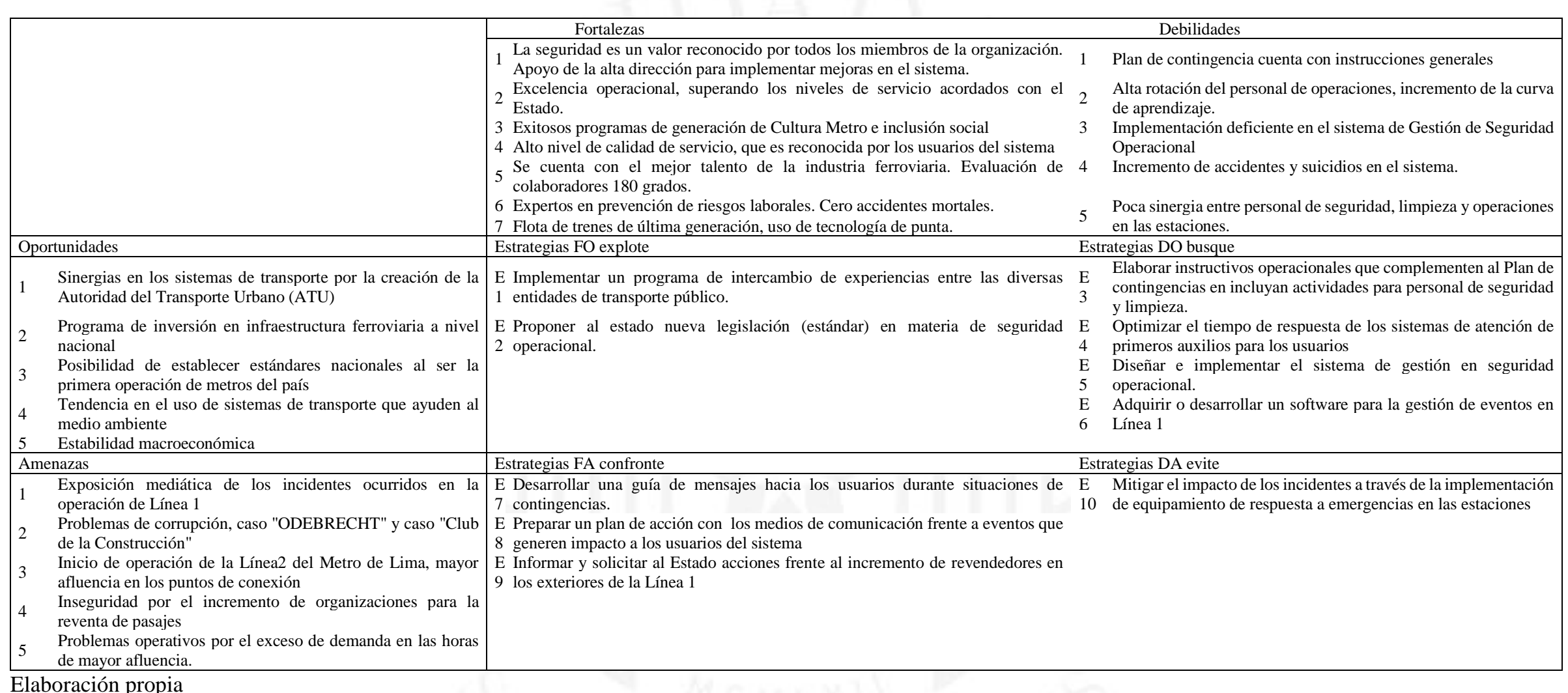

Elaboración propia 
En Línea 1 se clasifican las atenciones médicas en dos grupos:

- Atenciones por accidentes, producto de la interacción accidental del usuario con la infraestructura ferroviaria que trae como consecuencia lesiones hacia el pasajero, como por ejempló caídas a nivel, golpes contra la infraestructura, lesiones producto del cierre de puerta de los trenes, caídas a diferente nivel, etc.

- Atenciones por enfermedad, producto del estado de salud del usuario, quienes presentan síntomas como desmayos, dolores, vómitos, fiebre, convulsiones, como resultado de enfermedades preexistentes como diabetes, hipertensión, dislipidemia entre otros. Estas situaciones no tienen relación con la actividad ferroviaria y no son consideradas como accidentes ferroviarios.

Considerando que la consecuencia, en términos de gravedad, de un accidente está relacionado directamente al azar, la organización deberá preocuparse por controlar la accidentabilidad desde el enfoque de la probabilidad de ocurrencia, es decir, deberá enfocarse en reducir la cantidad de accidentes que ocurren en el sistema.

Por otro lado, los accidentes graves generan un impacto en los medios de comunicación sobre todo si existen variables como la demora en la atención o la falta $u$ omisión de protocolos de respuesta a emergencia, por ejemplo; el primero de mayo un ciudadano venezolano se lanzó a los rieles del tren en la estación Pirámides del Sol, en el distrito de San Juan de Lurigancho y fue arrollado por el tren perdiendo la pierna derecha (El Comercio, 2018). Línea 1 activó sus protocolos de emergencia y atendió al pasajero, quien fue atendido por servicios de primeros auxilios propios y externos y derivado oportunamente a un centro de salud especializado, sin embargo, a nivel operacional, el servicio se suspendió en el sector de San Juan de Lurigancho por alrededor de 2 horas aproximadamente. El evento generó noticias negativas en los medios de comunicación por un valor referencial de S/.37756,967.0 (Tres millones setecientos cincuenta y seis mil novecientos sesenta y siete soles). Este valor es calculado en función al valor del espacio utilizado en los medios de comunicación para difundir dichas noticias. (Línea 1, 2019)

Podemos afirmar que la problemática actual de la organización se basa en los siguientes aspectos:

- Incremento de los accidentes de los pasajeros durante su permanencia en la Línea 1. 
- Impacto de los accidentes en los medios de comunicación a través de la generación de noticias negativas. 


\section{CAPÍTULO II: OBJETIVOS Y ALCANCE DE LA INVESTIGACIÓN}

\subsection{Objetivo general.}

El objetivo general planteado para el presente trabajo es: Plantear una propuesta de solución que permita la reducción de accidentes de pasajeros transportados así como la reducción del valor de las noticias negativas que generan estos accidentes los medios de comunicación.

\subsection{Objetivos específicos.}

Los objetivos específicos definidos para el presente trabajo son:

- Identificar las casusas en el incremento de los accidentes con pasajeros de la Línea 1 del Metro de Lima y su respectivo impacto en el valor de las noticias negativas en los medios de comunicación.

- Proponer alternativas de solución para las causas encontradas.

- Determinar la viabilidad económica y financiera de las propuestas de solución seleccionadas

- Realizar la evaluación de la solución y el análisis costo beneficios de las soluciones implementadas

\subsection{Alcance y limitaciones de la investigación.}

El presente trabajo se llevará a cabo dentro del ámbito de operación de la Línea 1 del Metro de Lima en la extensión de 33 km de vía férrea y el ámbito de la infraestructura de sus 26 estaciones.

La atención de primeros auxilios básicos es una obligación de cualquier organización o persona capacitada que se encuentre en el ámbito de la operación, todos los colaboradores reciben capacitación e instrucción en primeros auxilios básicos y están preparados para atender cualquier situación, sin embargo, la atención puede complicarse y puede requerir la atención de servicios de primeros auxilios avanzados externos a cargo 
de entidades como el Cuerpo General de Bomberos Voluntarios del Perú (C.G.B.V.P.) o el Servicio de Atención Médica y Urgencias (SAMU)

La organización no se encuentra obligada a contratar un servicio de primeros auxilios avanzados, sin embargo, y producto de la poca eficacia (50\%) de los servicios de primeros auxilios externos, bomberos, SAMU, Línea 1, decide asignar un presupuesto y contratar un servicio de primeros auxilios avanzados que consta en la distribución de personal de salud (5) a los largo de las 26 estaciones del metro de Lima.

\subsection{Justificación de la investigación.}

\subsubsection{Justificación económica}

La implementación de las propuestas de mejoras cuentan con justificación económica, ya que la organización ha asignado los recursos necesarios para el planteamiento e implementación de la solución, además las implementaciones generarán beneficios los cuales se detallarán en el capítulo IV del presente trabajo, por lo que el proyecto se encuentra justificado económicamente.

\subsubsection{Justificación técnica}

El presente trabajo se encuentra justificado técnicamente debido a que se utilizarán las capacidades, recursos, materiales y herramientas de ingeniería para plantear soluciones e implementarlas. Además la organización está en camino a alinearse a normas técnicas internacionales relacionadas al sector ferroviario.

\subsubsection{Justificación social}

Reducir los accidentes de los pasajeros en el sistema no solo generará beneficios a la organización, sino que además, generará mejor bienestar a las personas que usan el sistema, contribuyendo a la misión de la organización que es generar desarrollo sostenible

y bienestar en los pasajeros, la por lo que el presente trabajo se encuentra justificado socialmente. 


\section{CAPÍTULO III: DIAGNÓSTICO DEL SISTEMA O PROCESO OBJETO DE ESTUDIO}

\subsection{Análisis del sistema o proceso objeto de estudio}

\subsubsection{Descripción detallada del sistema o proceso objeto de estudio.}

\section{Proceso de atención de accidentes:}

A continuación se hará una descripción detallada del proceso de atención de accidentes en la Línea 1.

Ante la necesidad de brindar atención de primeros auxilios a una o más personas en las estaciones o trenes, el personal de Línea 1 realiza las siguientes actividades:

\section{Personal de Estación o Encargado de Estación}

El Personal de Estación o Encargado de Estación que toma conocimiento de que una o varias personas que requieren asistencia, realizar lo siguiente:

- Constata la situación de la persona y recoge, si es posible, alguna declaración sobre la causa de su malestar, sobre todo para establecer si éste deriva de hechos personales o de situaciones vinculadas con la prestación del servicio o saber de antemano si se requerirá la intervención del Servicio de Primeros Auxilios Avanzado.

- Comunica el evento al Puesto Central Operativo (PCO) a través de la radio tetra, canal "Tráfico General", en caso de no contar con radio tetra disponible, usa el anexo telefónico, y en caso de encontrarse en el andén, usa el intercomunicador de emergencia. Solo en caso que no se encuentren disponibles los medios de comunicación mencionados, usará cualquier equipo de comunicación disponible.

- Brinda la atención de primeros auxilios; en caso la persona no desee la atención, recoge sus datos (nombre, número de D.N.I., dirección, $\mathrm{N}^{\circ}$ de 
tarjeta de LÍNEA 1, estación de ingreso, estación de salida) y solicita al usuario el llenado de una declaración jurada de atención. En caso exista negativa del usuario en firmar la declaración jurada, solicita apoyo de la PNP Ferroviaria para la constatación del hecho.

- Cuando la persona requiera, solicite o necesite atención médica, y se encuentre consiente, se le traslada al tópico de la estación, usando preferentemente la silla de ruedas, en caso se encuentre inconsciente o convulsionando, el agente de estación, aplica las técnicas de primeros auxilios respectivas y solicita apoyo al personal de la estación para despejar la zona y luego la traslada al tópico de la estación usando la tabla rígida. En ambos casos, cambia la frecuencia de la radio tetra a la frecuencia de emergencias, por dicha frecuencia, informa constantemente el estado de la persona y recibe instrucciones del servicio médico o PCO. Solo en el caso que no se encuentre disponible la radio tetra, procede a informar el evento por otro medio de comunicación disponible.

- En caso la persona se encuentre en la vía, el encargado de la estación, coordina con el personal de estaciones o personal de seguridad, el uso de la tabla rígida, y/o silla de ruedas, dependiendo de la naturaleza del caso.

- En el tópico, sigue aplicando los primeros auxilios básicos y sigue atento a las instrucciones del servicio médico o PCO y a la llegada del personal de primeros auxilios avanzados, SAMU o Bomberos.

- A la llegada del personal de salud, informa las acciones realizadas y se pone a disposición de las indicaciones que el personal de salud. Si la situación lo permite, recoge los datos de la persona (nombre, número de D.N.I., dirección, $\mathrm{N}^{\circ}$ de tarjeta de LÍNEA 1, estación de ingreso, estación de salida) y solicita al usuario el llenado de la declaración jurada de atención.

- Sea el caso que alguna persona se sienta mal o sufra algún accidente antes de hacer uso del servicio y no habiendo realizado el pago de su pasaje (que se encuentre en zona no paga), se le conducirá al tópico de la estación brindándosele la atención necesaria. Este caso recibe el mismo tratamiento y llenado de formatos que cualquier usuario atendido en zona paga.

- Al finalizar la atención médica el personal de estaciones redacta un reporte con los datos referentes al hecho: datos generales de la persona afectada por 
el malestar, su eventual declaración, el estado de operatividad de los andenes, zonas de ingreso, escaleras y otros puntos de la estación eventualmente señalados como causa del malestar o del accidente.

\section{Supervisor, Operador y Asistente del PCO}

El supervisor, operador o asistente del PCO que tome conocimiento de una o varias personas que requieran asistencia, realiza lo siguiente:

- Recibe la información del evento, estado de la persona, identificando lo sucedido, lugar donde ocurrió el evento.

- Supervisa a través del sistema de Circuito cerrado de televisión (CCTV), sobre la naturaleza del evento y/o emergencia validando la información reportada por el personal de estación, además tiene énfasis en el estado de la persona, realizando las siguientes acciones para los siguientes casos:

\section{Persona convulsionando o inconsciente:}

- Activa al menos dos puestos con Personal de Salud del Servicio de Primeros Auxilios Avanzados más cercanos a la estación donde se requiera la asistencia a través de la radio tetra, frecuencia de emergencias.

- Informa al Personal de Salud, la hora de llegada del próximo tren con dirección a la estación que requiere la asistencia, así como el estado del usuario: Persona inconsciente o convulsionando.

- Activa al menos dos Ambulancias del Servicio Primeros Auxilios Avanzados más cercanos a la estación donde se requiera la asistencia a través de la radio tetra, frecuencia de emergencias.

- Llama a través del teléfono de emergencias (teléfono rojo) a los Bomberos, SAMU, y Centro de Control de Seguridad (CCS). Siendo necesario llamar a las tres entidades mencionadas.

- Realiza difusión sonora, cada cinco minutos, en la estación donde ocurre el evento considerando el siguiente mensaje: Estimados clientes, en este momento estamos atendiendo una emergencia. Nuestro personal está realizando la atención de primeros auxilios y un equipo especializado está en camino para el apoyo en la atención. Les pedimos despejar el área y mantener la calma. Gracias por su colaboración. 
- Realiza difusión sonora, cada 05 minutos, a las estaciones afectadas considerando el siguiente mensaje: Estimados clientes, en estos momentos estamos atendiendo una emergencia. Nuestro servicio podría presentar retrasos, les pedimos mantener la calma y seguir las indicaciones de nuestro personal. Gracias por su comprensión.

- Solicita información, de la ubicación del personal de Salud y de la Ambulancia del servicio de Primeros Auxilios Avanzados a través de la radio Tetra, canal de emergencias hasta la llegada a la estación que requiere asistencia.

- Envía correo informativo a la organización y realiza la actualización de la comunicación y clasifica el evento en Nivel 3.

\section{Persona consciente:}

- Activa al personal de Salud del Servicio de Primeros Auxilios Avanzados más cercano a la estación donde se requiera la asistencia, a través de la radio tetra, frecuencia de emergencias.

- Informa al Personal de Salud, la hora de llegada del próximo tren con dirección a la estación que requiere la asistencia, así como el estado del usuario.

- Monitorea el movimiento del servicio médico enviado, confirmando que se brinde la atención médica.

- Evalúa el tiempo de respuesta del servicio médico contratado, pudiendo solicitar el apoyo de los Servicios Médicos Externos (SAMU, CBP, Otros).

- En caso de requerir el apoyo masivo de servicios médicos, solicita el apoyo de los Servicios Médicos Externos (SAMU, CBP, Otros) a través del teléfono de emergencias ( Teléfono Rojo)

- Envía correo informativo y de la actualización del evento, según el Nivel de Comunicación: Nivel 2 (Atención al usuario) o Nivel 3 (Traslado al centro de salud más cercano, persona inconsciente).

\section{Persona caída en la vía Férrea:}

- Activa el comando de parada de emergencia de los trenes en la estación afectada. 
- Luego de activar el comando de parada de emergencia se comunica con el encargado de estación, a través de la radio tetra, canal "tráfico general", y al Centro de Control de Seguridad, a través del teléfono de emergencia (rojo), autorizando el ingreso a la vía para la atención de primeros auxilios.

- Dispone la detención de los trenes que se encuentren próximos a ingresar a la estación afectada.

- Sigue los pasos de atención al usuario en función al estado de la persona: persona consciente o inconsciente

- Realiza difusión sonora, cada cinco minutos, en la estación donde ocurre el evento considerando el siguiente mensaje: Estimados clientes, en este momento estamos atendiendo una emergencia. Nuestro personal está realizando la atención de primeros auxilios y un equipo especializado está en camino para el apoyo en la atención. Les pedimos despejar el área, no ingresar a la vía y mantener la calma. Gracias por su colaboración.

- Realiza difusión sonora, cada 05 minutos, a las estaciones afectadas considerando el siguiente mensaje: Estimados clientes, en estos momentos estamos atendiendo una emergencia. Nuestro servicio podría presentar retrasos, les pedimos mantener la calma y seguir las indicaciones de nuestro personal. Gracias por su comprensión

- Cuando recibe confirmación del Agente de Estación que la persona ha sido retirada de la vía férrea, coordina la reanudación de la circulación en el tramo afectado.

\section{Persona al interior de un Tren:}

○ Informa sobre el evento a través de la radio tetra, canal "tráfico general", al personal de la estación siguiente para que se dirija al andén a brindar los primeros auxilios básicos en el interior del tren.

- Sigue los pasos descritos según el estado de la persona: persona consciente o inconsciente.

- Recibe la confirmación de que la persona ha sido evacuada del tren y ordena al conductor reanudar la marcha. 


\section{Conductores de Trenes}

El conductor de tren que tome conocimiento de una o varias personas que requieran asistencia, realiza lo siguiente:

\section{Acciones para la atención de una persona al interior de un Tren:}

- Informa sobre el evento (descrito por los usuarios a través del intercomunicador) a través de la radio tetra, canal "tráfico general", al PCO, indicando al menos el número de tren y el nombre de la próxima estación.

- Realiza difusión sonora al interior del tren y solicita el apoyo al personal de seguridad a bordo del tren, emitiendo el siguiente mensaje: Personal de Seguridad acercarse al coche $\mathrm{N}^{\circ}$ (describir número de coche) para la asistencia de un cliente.

- Llega a la siguiente estación y realiza la apertura general de puertas.

- Espera la confirmación del Personal de Estación o PCO de que el usuario ha sido evacuado y reanuda la marcha.

\section{Acciones para una persona caída en la vía Férrea:}

- Aplica freno de emergencia del tren e informa al PCO a través de la radio tetra, canal "tráfico general" informando el número de tren y el nombre de la estación afectada.

- Realiza difusión sonora al interior del tren, emitiendo el siguiente mensaje cada 05 minutos: Estimados clientes, en estos momentos el servicio ha sido detenido para atender una emergencia en la vía. Nuestro personal está realizando los protocolos de seguridad exigidos. Les pedimos mantener la calma y seguir las indicaciones de nuestro personal. Gracias por su colaboración.

- Espera la confirmación del PCO informando que la vía se encuentra liberada y procede a reanudar la marcha.

- En caso el usuario se retire por sus propios medios de la vía, informa dicha situación y espera la confirmación del PCO para reanudar la marcha. 


\section{Personal del Servicio de Primeros Auxilios Avanzado}

El personal del Servicio de Primeros Auxilios Avanzados que toma conocimiento de una o varias personas que requieran asistencia de primeros auxilios, realiza lo siguiente:

- Recibe la información del PCO del lugar, tipo del evento y hora del próximo tren a través de la radio Tetra, canal "Emergencias".

- Evalúa la frecuencia del próximo tren y la disponibilidad de la ambulancia e informa al PCO el medio que utilizará para dirigirse a la estación que requiere el auxilio.

- En el caso de que el usuario se encuentre en la vía, usa la ambulancia como único medio de transporte

- Informa a través de la radio tetra, canal de emergencias, la hora de partida de la estación de origen y la hora de llegada a la estación destino o a la estación más cercana, dependiendo si la persona a ser atendida se encuentra fuera o dentro de la estación

- Solicita al PCO información del evento, teniendo énfasis en el lugar exacto donde se encuentra el usuario así como su estado de conciencia.

- En caso el usuario se encuentre inconsciente y de ser necesario, coordina con el agente de estación, a través de la radio Tetra, canal "emergencias", las acciones complementarias a los primeros auxilios básicos hasta su llegada a la estación.

- Al llegar a la estación, se dirige hacia el usuario y brinda los primeros auxilios avanzados, de ser necesario solicita apoyo al AVP o agente de estación para trasladar o mover al usuario con la tabla rígida o la silla de ruedas, dependiendo de la naturaleza del caso.

- En caso el usuario se encuentre en la vía, informa su ingreso al PCO.

- Decide si el usuario requiere ser trasladado e informa sobre esta decisión al PCO indicando el nombre del establecimiento de salud de destino, la hora de partida de la estación y la hora de llegada al centro de salud, a través de la radio tetra, canal emergencias.

- Termina la atención y redacta un informe y lo envía al área de Seguridad en un plazo no mayor a 24 horas.

- $\quad$ En caso de fallecimiento de la persona, informa la situación al PCO. 


\section{Servicio de Agentes de Vigilancia Privada (AVP):}

El personal del Servicio de Agentes de Vigilancia Privada (AVP) que tome conocimiento de una o varias personas que requieran asistencia de primeros auxilios, realiza lo siguiente:

En las estaciones y andenes:

- Informa al Personal de Estación, a través de los medios de comunicación disponibles, sobre el evento, indicando el lugar exacto del usuario y su estado de conciencia. En caso de encontrarse en el Andén informa el evento al PCO través del intercomunicador de emergencias.

- Apoya en la aplicación de los auxilios básicos y espera la llegada del personal de estaciones.

- Apoya en la evacuación del usuario hacia el tópico y queda atento a las indicaciones del Personal de Estación.

- Informa el evento al Centro de Control de Seguridad.

\section{Persona al interior de un Tren:}

- Informa primero al Conductor del tren, a través del intercomunicador y luego a su Centro de Control con los medios de comunicación disponibles, sobre el evento, indicando el coche donde se encuentra el usuario y su estado de conciencia.

- Se acerca al número de coche indicado por el conductor y apoya en los primeros auxilios básicos.

- A la llegada a la siguiente estación, apoya en la evacuación del usuario realizando el relevo con el AVP de andén o de estación, retornando al servicio en el tren asignado, solo en el caso que no cuente con relevo de AVP en el andén, apoya la evacuación hacia el tópico, e informa dicha situación al Centro de Control de Seguridad.

\section{Persona caída en la vía Férrea:}

- Informa el evento al PCO a través del intercomunicador de emergencia, indicando su nombre y apellido y el nombre de la estación. Espera en el intercomunicador la comunicación del PCO indicando que la vía se encuentra bloqueada y que es posible ingresar a la vía. 
- Se acercará a la estación de emergencia que se encuentra en el andén y dispone de la tabla rígida, collarín, inmovilizador de cabeza y correas de sujeción.

- Ingresa a la vía con la tabla rígida, collarín, inmovilizador de cabeza y correas de sujeción, para apoyar en los primeros auxilios básicos.

- Espera la llegada del encargado de la estación y apoyará el traslado hacia el tópico. Toda caída involuntaria a la vía puede generar lesiones considerables, por lo que independiente al estado de consciencia del usuario, se le evacua aplicando las técnicas de primeros auxilios correspondientes (inmovilización).

- Informa el evento al Centro de Control de Seguridad.

Terminada la atención, en cualquiera de los casos, redacta un reporte y lo enviará al área de Seguridad en un plazo no mayor a 24 horas.

El proceso de atención de emergencias en Linea 1 encuentra descrito en la Figura 3.1 .

En la tabla 3.1 se observa que la ubicación del personal de salud, durante todo el horario de operación es el siguiente:

- Enfermero 1 en la Estación Villa el Salvador

- Enfermero 2 en la Estación Atocongo

- Enfermero 3 en la Estación La Cultura

- Enfermero 4 en la Estación Los Jardines

- Enfermero 5 en la Estación Bayovar 
Figura 3.1.

Flujograma actual de atención de accidentes en Línea 1

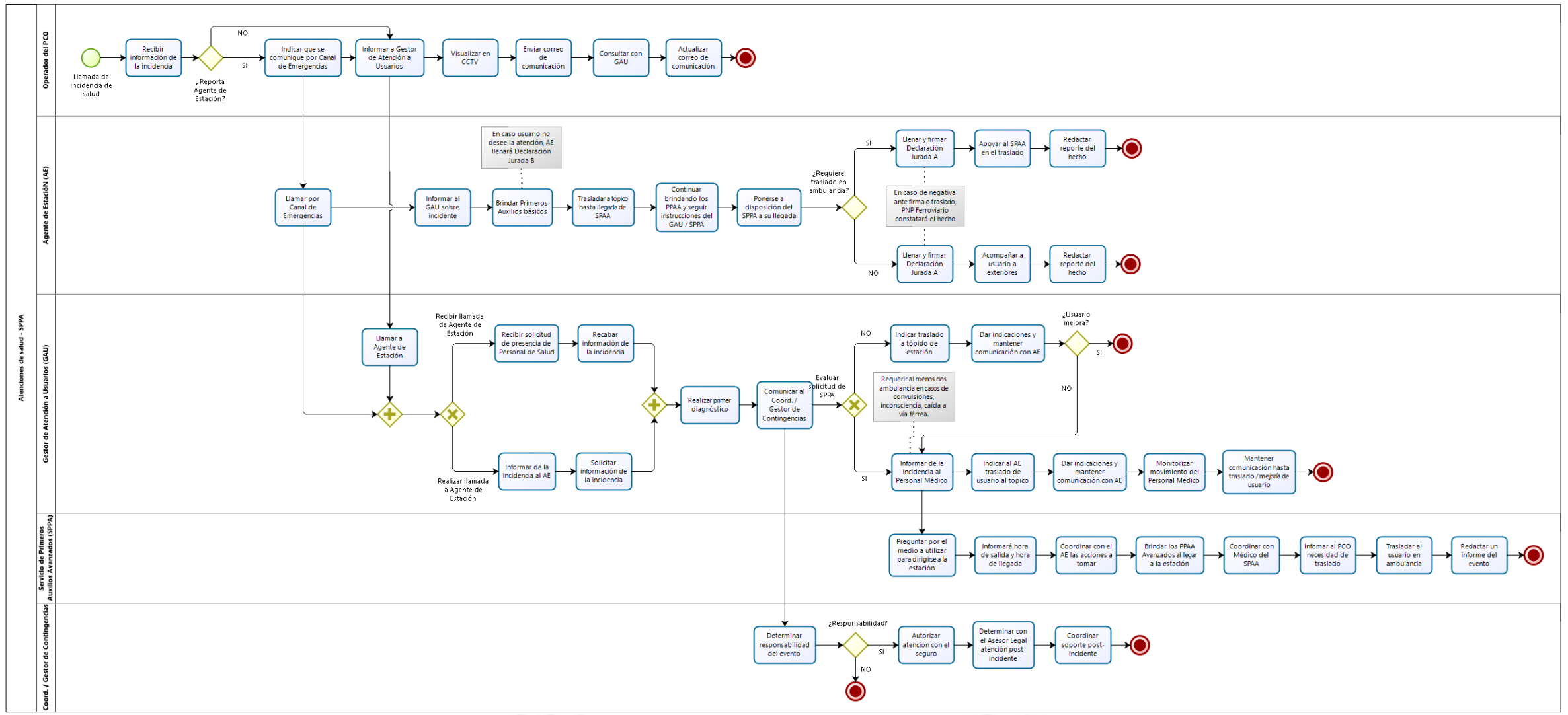

Elaboración Propia 


\section{Tabla 3.1}

Ubicación actual del personal de salud

\begin{tabular}{|c|c|c|c|c|c|c|c|c|c|c|c|c|c|c|c|c|c|c|c|c|c|c|c|}
\hline \multirow{2}{*}{$\begin{array}{l}\text { Horario / Estación: } \\
\text { Lunes a domingo }\end{array}$} & VES PIN & PUM & VMA & MAU & SJU & ATO & $\mathrm{JCH}$ & AYA & $\mathrm{CAB}$ & ANG & SBS & CUL & NAR & GAM & MIG & ELA & PRE & CAA & PIR & JAR POS & SCA & SMA SRA & BAY \\
\hline & E1 & & & & & E2 & & & & & & E3 & & & & & & & E4 & & & & E5 \\
\hline
\end{tabular}

Nota: E1=enfermero 1; E2=enfermero 2; E3=enfermero 3; E4=enfermero 4; E5=enfermero 5

Elaboración Propia 


\section{Proceso de identificación de peligros y evaluación de riesgos (Prevención de}

accidentes):

A continuación detallaremos el proceso de identificación de peligros y evaluación de riesgos de las estaciones y trenes:

En la primera parte del desarrollo de esta matriz se identifican y clasifican los procesos, sub procesos y actividades rutinarias y no rutinarias con la finalidad de identificar los principales peligros, riesgos y los controles asociados a dichas actividades, asimismo, se deberá tener en cuenta los controles existentes. En esta etapa es necesaria la participación del siguiente personal:

- Gerente de Operaciones Ferroviarias (Líder del proceso).

- Jefes de Área de la Unidad (Responsables de los procesos)

- Ingenieros Supervisores/Ingenieros Residentes

- Jefes/Ingeniero/Técnico y/o especialistas de Seguridad de Línea 1.

- Representantes del Sub Comité de Seguridad y Salud en el Trabajo de Línea 1.

- Otros (en caso se requiera personal especializado).

\section{Definir el proceso, sub-proceso.}

- A través del mapa de procesos de Línea 1, se identifican el proceso y el subproceso de atención al cliente en estaciones y trenes.

- Luego se definen las actividades que componen el proceso de atención de usuarios en las estaciones y trenes.

\section{Identificación de puestos de trabajo o funciones especiales por actividad}

Identificar los puestos de trabajo o funciones especiales que participan en la actividad a analizar. Ver Tabla 3.2. 
Tabla 3.2

Matriz de actividades por puesto de trabajo

\section{MATRIZ DE ACTIVIDADES POR PUESTO DE TRABAJO}

\begin{tabular}{|c|l|l|l|}
\hline Fecha de Actualización : & & Proyecto: & \\
\hline Actualizado por: & \multicolumn{2}{|l|}{} \\
\hline Puesto : & \multicolumn{2}{|l}{} \\
\hline Área : & \multicolumn{2}{|l}{} \\
\hline
\end{tabular}

- Nota: Se deberá colocar las actividades y puestos de trabajo por cada

proyecto

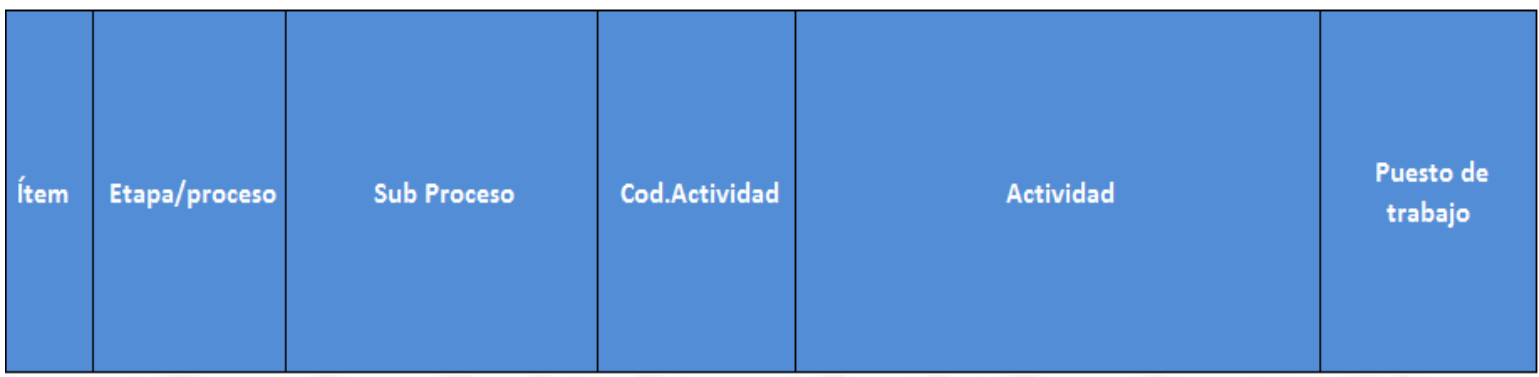

Fuente: Concar (2017)

\section{Identificación de Peligros.}

Luego se procede a completar la sección de identificación de peligros. Ver tabla 3.3.

Tabla 3.3

Tabla de identificación de peligros.

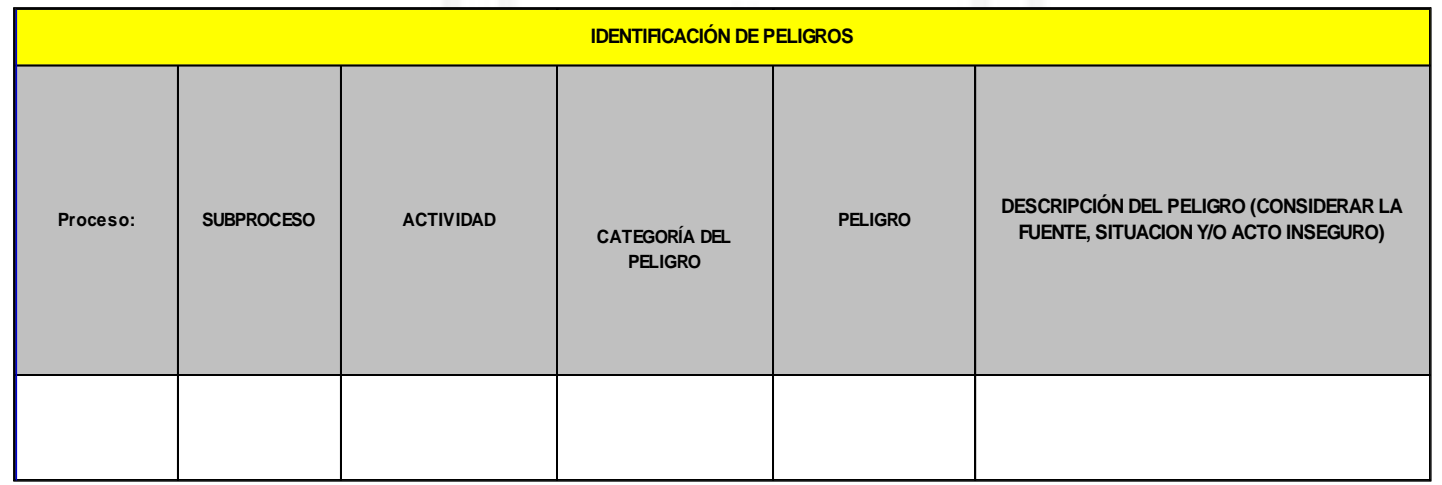

Fuente: Concar (2017) 


\section{Evaluación de riesgo.}

Luego se procede a completar la sección de evaluación del riesgo. Ver tabla 3.4.

Tabla 3.4

Tabla de evaluación del riesgo.

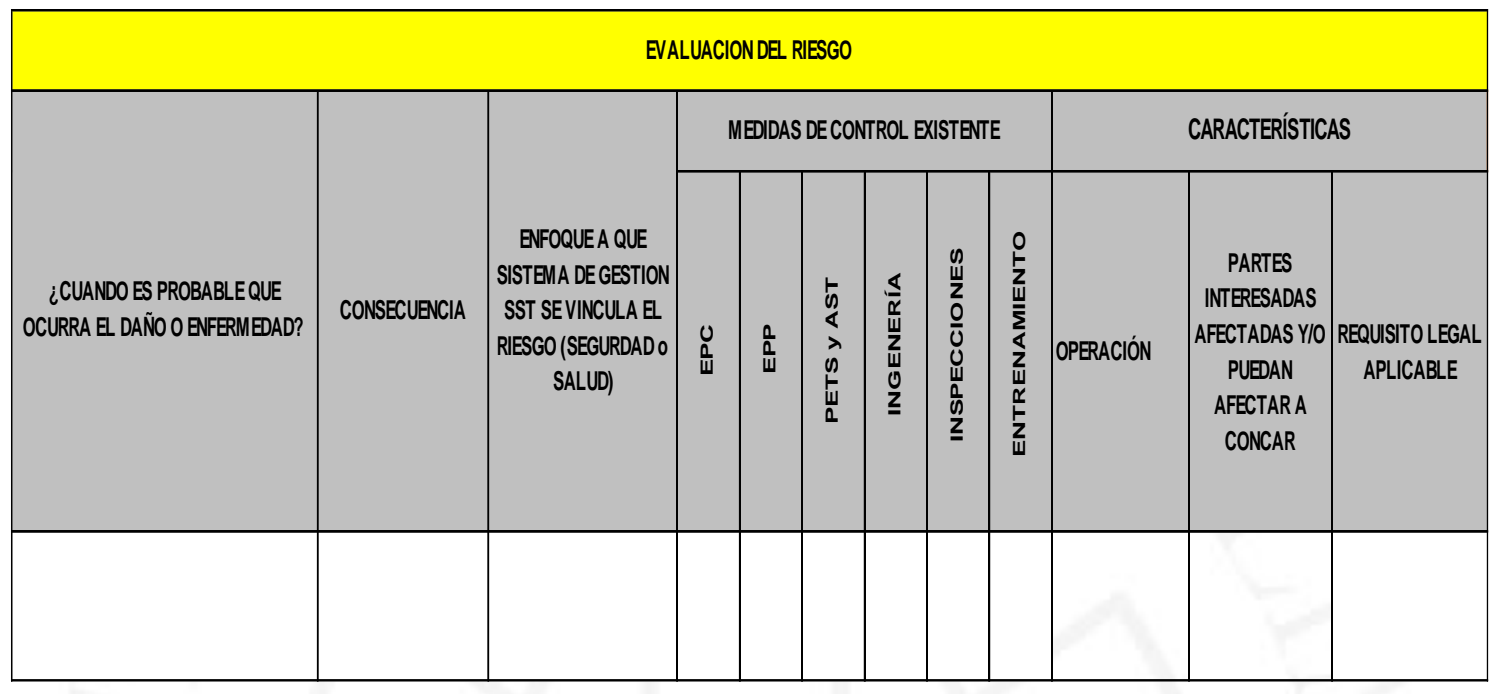

Fuente: Concar (2017)

- ¿Cuándo es probable que ocurra un daño o una enfermedad?: en esta parte se describe la situación específica que dada las condiciones y manifestación del peligro hay mayor posibilidad de causar un accidente/incidente el peligro.

- Consecuencia: Describe el posible resultado del evento evaluado, puede ser lesión personal o daño a la salud ocupacional.

- Enfoque a que Sistema de Gestión de Seguridad se vincula el riesgo: Considera si la lesión o daño está relacionado con un accidente operacional.

- Medidas de Control Existente: Son las medidas para controlar el riesgo estas pueden ser: equipos de protección colectiva (EPC), equipos de protección personal (EPP), procedimiento escrito de trabajo seguro (PETS), Análisis de seguridad (AST), ingeniería, inspecciones, entrenamiento u otros especifico.

- Operación: Se refiere a las características de la Operación, pueden ser: Rutinaria y no rutinaria.

- Rutinaria, son actividades programadas y frecuentes.

- No rutinaria, son actividades periódicas, ocasionales, o de emergencia. 
- Partes interesadas afectadas y/o puedan afectar a Concar: Pueden ser “Terceros o Propios", se refiere si los riesgos son causados por "terceros o propios" de la operación de CONCAR.

- Requisito legal aplicable: Detallar la Ley o Norma aplicable.

\section{Valoración del Riesgo.}

En esta parte se procede a completar la tabla 3.5, debemos tener en cuenta que en la que para llevar esta tabla debemos tener en cuenta la tabla de índice de riesgos y la tabla de valor de severidad que se detalla en la tabla 3.6

Tabla 3.5

Tabla de valoración de los riesgos.

\begin{tabular}{|c|c|c|c|c|c|c|}
\hline \multicolumn{7}{|c|}{ VALORACION DEL RIESGO } \\
\hline \multicolumn{6}{|c|}{ ÍNDICES } & $\begin{array}{c}\text { RIESGO } \\
\text { PURO }\end{array}$ \\
\hline 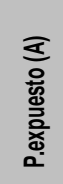 & 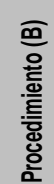 & 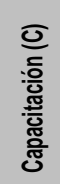 & 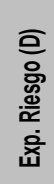 & 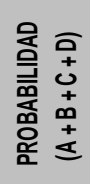 & 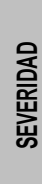 & 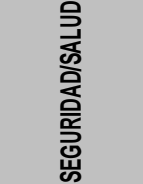 \\
\hline & & & & & & 0 \\
\hline & & & & & & \\
\hline
\end{tabular}

Fuente: Concar (2017) 
Tabla 3.6

Tabla de índice de riesgos

TABLA DE ÍNDICES DE RIESGO

\begin{tabular}{|c|c|c|c|c|}
\hline \multirow{2}{*}{$\begin{array}{l}\text { VALOR } \\
\text { DEL } \\
\text { ÍNDICE }\end{array}$} & \multicolumn{4}{|c|}{ ÍNDICES } \\
\hline & $\begin{array}{c}\text { Personas Expuestas } \\
\text { (A) }\end{array}$ & $\begin{array}{l}\text { Procedimientos Existentes } \\
\text { (B) }\end{array}$ & $\begin{array}{l}\text { Capacitación } \\
\text { (C) }\end{array}$ & $\begin{array}{l}\text { Exposición al Riesgo } \\
\text { (D) }\end{array}$ \\
\hline 1 & De 1 a 3 & $\begin{array}{l}\text { Existen son satisfactorios y } \\
\text { suficientes }\end{array}$ & $\begin{array}{l}\text { Personal entrenado, Conoce } \\
\text { el peligro y lo previene }\end{array}$ & BAJO - Al menos 1 vez al año \\
\hline 2 & $\operatorname{De} 4$ a 12 & $\begin{array}{l}\text { Existen Parcialmente y no } \\
\text { son satisfactorios o } \\
\text { suficientes }\end{array}$ & \begin{tabular}{|l|} 
Personal parcialmente \\
entrenado, conoce el peligro \\
pero no toma acciones de \\
control
\end{tabular} & MEDIO - Al menos 1 vez al mes \\
\hline 3 & Más de 12 & No Existen & $\begin{array}{l}\text { Personal no entrenado, no } \\
\text { conoce peligros, no toma } \\
\text { acciones de control }\end{array}$ & ALTO - Al menos 1 vez al día \\
\hline
\end{tabular}

\begin{tabular}{|c|c|}
\hline \multirow{2}{*}{$\begin{array}{l}\text { VALOR DEL } \\
\text { INDICE }\end{array}$} & SEVERIDAD \\
\hline & Personas \\
\hline \multirow{2}{*}{1} & Lesión sin incapacidad \\
\hline & Dis confort / incomodidad \\
\hline \multirow[t]{2}{*}{2} & $\begin{array}{l}\text { Lesión con incapac. Temporal (cuando la lesión genera en el } \\
\text { accidentado la imposibilidad de utilizar su organismo; se } \\
\text { otorgará tratamiento médico hasta su plena recuperación) }\end{array}$ \\
\hline & Daño a la salud reversible \\
\hline \multirow[t]{2}{*}{3} & $\begin{array}{l}\text { Lesión con incapacidad Permanente (cuando la lesión genera la } \\
\text { pérdida anatómica o funcional total o parcial de un miembro u } \\
\text { órgano; o de las funciones del mismo. Se considera a partir } \\
\text { de la pérdida del dedo meñique) o Muerte. }\end{array}$ \\
\hline & Daño a la salud irreversible \\
\hline
\end{tabular}

Fuente: Concar (2017)

\section{Riesgo Puro}

El riesgo puro es calculado por la multiplicación del índice de probabilidad y el índice de severidad y denota el valor de riesgo puro del proceso analizado.

\section{Determinación de controles}

- Eficiencia del Control: Determinarás si es necesario implementar controles adicionales para mantener el riesgo en un nivel aceptable. Se debe tener en cuenta que la eficiencia del control no quiere decir que se está aumentando una medida de control sino que se está evaluando que tan eficientes son las medidas de control existentes. Se completará la descripción que corresponda al control analizado, puede ser: Excelente, Bueno, Malo, Bajo nivel o en caso no aplique N.A. Se empleará la tabla 3.7. 
Tabla 3.7

Tabla de eficiencia de control

\begin{tabular}{|c|c|c|c|c|}
\hline \multicolumn{5}{|c|}{ EFICIENCIA DE CONTROL } \\
\hline 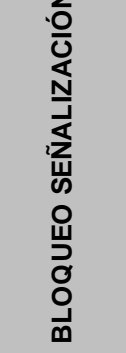 & 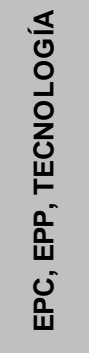 & $\stackrel{\infty}{\square}$ & 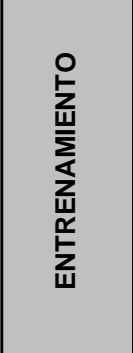 & 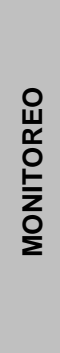 \\
\hline Excelente & Bueno & Malo & Bajo nivel & N.A \\
\hline 0.9 & 0.75 & 0.25 & 0.1 & NA \\
\hline
\end{tabular}

Fuente: Concar (2017)

- Riesgo Residual: Riesgo que resulta después de evaluar las medidas de control adoptadas.

Riesgo Residual $=\mathrm{RP}-(\mathrm{RP} *$ Mitigación $)$

Donde RP = Riesgo Puro.

- Mitigación: Resultado que se obtiene del promedio de la valoración de las medidas de efectividad del nivel de control, este resultado se lleva a porcentaje y se compara con la "Tabla de Significancia del Riesgo Residual" y se establece que otras decisiones deben tomarse para priorizar los controles de acuerdo a la tabla 3.7. 
Tabla 3.8

Tabla de efectividad del nivel de control

\begin{tabular}{|c|c|c|c|c|c|c|}
\hline \multicolumn{7}{|c|}{ TABLA DE EFECTIVIDAD DEL NIVEL DEL CONTROL } \\
\hline$\%$ & DESCRIPCION & $\begin{array}{l}\text { Sistemas de Bloqueo y } \\
\text { Señalización }\end{array}$ & Equipos/ Tecnologia/ EPP/EPC & Monitoreo/ Mantenimiento/ Inspección & Personal/ Entrenamiento & PETS/INSTRUCTIVOS \\
\hline 90 & Excelente & $\begin{array}{l}\text { El sistema de Bloqueo físico de } \\
\text { energías es grupal y está a prueba } \\
\text { de contactos accidenteales y/o } \\
\text { intencionales, se tiene identificado } \\
\text { todos los puntos para el bloqueo de } \\
\text { energias. }\end{array}$ & $\begin{array}{l}\text { El equipo garantiza la integridad } \\
\text { total, sin daños a la seguridad y } \\
\text { salud del trabajador }\end{array}$ & $\begin{array}{l}\text { El monitoreo de los agentes que pueden generar } \\
\text { lesiones al trabajador en las diferentes áreas de } \\
\text { trabajo son planificadas, efectivas y formales, todos } \\
\text { los equipos de monitoreo cuentan con sus } \\
\text { certificados de calibración externa. La maquinaria, } \\
\text { equipos o herramientas cuentan con su plan de } \\
\text { mantenimiento preventivo ejecutado. Los } \\
\text { responsables de las áreas realizan inspecciones } \\
\text { específicas y multidisciplinarias. }\end{array}$ & $\begin{array}{l}\text { Los empleados cuentan con una } \\
\text { formación, habilidad, experiencia } \\
\text { profesional, entrenamiento } \\
\text { específico y formal con una } \\
\text { evaluación de la eficácia del } \\
\text { entrenamiento, y con } \\
\text { conocimientos amplios en el } \\
\text { gerenciamento de Seguridad y } \\
\text { Salud Ocupacional. }\end{array}$ & $\begin{array}{l}\text { Los procedimientos son aprobados } \\
\text { por el equipo multidisciplinario en } \\
\text { Seguridad y Salud Ocupacional y } \\
\text { son de conocimiento y uso por todas } \\
\text { las áreas pertinentes, además se } \\
\text { evalua la eficacia de la } \\
\text { implementación. }\end{array}$ \\
\hline 75 & Bueno & $\begin{array}{l}\text { El sistema de Bloqueo físico de } \\
\text { eneregías es personal y evita } \\
\text { contatos accidentales }\end{array}$ & $\begin{array}{l}\text { El equipo garantiza parcialmente la } \\
\text { integridad de la seguridad y salud } \\
\text { de los trabajadores. }\end{array}$ & $\begin{array}{l}\text { El monitoreo de los agentes que pueden generar } \\
\text { lesiones al trabajador en las diferentes áreas de } \\
\text { trabajo no son planificadas los equipos de monitoreo } \\
\text { solamente cuentan con una calibración interna. La } \\
\text { maquinaría, equipos o herramientas cuentan con su } \\
\text { plan de mantenimiento preventivo pero no es } \\
\text { ejecutado según lo programado. Las inspecciones } \\
\text { que se realizan son generales. }\end{array}$ & \begin{tabular}{|l|} 
Los empleados cuentan con \\
habilidades y experiencia \\
profesional, entrenamiento \\
específico y formal con una \\
evaluación de eficacia del \\
entrenamiento, pero su \\
conocimiento en el gerenciamiento \\
de seguridad y salud ocupacional \\
no son muy amplios.
\end{tabular} & $\begin{array}{l}\text { Los procedimientos son aprobados } \\
\text { solamente por un equipo técnico y } \\
\text { son de conocimiento y uso de las } \\
\text { áreas pertinentes pero no se ha } \\
\text { evaluado la eficacia de } \\
\text { implementación. }\end{array}$ \\
\hline 25 & Malo & $\begin{array}{l}\text { El sistema de Bloqueo físico de } \\
\text { energias es frágil y no evita contatos } \\
\text { accidentales }\end{array}$ & $\begin{array}{l}\text { El equipo no garantiza la integridad } \\
\text { de la seguridad y salud de los } \\
\text { trabajadores. }\end{array}$ & $\begin{array}{l}\text { El monitoreo de los agentes que pueden generar } \\
\text { lesiones al trabajador son realizados } \\
\text { exporadicamente. existe solamente un plan de } \\
\text { mantenimiento correctivo para la maquinarias, } \\
\text { equipos y herramientas. Las inspecciones que se } \\
\text { realizan son esporadicas y las realiza el personal de } \\
\text { PdR\&GA. }\end{array}$ & $\begin{array}{l}\text { Los empleados no cuentan con } \\
\text { habilidades y experiencia } \\
\text { profesional, su entrenamiento es } \\
\text { general y formal, sin evaluación de } \\
\text { eficacia de entrenamiento, su } \\
\text { conocimiento en seguridad y salud } \\
\text { ocupacional es básico. }\end{array}$ & $\begin{array}{l}\text { Los procedimientos no estan } \\
\text { aprobados por el equipo tecnico y no } \\
\text { son conocidos ni utilizados por todas } \\
\text { las áreas pertinentes. }\end{array}$ \\
\hline 10 & Bajo nivel & $\begin{array}{l}\text { No existe el sistema de bloqueo } \\
\text { fisico de eneregias }\end{array}$ & $\begin{array}{l}\text { El equipo no cumple con los } \\
\text { estandares establecidos por la } \\
\text { empresa. }\end{array}$ & $\begin{array}{l}\text { No se monitorea, No existe o no se cumple en plan de } \\
\text { mantenimiento preventivo, ni correctivo, el plan de } \\
\text { inspecciones no existe o no se cumple. }\end{array}$ & $\begin{array}{l}\text { Los empleados no cuentan con } \\
\text { entrenamiento, habilidades y } \\
\text { experiencia. }\end{array}$ & Los procedimientos no existen \\
\hline
\end{tabular}

Fuente: Concar (2017) 
- Significancia; Clasificación final del riesgo evaluado, después de analizar la eficiencia de control. Puede ser: Intolerable, Importante, Tolerable o Trivial.

\section{Tabla de Significancia Riesgo Residual.}

Una vez obtenido el riesgo residual utilizamos la tabla 3.9 para definir y clasificar el nivel de control.

Tabla 3.9

Tabla de significancia riesgo residual

\begin{tabular}{|c|l|l|l|l|l|}
\hline \multicolumn{2}{|c|}{ TABLA DE SIGNIFICANCIA RIESGO RESIDUAL } \\
\hline CLASE & $\begin{array}{c}\text { CLASIFICACIÓN } \\
\text { DEL RIESGO }\end{array}$ & VALOR DE RIESGO & $\begin{array}{c}\text { \% EFECTIVIDAD DEL CONTROL(para } \\
\text { reducir el nivel de riesgo debemos } \\
\text { asegurar que la efectividad de los } \\
\text { Controles Ileguen a los porcentajes } \\
\text { establecidos) }\end{array}$ & $\begin{array}{l}\text { CLASIFICACION DEL NIVEL } \\
\text { DE CONTROL }\end{array}$ \\
\hline & & & & datos de la tabla eficiencia control & $\begin{array}{l}\text { datos de la tabla de la decisión } \\
\text { para la implementación de las } \\
\text { medidas de control }\end{array}$ \\
\hline A & Intolerable & igual $0>24$ & Altamente Especializado & $90 \%$ & Mejor Prática Operacional \\
\hline B & Importante & 17 A 23 & Especializado & $75 \%$ & Prática Operacional Especifica \\
\hline C & Tolerable & 5 A 16 & Definido & $25 \%$ & Prática Operacional Formal \\
\hline D & Trivial & $<4$ & Básico, Lógico & $10 \%$ & Prática Operacional Casual \\
\hline
\end{tabular}

Fuente: Concar (2017)

Según la significancia podemos saber si la tarea se puede realizar o necesita más medidas de control para ejecutarse.

Debemos tener en cuenta que para reducir el nivel de riesgo debemos asegurar que la efectividad de los controles lleguen a los porcentajes establecidos en la tabla de efectividad del nivel del control.

\section{Determinación de controles}

En etapa y luego de haber determinado los valores de significancia del riesgo residual se aplicará la tabla 3.10 
Tabla 3.10

Tabla de decisión para la implementación de medidas de control.

\begin{tabular}{|c|c|c|c|c|c|c|}
\hline $\begin{array}{l}\text { VALOR DE } \\
\text { RIESGO }\end{array}$ & $\begin{array}{l}\text { DESCRIPCION } \\
\text { DEL RIESGO }\end{array}$ & SÍMBOLO & MPO & POE & POF & POC \\
\hline igual $0>24$ & Intolerable & $\mathbf{A}$ & $x$ & & & \\
\hline $18-23$ & Importante & B & & $\mathbf{x}$ & & \\
\hline $6-17$ & Tolerable & $\mathbf{C}$ & & & $\mathbf{x}$ & \\
\hline$<5$ & Trivial & D & & & & $x$ \\
\hline \multicolumn{7}{|c|}{ NÍVEL DE CONTROL QUE DEBE ESTAR IM PLEM ENTADO PARA CONTROLAR "EFETIVAM ENTE" EL RIESGO } \\
\hline A & \multicolumn{6}{|c|}{$\begin{array}{l}\text { MEJOR PRACTICA OPERACIONAL (MPO): No debe comenzar ni continuar el trabajo hasta que } \\
\text { se reduzca el riesgo. Si no es posible reducir el riesgo, incluso con recursos ilimitados, debe } \\
\text { prohibirse el trabajo. E Gerente de proyecto, debe solicitar autorizacion para iniciar las actividade, } \\
\text { esta decisión debe ser autorizada por la Gerencia Operaciones y/o Gerencia Tecnica segun sea } \\
\text { el caso y debe ser dif undida por escrito al proyecto. }\end{array}$} \\
\hline B & \multicolumn{6}{|c|}{$\begin{array}{l}\text { PRÁCTICA OPERACIONAL ESPECÍfICA (POE): Se puede iniciar actividades bajo supervision } \\
\text { permanente y se deben emplear permisos de trabajo de alto riesgo. Se deben mantener los } \\
\text { controles en todo momento y debe evaluarse periodicamente que las medidas de control } \\
\text { implementadas sean ef ectivas. Se debe evaluar la posibilidad de reducir el riesgo, determinando } \\
\text { las inversiones precisas y las medidas de control en un período determinado con el objetivo de } \\
\text { llevarlo a un nivel tolerable. }\end{array}$} \\
\hline C & \multicolumn{6}{|c|}{$\begin{array}{l}\text { PRÁCTICA OPERACIONAL FORM AL (POF): Se puede iniciar actividades bajo supervision } \\
\text { eventual y con una persona encargada responsable de liderar el Analisis Seguro de Trabajo, asi } \\
\text { mismo se deben evaluar periodicamente que las medidas de control implementadas sean } \\
\text { efectivas. } \\
\text { Cuando el riesgo es tolerable y está asociado con consecuencias extremadamente dañinas } \\
\text { (mortal o muy graves), las medidas de control deben ser implementadas de forma inmediata. Se } \\
\text { de evaluar la posibilidad de reducir el riesgo, determinando las inversiones precisas y las medidas } \\
\text { de control en un período determinado con el objetivo de llevarlo a un nivel trivial. }\end{array}$} \\
\hline D & \multicolumn{6}{|c|}{$\begin{array}{l}\text { PRÁCTICA OPERACIONAL CASUAL (POC): Se deben mantener la eficiencia de los controles } \\
\text { implemenatdos y no se necesita adoptar ninguna acción adicional. }\end{array}$} \\
\hline
\end{tabular}

Fuente: Concar (2017)

\section{Medidas de control adicionales para riesgos con significancia importante e}

\section{intolerables}

Finalmente se colocarán las medidas adicionales que se hayan decidido implementar para disminuir el nivel del riesgo, estas deberán ser aprobadas de acuerdo a lo declarado en la sección de responsabilidades del presente procedimiento.

Para la definición de estas medidas de control adicionales deberán participar:

- Gerente de Operaciones,

- Superintendente de Seguridad y Medio Ambiente

- Otros, (personal especializado, solo si es necesario).

Con la finalidad de entender la aplicación de las fases descritas en los párrafos anteriores, en la tabla 3.10 se muestra un ejemplo de la aplicación del este procedimiento. 
Tabla 3.11

Matriz de identificación de peligros y evaluación de riesgos para la atención de pasajeros en las estaciones

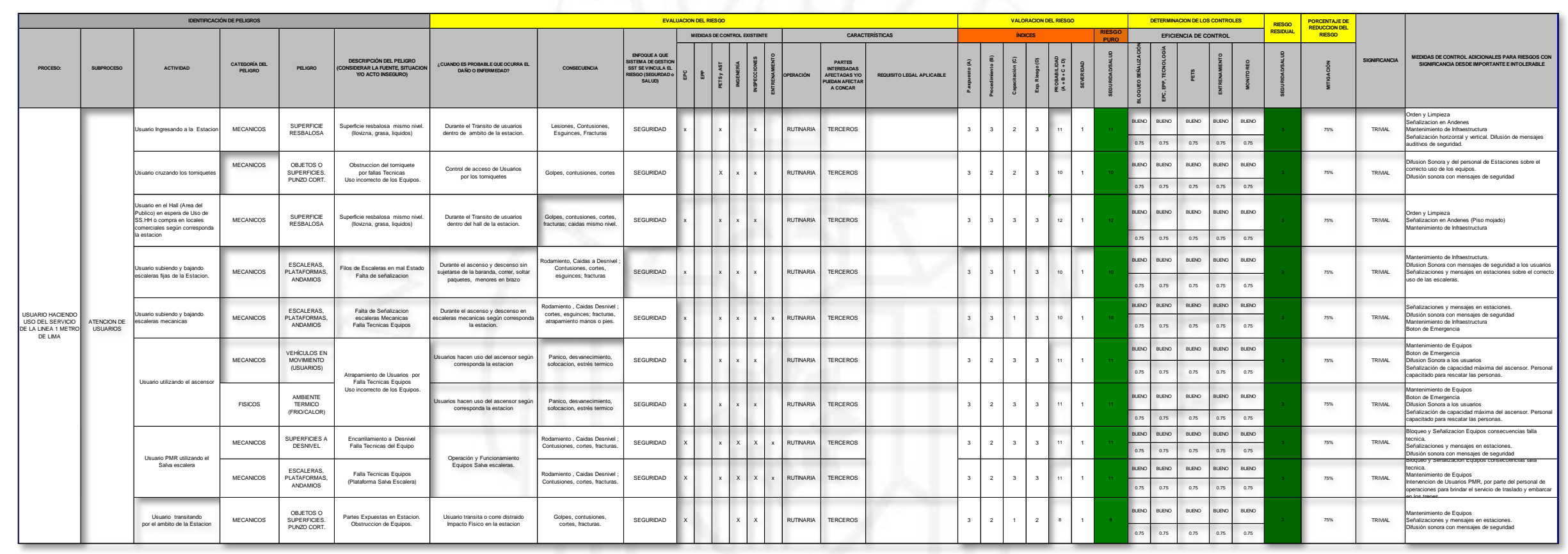

Fuente: GyM Ferrovías (2018) 


\subsubsection{Análisis de los indicadores específicos de desempeño del sistema o proceso.}

Línea 1 cuenta con un plan de actividades que permiten reducir la accidentabilidad de los usuarios a través de acciones de prevención como son: Señalización, inspecciones a las instalaciones, campañas audiovisuales dirigidas los usuarios, entre otras estrategias. Para el caso las atenciones por enfermedad resultan que las estrategias de reducción de estos casos obedecen a una política de salud pública, siendo poca efectiva las actividades que Línea 1 pudiese aplicar. Por otro lado, si es responsabilidad Línea 1 cumplir con lo estipulado en los planes de contingencias y demostrar diligencia en la aplicación de protocolos que ayuden a brindar soporte adecuado y oportuno en la asistencia de personas que requieran atención de primeros auxilios. En el año 2015 Línea 1, sin necesidad de estar obligado contractualmente, contrató un servicio de prestación de primeros auxilios avanzados para la atención accidentes y enfermedades, el servicio consta de la asignación de personal de salud y ambulancias distribuidas a lo largo de las 26 estaciones. Dicha asignación estaba en función a la distancia entre estaciones y no se habían considerado aspectos como probabilidad de ocurrencia de atenciones médicas por estación, frecuencia de paso de trenes, tráfico, horas punta y horas valle y otras variables que podrían optimizar la asignación de recursos y así minimizar los tiempos de respuesta a emergencias.

Durante el año 2018 se registraron un total de 559 accidentes con pasajeros y un total de 2,916 atenciones por enfermedad común. Ver Tabla 3.12 Asimismo realizando un análisis de la estadística, se puede observar que existe una tendencia al alza.

Por otro lado la cantidad de pasajeros transportados en el año 2018 se incrementó en casi 3 millones de pasajeros, respecto al año 2017 (Ver Figura 3.2) por lo que la probabilidad de tener más casos de accidentes y atenciones por enfermedades también se incrementó, sin embargo este incremento no es proporcional al incremento de usuarios al sistema. Tal como se observa en la Tabla 3.13 los indicadores de accidentabilidad por millón de pasajeros transportados tuvieron un leve incremento durante todo el 2018. 
Tabla 3.12

Estadística de incidentes con usuarios durante el año 2018.

\begin{tabular}{|l|rcccccc|}
\hline & \multicolumn{7}{|c|}{$\mathbf{N}^{\circ}$ de eventos } \\
\hline Mes & $\begin{array}{r}\text { Pasajeros } \\
\text { transportados }\end{array}$ & $\begin{array}{c}\text { Ingresos a } \\
\text { la vía }\end{array}$ & $\begin{array}{c}\text { Caídas } \\
\text { en } \\
\text { estación }\end{array}$ & $\begin{array}{c}\text { Impacto } \\
\text { físico } \\
\text { (golpes) }\end{array}$ & $\begin{array}{c}\text { Golpes en } \\
\text { el cierre } \\
\text { de puertas }\end{array}$ & $\begin{array}{c}\text { Atención } \mathbf{x} \\
\text { Enfermedad }\end{array}$ & $\begin{array}{c}\text { Total } \\
\text { Accidentes }\end{array}$ \\
\hline ENE & $8,764,205$ & 5 & 16 & 0 & 21 & 121 & $\mathbf{4 2}$ \\
FEB & $8,629,584$ & 3 & 14 & 0 & 15 & 157 & $\mathbf{3 2}$ \\
MAR & $9,475,698$ & 5 & 18 & 1 & 6 & 167 & $\mathbf{3 0}$ \\
ABR & $9,195,364$ & 3 & 18 & 0 & 13 & 178 & $\mathbf{3 4}$ \\
MAY & $10,036,151$ & 3 & 22 & 0 & 20 & 199 & $\mathbf{4 5}$ \\
JUN & $9,954,778$ & 1 & 30 & 0 & 19 & 254 & $\mathbf{5 0}$ \\
JUL & $10,366,547$ & 2 & 31 & 2 & 16 & 213 & $\mathbf{5 1}$ \\
AGO & $10,928,543$ & 5 & 23 & 3 & 6 & 289 & $\mathbf{3 7}$ \\
SET & $10,962,378$ & 3 & 23 & 3 & 14 & 338 & $\mathbf{4 3}$ \\
OCT & $11,411,104$ & 3 & 44 & 1 & 12 & 364 & $\mathbf{6 0}$ \\
NOV & $11,549,058$ & 1 & 42 & 0 & 8 & 201 & $\mathbf{5 1}$ \\
DIC & $12,844,770$ & 4 & 45 & 3 & 32 & 435 & $\mathbf{8 4}$ \\
\hline Total & $\mathbf{1 2 4 , 1 1 8 , 1 8 0}$ & $\mathbf{3 8}$ & $\mathbf{3 2 6}$ & $\mathbf{1 3}$ & $\mathbf{1 8 2}$ & $\mathbf{2 9 1 6}$ & $\mathbf{5 5 9}$ \\
\hline
\end{tabular}

Fuente: GyM Ferrovías (2018)

Figura 3.2

Número de pasajeros transportados durante el 2018.

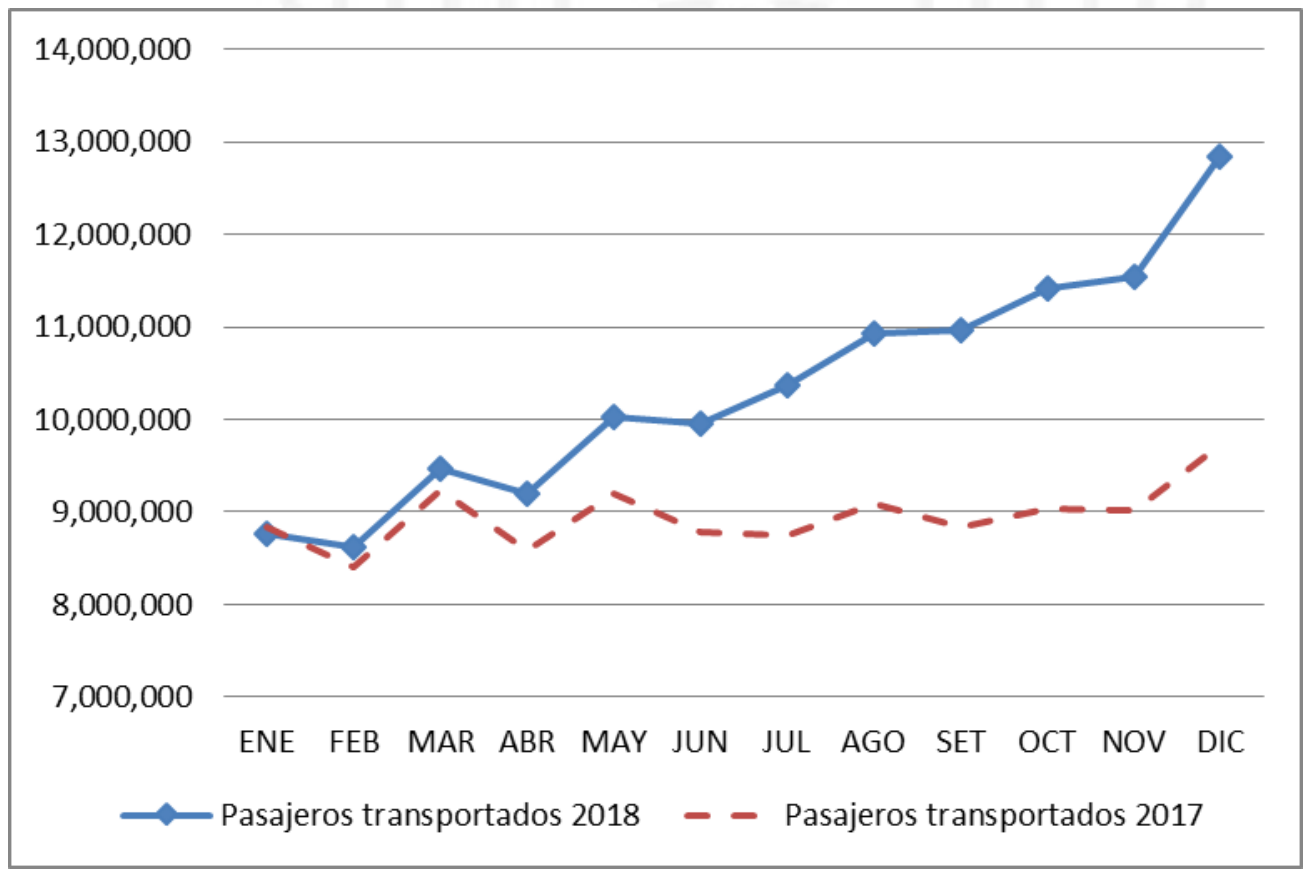

Fuente: GyM Ferrovías (2018) 
Tabla 3.13

Indicadores de accidentabilidad por millón de pasajeros transportados durante el año 2018

\begin{tabular}{lllllll}
\hline Mes & $\begin{array}{c}\text { Usuario en } \\
\text { la Vía x M }\end{array}$ & $\begin{array}{c}\text { Caída en } \\
\text { Estación x } \\
\mathbf{M}\end{array}$ & $\begin{array}{c}\text { Impacto } \\
\text { Físico x } \\
\mathbf{M}\end{array}$ & $\begin{array}{c}\text { Atasco en } \\
\text { Puerta } \mathbf{~ M ~}\end{array}$ & $\begin{array}{c}\text { Atención } \\
\text { de Usuarios } \\
\mathbf{x ~ M}\end{array}$ & $\begin{array}{c}\text { Accident } \\
\text { abilidad } \\
\mathbf{x ~ M}\end{array}$ \\
\hline ENE & 0.6 & 1.8 & 0.0 & 2.4 & 13.8 & 4.2 \\
FEB & 0.3 & 1.6 & 0.0 & 1.7 & 18.2 & 3.4 \\
MAR & 0.5 & 1.9 & 0.1 & 0.6 & 17.6 & 2.6 \\
ABR & 0.3 & 2.0 & 0.0 & 1.4 & 19.4 & 3.4 \\
MAY & 0.3 & 2.2 & 0.0 & 2.0 & 19.8 & 4.2 \\
JUN & 0.1 & 3.0 & 0.0 & 1.9 & 25.5 & 4.9 \\
JUL & 0.2 & 3.0 & 0.2 & 1.5 & 20.6 & 4.7 \\
AGO & 0.5 & 2.1 & 0.3 & 0.5 & 26.4 & 2.9 \\
SET & 0.3 & 2.1 & 0.3 & 1.3 & 30.8 & 3.6 \\
OCT & 0.3 & 3.9 & 0.1 & 1.1 & 31.9 & 5.0 \\
NOV & 0.1 & 3.6 & 0.0 & 0.7 & 17.4 & 4.3 \\
DIC & 0.3 & 3.5 & 0.2 & 2.5 & 33.9 & 6.2 \\
\hline TOTAL & $\mathbf{0 . 3}$ & $\mathbf{2 . 6}$ & $\mathbf{0 . 1}$ & $\mathbf{1 . 5}$ & $\mathbf{2 3 . 5}$ & $\mathbf{4 . 2}$ \\
\hline
\end{tabular}

Fuente: GyM Ferrovías (2018)

Debido a que la asignación del personal de salud no era la óptima los indicadores de tiempos de respuesta podían llegar a 44 minutos en algunos casos y en promedio 30 minutos. Ver Figura 3.3

Figura 3.3

Tiempo de respuesta para la atención de incidentes médicos Línea 1, 2018.

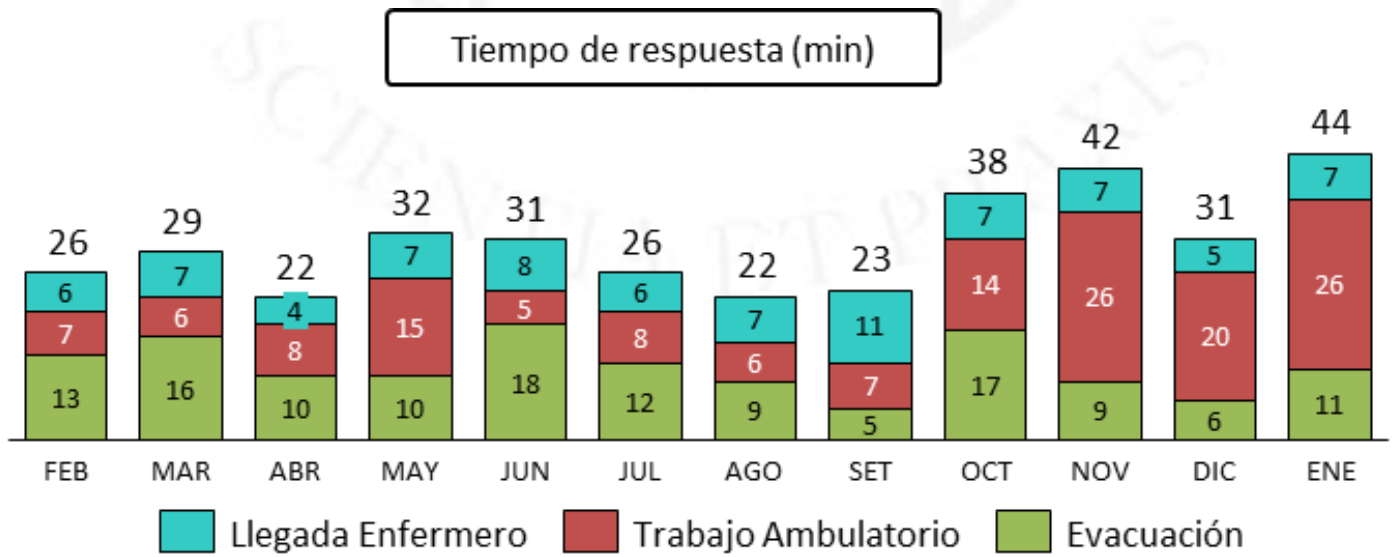

Elaboración propia. 
El nivel de riesgo frente a una situación que requiera ayuda médica en un sistema que transporta miles de personas al día es muy alto tal como se analiza a continuación:

- Amenazas: alta probabilidad de que un usuario sufra una enfermedad y/o accidente, esto se debe a que no podemos controlar el estado de salud de los pasajeros, esta probabilidad aumenta en las horas pico y su incidencia es proporcional a la cantidad de pasajeros transportados.

- Vulnerabilidad: está relacionada a la capacidad de la Línea 1 de reaccionar frente a una emergencia compleja, para nuestro caso la vulnerabilidad depende la capacidad de respuesta de las unidades ambulancias propias y de terceros que resuelvan casos de mayor complejidad.

Por lo general la demora en la ejecución o la ejecución prolongada de los protocolos de atención de pasajeros generan noticias negativas, las cuales se expanden rápidamente por las redes sociales y los medios de comunicación, generando una mala imagen para la organización.

En al año 2018, ocurrieron accidentes e incidentes que generaron noticias negativas en los medios de comunicación por un valor referencial de 6 millones de soles (Línea 1, 2019). Valor que es calculado en función al valor del tiempo que le dedican en los medios de comunicación estas noticias. En tal sentido es necesario la implementación de medidas que ayuden a reducir y mitigar el impacto mediático generado por este tipo de incidentes.

Referente a la identificación de peligros y evaluación de riesgos, el 100\% de los procesos relacionados con la operación ferroviaria cuenta con su matriz IPER elaborado, sin embargo, los controles establecidos en las matrices no son efectivos ya que como se menciona en el presente punto, los indicadores de accidentabilidad han ido en aumento.

\subsection{Determinación de las causas raíz de los problemas hallados}

Para determinar las casusas raíces del problema a mejorar, se utilizó la herramienta de diagrama de espina de pescado o también llamado diagrama de Ishikawa. Ver figura 3.4.

Problema hallado: Incremento de accidentes por millón de pasajeros transportados en la Linea 1 del metro de Lima y su respectivo impacto negativo en los medios de comunicación. 
Con el diagrama causa - efecto se obtienen las siguientes causas raíces:

- Demoras u omisión de actividades en el proceso de atención de Primeros Auxilios Avanzados.

- No existe una política de seguridad operacional definida.

- Proceso de identificación de peligros y riesgos deficiente.

- Materiales inadecuados.

- Inspecciones deficientes.

- Falta de conocimiento interno sobre la seguridad operacional.

- Pasajeros no respetan las normas de uso del sistema.

- Problemas de salud de los pasajeros.

- Escasa promoción de la seguridad para pasajeros.

- Escasa señalización preventiva.

- No hay análisis de fallos de equipos y sistemas.

- $\quad$ No se mide el desempeño en seguridad operacional.

Como se observa en la Figura 3.4., se encontraron varias causas raíz, para lograr identificar las principales, se acordó con la gerencia general asignarle valores según el grado de importancia considerándose los siguientes valores:

- 20 - muy importante

- 15 - importante

- 10 - importancia moderada

- 5 - algo importante

- 1 - poco importante 
Figura 3.4.

Diagrama de Ishikawa

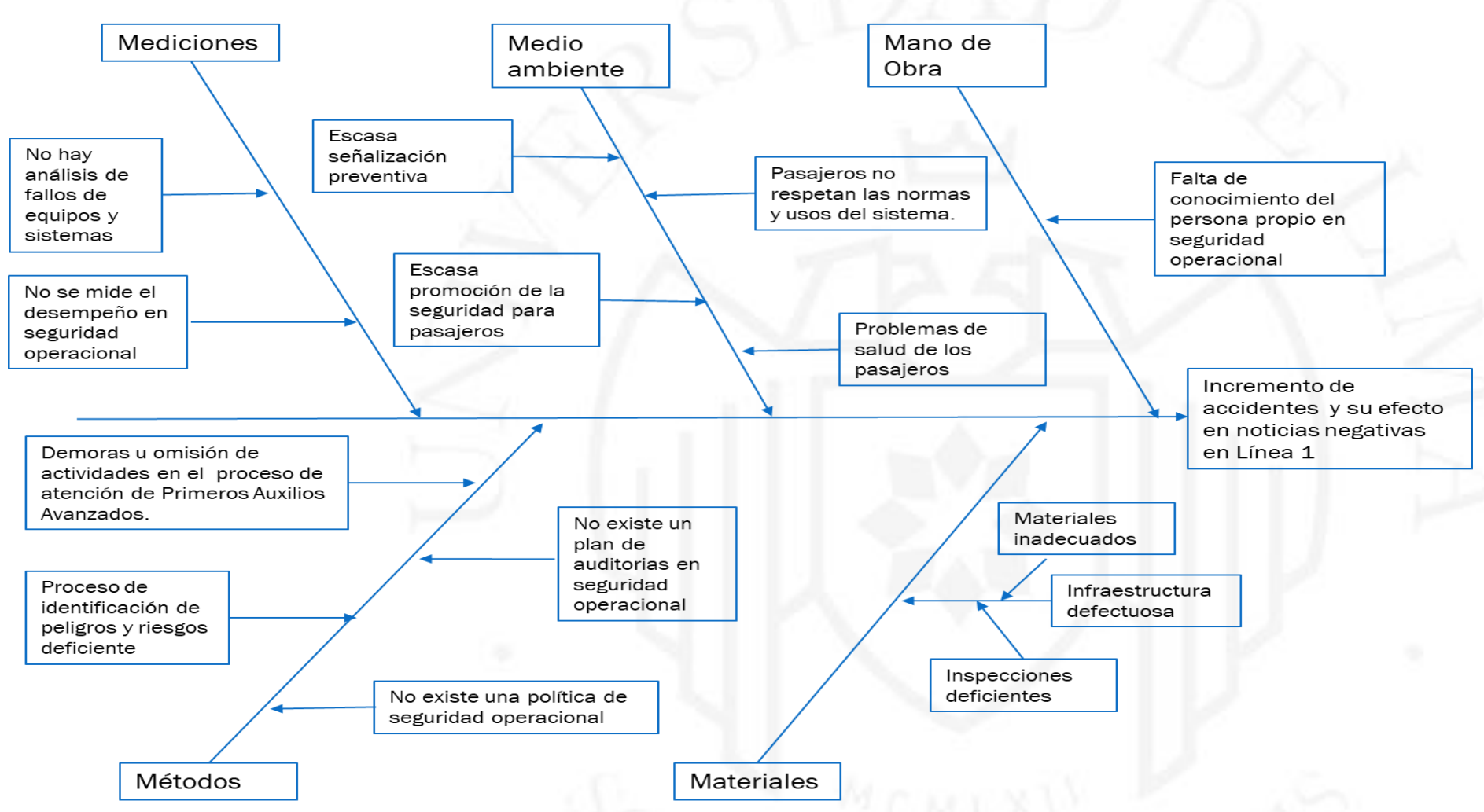

Elaboración Propia 
Tabla 3.14

Tabla de puntaje para el diagrama de Pareto

\begin{tabular}{|c|c|c|c|c|}
\hline id & Causa Raíz & Puntaje & Total & Acumulado \\
\hline 1 & $\begin{array}{l}\text { Demoras u omisión de actividades en el proceso de atención de } \\
\text { Primeros Auxilios Avanzados }\end{array}$ & 20 & $15 \%$ & $15 \%$ \\
\hline 2 & No existe una política de seguridad operacional definida & 20 & $15 \%$ & $30 \%$ \\
\hline 3 & $\begin{array}{l}\text { Proceso de identificación de peligros y evaluación de riesgos } \\
\text { deficiente }\end{array}$ & 20 & $15 \%$ & $45 \%$ \\
\hline 4 & No existe un plan de auditorías en seguridad operacional & 20 & $15 \%$ & $61 \%$ \\
\hline 5 & Falta de conocimiento interno sobre la seguridad operacional & 10 & $8 \%$ & $68 \%$ \\
\hline 6 & Pasajeros no respetan las normas de uso del sistema & 10 & $8 \%$ & $76 \%$ \\
\hline 7 & No hay análisis de fallos de equipos y sistemas & 10 & $8 \%$ & $83 \%$ \\
\hline 8 & Escasa promoción de la seguridad para pasajeros & 5 & $4 \%$ & $87 \%$ \\
\hline 9 & Materiales inadecuados & 5 & $4 \%$ & $91 \%$ \\
\hline 10 & Inspecciones deficientes & 5 & $4 \%$ & $95 \%$ \\
\hline 11 & Escasa señalización preventiva & 5 & $4 \%$ & $98 \%$ \\
\hline 12 & No se mide el desempeño en seguridad operacional & 1 & $1 \%$ & $99 \%$ \\
\hline 13 & Problemas de salud de los pasajeros & 1 & $1 \%$ & $100 \%$ \\
\hline
\end{tabular}

132

Nota: Elaboración de tabla de puntaje para el diagrama de Pareto de acuerdo a opinión del gerente general.

Elaboración Propia

Se decidió atacar las primeras siete causas que abarcan el $83 \%$ del problema, identificándolas como causas principales tal como se muestra en la Figura 3.5. 
Figura 3.5

Diagrama de Pareto

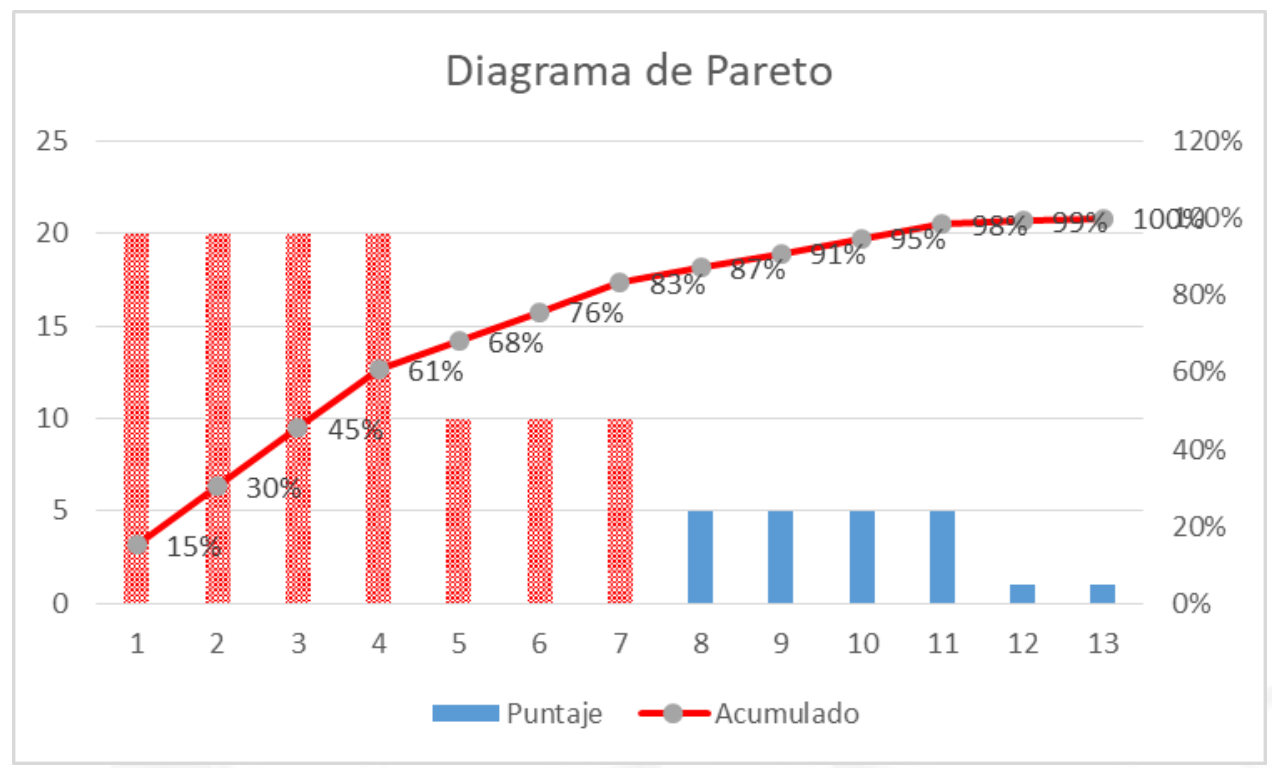

Elaboración Propia

A continuación listamos las 7 principales causas descritas en la tabla 3.14:

- Demoras u omisión de actividades en el proceso de atención de Primeros Auxilios Avanzado.

- No existe una política de seguridad operacional definida

- Proceso de identificación de peligros y evaluación de riesgos deficiente

- No existe un plan de auditorías en seguridad operacional

- Falta de conocimiento interno sobre la seguridad operacional

- Pasajeros no respetan las normas de uso del sistema

- No hay análisis de fallos de equipos y sistemas 


\section{CAPÍTULO IV: DETERMINACIÓN DE LA PROPUESTA DE SOLUCIÓN}

\subsection{Planteamiento de alternativas de solución.}

Luego de haber realizado el análisis de causa efecto y determinar las causas raíz, se procede de determinar las posibles soluciones a las causas encontradas

A continuación se muestran las causas con sus posibles soluciones en la tabla

\section{1.}

Tabla 4.1.

Matriz Causa - Solución

\begin{tabular}{|c|c|c|}
\hline $\mathbf{N}^{\circ}$ & Causas & Posibles Soluciones \\
\hline 1 & $\begin{array}{l}\text { Demoras u omisión de actividades en el } \\
\text { proceso de atención de Primeros Auxilios } \\
\text { Avanzados }\end{array}$ & Optimizar los tiempos de respuesta a emergencias. \\
\hline 2 & $\begin{array}{l}\text { No existe una política de seguridad } \\
\text { operacional definida }\end{array}$ & Definir una política de seguridad operacional \\
\hline 3 & $\begin{array}{l}\text { Proceso de identificación de peligros y } \\
\text { riesgos deficiente }\end{array}$ & $\begin{array}{l}\text { Medir la eficacia del proceso de identificación de } \\
\text { peligros y evaluación de riesgos }\end{array}$ \\
\hline 4 & $\begin{array}{l}\text { No existe un plan de auditorías en seguridad } \\
\text { operacional }\end{array}$ & Elaborar un plan de auditorias \\
\hline 5 & $\begin{array}{l}\text { Falta de conocimiento interno sobre la } \\
\text { seguridad operacional }\end{array}$ & $\begin{array}{l}\text { Elaborar un programa de capacitación en seguridad } \\
\text { operacional }\end{array}$ \\
\hline 7 & $\begin{array}{l}\text { Pasajeros no respetan las normas de uso del } \\
\text { sistema } \\
\text { No hay análisis de fallos de equipos y } \\
\text { sistemas }\end{array}$ & $\begin{array}{l}\text { Elaborar campañas de sensibilización hacia los } \\
\text { usuarios } \\
\text { Registrar los fallos y análisis sus causas para } \\
\text { verificar tendencias }\end{array}$ \\
\hline
\end{tabular}

Elaboración Propia

Observamos que las soluciones del 2 al 7 pueden agruparse en una sola quedando finalmente las siguientes soluciones:

1. Optimización de los tiempos de respuesta del servicio de Primeros Auxilios Avanzados.

2. Implementación de un sistema de gestión de seguridad operacional en base a normas internacionales. Los sistemas de gestión definen políticas, cuentan con mecanismos para medir la eficacia de la identificación de peligros y evaluación de riesgos, cuentan con 
procedimientos y programas de auditorías al sistema, mantienen programas de capacitación interna y externa y finalmente son capaces de registrar fallos para su posterior análisis.

\subsection{Selección de alternativas de solución.}

En esta sección se determinará qué soluciones son las que se deben implementar primero, las cuales estarán dentro del alcance del presente trabajo.

\subsubsection{Determinación y ponderación de criterios evaluación de las alternativas.}

En conjunto con la alta dirección de la empresa, se definieron cuatro factores para evaluar las diferentes alternativas de solución.

A. Aporte a la imagen de Línea 1: Cómo contribuye la solución a mejorar la imagen de la compañía, es decir, mejorar el valor de la marca.

B. Baja inversión: Nivel relativo de inversión económica de la solución.

C. Alto beneficio: Nivel relativo de beneficio neto que brinda la solución.

D. Fácil de implementar: Tiempo y esfuerzo requerido para implementar la solución.

A continuación se muestra la matriz de enfrentamiento para determinar cada uno de los pesos de los factores. Ver tabla 4.2.

Tabla 4.2.

Matriz de enfrentamiento para determinar los pesos

\begin{tabular}{|l|ccccccc|}
\hline Factores & & A & B & C & D & Total & Peso \\
\hline Aporte a la imagen & A & 1 & 1 & 1 & 1 & 4 & $40 \%$ \\
Baja inversión & B & 0 & 1 & 1 & 1 & 3 & $30 \%$ \\
Alto beneficio & C & 0 & 0 & 1 & 1 & 2 & $20 \%$ \\
Fácil implementación & D & 0 & 0 & 0 & 1 & 1 & $10 \%$ \\
& & & & & & 10 & $100 \%$ \\
\hline
\end{tabular}

Elaboración Propia 


\subsubsection{Evaluación cualitativa y/o cuantitativa de alternativas de solución.}

A continuación se muestra la evaluación cualitativa y cuantitativa de las alternativas de solución planteadas respecto a cada factor:

1. Optimización de los tiempos de respuesta del servicio de Primeros Auxilios Avanzados.

Factores

\begin{tabular}{l|l}
\hline A. Aporte a la imagen & $\begin{array}{l}\text { Tiene un alto aporte a la imagen de la institución debido a que la } \\
\text { atención oportuna y rápida evita los reclamos y quejas a través } \\
\text { de los medios de comunicación. }\end{array}$ \\
\hline B. Baja inversión & $\begin{array}{l}\text { La inversión es baja ya que la solución se hará con personal } \\
\text { propio. }\end{array}$ \\
\hline C. Alto beneficio & $\begin{array}{l}\text { Tiene alto beneficio ya que se mejorará los tiempos de respuesta } \\
\text { a emergencias }\end{array}$ \\
\hline D. Fácil & $\begin{array}{l}\text { Es fácil de implementar debido a que solo es necesario definir } \\
\text { las nuevas ubicaciones del personal de salud. }\end{array}$ \\
implementación &
\end{tabular}

2. Implementación de un sistema de gestión de seguridad operacional en base a normas internacionales

Factores

\section{Descripción}

\begin{tabular}{l|l}
\hline A. Aporte a la imagen & $\begin{array}{l}\text { Tiene un aporte considerable debido a que sería la primera línea } \\
\text { de metro de Sudamérica en implementar un modelo de gestión } \\
\text { en base a normas internacionales. }\end{array}$ \\
\hline B. Baja inversión & $\begin{array}{l}\text { La inversión es mediana ya que se contratará recursos exclusivos } \\
\text { para la implementación de esta solución }\end{array}$ \\
\hline C. Alto beneficio & $\begin{array}{l}\text { Tiene alto beneficio ya que impactará en la reducción de } \\
\text { accidentes. }\end{array}$ \\
\hline D. Fácil & $\begin{array}{l}\text { La implementación del sistema dependerá del liderazgo de la alta } \\
\text { dirección por lo que se considera que no tendrá inconvenientes }\end{array}$ \\
\hline
\end{tabular}




\subsubsection{Priorización y selección de soluciones}

Para el presente trabajo y en conjunto con la opinión y aprobación de la alta dirección, se ha decidido implementar las dos propuestas elegidas en la sección 4.1. A continuación se muestra el ranking de factores a fin de elegir el orden de implementación. Ver Tabla 4.3.

Tabla 4.3.

Ranking de factores para la selección de las propuestas

\begin{tabular}{|c|c|c|c|c|c|}
\hline \multirow[b]{2}{*}{ Factores } & \multirow[b]{2}{*}{ Pesos } & \multicolumn{2}{|c|}{$\begin{array}{l}\text { 1. Optimización de los } \\
\text { tiempos de respuesta del } \\
\text { servicio de Primeros Auxilios } \\
\text { Avanzados. }\end{array}$} & \multicolumn{2}{|c|}{$\begin{array}{l}\text { 2. Implementación de un } \\
\text { sistema de gestión en base a } \\
\text { normas internacionales. }\end{array}$} \\
\hline & & Calif. & Punt. & Calif. & Punt. \\
\hline A. Aporte a la imagen & $40 \%$ & 5 & 2 & 5 & 2 \\
\hline B. Baja inversión & $30 \%$ & 1 & 0.3 & 1 & 0.3 \\
\hline C. Alto beneficio & $20 \%$ & 3 & 0.6 & 5 & 1 \\
\hline D. Fácil implementación & $10 \%$ & 5 & 0.5 & 3 & 0.3 \\
\hline & & & 3.4 & & 3.6 \\
\hline
\end{tabular}

Nota: Escala 1-Malo; 3-Regular; 5-Bueno Elaboración Propia

Como se muestra en la tabla 4.3., el orden de implementación de ambas propuestas sería el siguiente:

1. Implementación de un sistema de gestión de seguridad operacional en base a normas internacionales

2. Optimización de los tiempos de respuesta del servicio de Primeros Auxilios Avanzados. 


\section{CAPÍTUlO V: DESARROLLO, PLANIFICACIÓN Y RESULTADOS ESPERADOS DE LA SOLUCIÓN}

\subsection{Ingeniería de Solución}

\subsubsection{Implementación de un sistema de gestión de seguridad operacional en base a normas internacionales.}

El modelo del sistema de gestión de la seguridad operacional (SMS por sus siglas en inglés) se basará en el modelo establecido por la Organización de Aviación Civil (OACI) documento $\mathrm{N}^{\circ} 9858$ (Ministerio de Transportes y Comunicaciones, 2018), de igual manera la Administración Federal de Transito (FTA por sus siglas en inglés) recomienda la implementación de un $S M S$ con los mismos criterios establecidos por la OACI los cuales se describen a continuación:

El diseño y estructura del SMS de Línea 1 se basará en el resultado del análisis de linea base y de las brechas detectadas entre lo existente y lo deseado y además constará de doce elementos y diez procedimientos y cuatro pilares.

Los pilares y elementos del sistema de gestión son los siguientes:

- Política y objetivos de seguridad

- Gestión de riesgos

- Aseguramiento de la seguridad

- Promoción de la seguridad

Los diez procedimientos listados a continuación permiten planificar, controlar y mejorar los procesos operacionales y de soporte, manteniendo el riesgo en un nivel aceptable y mejorando el desempeño de la seguridad operacional:

1. Control de documentos y registros.

2. Gestión de Riesgos de Seguridad Operacional.

3. Comunicaciones del SMS.

4. Revisión Periódica de las Políticas y Objetivos de Seguridad Operacional.

5. Entrenamiento de Seguridad Operacional. 
6. Elaboración, Análisis y Uso de la Información Estadística de Seguridad Operacional.

7. Auditorias de Seguridad Operacional.

8. Gestión del Cambio de Seguridad Operacional.

9. Medición del Rendimiento, Efectividad, Resultados o una Situación Subestándar del SMS.

10. Confidencialidad de la Información de Seguridad Operacional.

La aplicación de todos los procesos relacionados con el $S M S$ y el debido control de los procesos y recursos necesarios siguen el Ciclo Deming definido en la siguiente figura.

Figura 5.1

Ciclo de Deming.

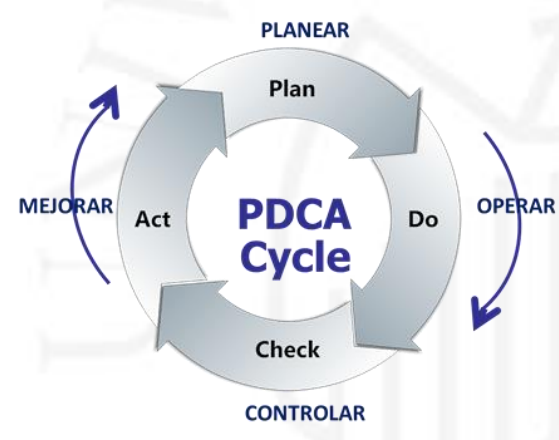

Fuente: Organización Internacional de Normalización (2018)

El mejoramiento continuo sólo es posible si se tiene la información necesaria sobre el estado de cada uno de los elementos del sistema de gestión y de los resultados obtenidos.

\subsubsection{Optimización de los tiempos de respuesta del servicio de Primeros Auxilios} Avanzados.

Para la ingeniería de solución se utilizará de un modelo de optimización lineal en donde la función a objetivo será el tiempo de respuesta por cada enfermero.

La cantidad de enfermeros disponibles son 05 , los cuales se distribuirán en el ámbito de las 26 estaciones considerando las siguientes restricciones: 
Cada enfermero no deberá superar más de 10 minutos de traslado entre estaciones, para ello se tomará como referencia la tabla de distancia en tiempo entre estaciones detallada en el Anexo 1.

Debido a que se ha propuesto utilizar programación lineal, se define que cada enfermero tendrá un ámbito de acción compuesto por 05 estaciones, para lo cual se contará con 05 modelos de optimización en función a la casuística histórica de atención del mes de abril y en función a los horarios de operación del sistema, uno de los modelos de optimización considerará 06 estaciones con la finalidad de completar el rango de las 26 estaciones.

A continuación describimos el tipo de horarios y frecuencia de paso de trenes:

De lunes a viernes:

- Hora punta mañana de: 6:00 hrs a 9:30 h con un intervalo de paso de 3 minutos

- Hora valle mañana: de 09:31 hrs a 16:59 hrs con un intervalo de paso de 6 minutos

- Hora punta tarde: de 17:00 a 22:00 con un intervalo de paso de 3 minutos Sábados:

- De 9:00 a 22:00 hrs con un intervalo de paso de 6 minutos

Domingos:

- De 9:00 a 22:00 hrs con un intervalo de paso de 9 minutos

Se ha considerado que en promedio el traslado de estación a estación es de 2 minutos tal como se encuentra detallado en el Anexo 1.

Se tomará como referencia la cantidad de eventos históricos del mes de diciembre 2018, los cuales se muestran en la Tabla 5.1 
Tabla 5.1

Número de Eventos mes de diciembre 2018 por estación

\begin{tabular}{|l|c|}
\hline \multicolumn{2}{|c|}{ Total Abril } \\
\hline Estación & N $^{\circ}$ de Eventos \\
\hline 01. VES & 16 \\
02. PIN & 4 \\
03. PUM & 9 \\
04. VMA & 12 \\
05. MAU & 18 \\
06. SJU & 11 \\
07. ATO & 18 \\
08. JCH & 27 \\
09. AYA & 19 \\
10. CAB & 19 \\
11. ANG & 39 \\
12. SBS & 22 \\
13. CUL & 37 \\
14. NAR & 23 \\
15. GAM & 45 \\
16. MIG & 54 \\
17. ELA & 27 \\
18. PRE & 19 \\
19. CAA & 46 \\
20. PIR & 0 \\
21. JAR & 36 \\
22. POS & 8 \\
23. SCA & 16 \\
24. SMA & 9 \\
25. SRO & 5 \\
26. BAY & 20 \\
\hline Total & $\mathbf{5 5 9}$ \\
\hline
\end{tabular}

Elaboración Propia

En el mes de diciembre se requirieron 559 atenciones de primeros auxilios, sin embargo, debido a que la cantidad de usuarios en el sistema no es constante, se han distribuido la cantidad de eventos en función a las franjas horaria y frecuencia de paso de los trenes tal como se muestra en la Tabla 5.2 y la Tabla 5.3. 
Tabla 5.2

Número de Eventos por horario de lunes a viernes por estación

L-V Hora punta mañana

\begin{tabular}{|cc|}
\hline Estación & $\begin{array}{c}\mathbf{N}^{\circ} \text { de } \\
\text { Eventos }\end{array}$ \\
\hline
\end{tabular}

01. VES 3

02. PIN 2

03. PUM 0

04. VMA 3

05. MAU 2

06. SJU 1

07. ATO 10

08. JCH 6

09. AYA 5

10. $\mathrm{CAB} \quad 1$

11. ANG 10

12. SBS 8

13. CUL 13

14. NAR 3

15. GAM 6

16. MIG 15

17. ELA 5

18. PRE 6

19. CAA 18

20. PIR 0

21. JAR 10

22. POS 0

23. SCA 3

24. SMA 2

25. SRO 1

26. BAY 7

Total 140

Elaboración Propia
L-V Hora valle

\begin{tabular}{|cc|}
\hline Estación & $\begin{array}{c}\mathbf{N}^{\circ} \text { de } \\
\text { Eventos }\end{array}$ \\
\hline
\end{tabular}

01. VES 7

02. PIN 2

03. PUM 5

04. VMA 6

05. MAU 10

06. SJU 3

07. ATO 4

08. JCH 7

09. AYA 9

10. $\mathrm{CAB} \quad 10$

11. ANG 7

12. SBS 3

13. CUL 4

14. NAR 8

15. GAM 20

16. MIG 19

17. ELA 10

18. PRE 5

19. CAA 11

20. PIR 0

21. JAR 7

22. POS 5

23. SCA 3

24. SMA 5

25. SRO 2

26. BAY 10

Total 182
L-V Hora punta noche

\begin{tabular}{|c|c|}
\hline Estación & $\begin{array}{c}\mathbf{N}^{\circ} \text { de } \\
\text { Eventos }\end{array}$ \\
\hline 01. VES & 2 \\
\hline 02. PIN & 0 \\
\hline 03. PUM & 2 \\
\hline 04. VMA & 1 \\
\hline 05. MAU & 4 \\
\hline 06. SJU & 4 \\
\hline 07. ATO & 1 \\
\hline 08. JCH & 9 \\
\hline 09. AYA & 2 \\
\hline 10. CAB & 2 \\
\hline 11. ANG & 15 \\
\hline 12. SBS & 5 \\
\hline 13. CUL & 10 \\
\hline 14. NAR & 9 \\
\hline 15. GAM & 10 \\
\hline 16. MIG & 7 \\
\hline 17. ELA & 4 \\
\hline 18. PRE & 4 \\
\hline 19. CAA & 11 \\
\hline 20. PIR & 0 \\
\hline 21. JAR & 13 \\
\hline 22. POS & 2 \\
\hline 23. SCA & 4 \\
\hline 24. SMA & 2 \\
\hline 25. SRO & 1 \\
\hline 26. BAY & 1 \\
\hline Total & 125 \\
\hline
\end{tabular}


Tabla 5.3

Número de eventos por estación por sábado y domingo

\begin{tabular}{|c|c|c|c|}
\hline \multicolumn{2}{|l|}{ Sábados } & \multicolumn{2}{|c|}{ Domingos } \\
\hline Estación & $\mathbf{N}^{\circ}$ de Eventos & Estac & $\mathbf{N}^{\circ}$ de Eventos \\
\hline 01. VES & 1 & 01. VES & 3 \\
\hline 02. PIN & 0 & 02. PIN & 0 \\
\hline 03. PUM & 2 & 03. PUM & 0 \\
\hline 04. VMA & 2 & 04. VMA & 0 \\
\hline 05. MAU & 1 & 05. MAU & 1 \\
\hline 06. SJU & 2 & 06. SJU & 1 \\
\hline 07. ATO & 1 & 07. ATO & 2 \\
\hline 08. JCH & 2 & 08. JCH & 3 \\
\hline 09. AYA & 2 & 09. AYA & 1 \\
\hline 10. CAB & 3 & 10. CAB & 3 \\
\hline 11. ANG & 4 & 11. ANG & 3 \\
\hline 12. SBS & 3 & 12. SBS & 3 \\
\hline 13. CUL & 5 & 13. CUL & 5 \\
\hline 14. NAR & 3 & 14. NAR & 0 \\
\hline 15. GAM & 7 & 15. GAM & 2 \\
\hline 16. MIG & 10 & 16. MIG & 3 \\
\hline 17. ELA & 4 & 17. ELA & 4 \\
\hline 18. PRE & 2 & 18. PRE & 2 \\
\hline 19. CAA & 5 & 19. CAA & 1 \\
\hline 20. PIR & 0 & 20. PIR & 0 \\
\hline 21. JAR & 5 & 21. JAR & 1 \\
\hline 22. POS & 0 & 22. POS & 1 \\
\hline 23. SCA & 2 & 23. SCA & 4 \\
\hline 24. SMA & 0 & 24. SMA & 0 \\
\hline 25. SRO & 0 & 25. SRO & 1 \\
\hline 26. BAY & 1 & 26. BAY & 1 \\
\hline
\end{tabular}

Elaboración Propia

En este caso una adecuada distribución de los enfermeros que permita obtener menores tiempos de respuesta a solicitudes de atención de primeros auxilios. Los problemas de optimización generalmente se clasifican en lineales y no lineales, según las relaciones del problema sean lineales con respecto a las variables.

Una vez asignada la zona de cobertura de los enfermeros, (5 o 6 estaciones por enfermero) se procede a minimizar el tiempo de respuesta en función a la cantidad de eventos y en función al tiempo de desplazamiento de estación por estación.

Se realizaron 5 propuestas, (Ver Anexo 2) que resultaron en una solución óptima tal como se detalla en la tabla 5.4. 
Tabla 5.4

Tabla de solución óptima

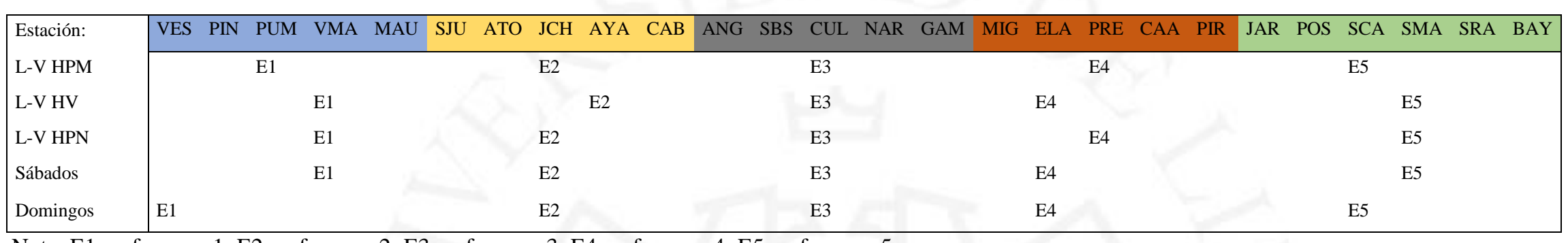

Nota: E1=enfermero 1; E2=enfermero 2; E3=enfermero 3; E4=enfermero 4; E5=enfermero 5

Elaboración Propia 


\subsection{Plan de Implementación de la solución.}

Para la implementación de ambas soluciones, se definieron los siguientes responsables:

- Sponsor del proyecto: Gerente General.

- Dueño del proyecto: Jefe de Seguridad y Medio Ambiente.

- Consultor Especializado: Superintendente de Seguridad Operacional

- Área de Gestión Humana: Son los encargados de realizar la búsqueda de las personas más apropiadas para los dos nuevos puestos. Son los encargados de capacitar al personal de acuerdo a los cambios propuestos por los consultores.

\subsubsection{Objetivos $y$ metas.}

Se definieron los siguientes objetivos y metas:

1. Optimización de los tiempos de respuesta del servicio de Primeros Auxilios Avanzados:

- Reducir los tiempos de respuesta a emergencia del servicio de primeros auxilios avanzados en un $30 \%$, de 10 minutos a 7 minutos en promedio.

2. Implementación de un sistema de gestión de seguridad operacional basado en normas internacionales:

- Con la implementación del sistema de gestión se espera reducir la cantidad de accidentes de pasajeros en un $10 \%$ respecto al año anterior.

\subsubsection{Elaboración del presupuesto requerido para la ejecución de la solución.}

1. Optimización de los tiempos de respuesta del servicio de Primeros Auxilios Avanzados.

Los costos asociados a la optimización de los tiempos de respuesta del servicio de Primeros Auxilios Avanzado en las estaciones se detallan en la tabla 5.5. 
Tabla 5.5

Costos asociados a la optimización del servicio de primeros auxilios avanzados

\begin{tabular}{cc}
\hline Actividades & H- \\
\hline Fase 1: Planificación y propuesta de solución & H \\
\hline Análisis de incidentes, accidentes y tiempos de respuestas. & 240 \\
Determinación de necesidades. & 48 \\
Planteamiento de la solución. & 48 \\
Preparación de la presentación a la Gerencia General. & 96 \\
Fase 2: Aprobación & 48 \\
\hline Presentación de la propuesta a la Gerencia General. & 48 \\
\hline Fase 3: Ejecución & 48 \\
\hline Reunión inicial con el proveedor para la presentación de la propuesta de & 336 \\
implementación & 48 \\
Revisión de documentos e instructivos operacionales & 48 \\
Ejecución de marcha blanca. & 96 \\
Recolección de datos, medición de desempeño. & 192 \\
\hline
\end{tabular}

Elaboración propia

Total H-H 624

El valor promedio de hora hombre de un analista de seguridad en Linea 1 es de S/.50 (cincuenta soles). El trabajo demandaría 624 horas por lo que el valor referencial del proyecto sería de S/ 31,200.0 (treinta y un mil doscientos soles)

2. Implementación de un sistema de gestión de seguridad operacional basado en normas internacionales:

Para la implementación del sistema de gestión SMS se contratará a una consultara y para el mantenimiento se contratará a un coordinador de sistema de gestión dentro de la empresa.

El servicio de consultoría se realizará en las instalaciones de Linea 1 y tiene un valor de S/. 49,000 (cuarenta y nueve mil soles) por toda la duración del proyecto

En el caso del mantenimiento del sistema de gestión se contratará a un coordinador de sistema de gestión, el cual tiene un valor de mercado de S/5,000 (cinco mil soles) mensuales al cual se le añadirá el $40 \%$ del costo empresa, teniendo un costo final para la organización de S/. 7,000 (siete mil soles) mensuales. 


\subsubsection{Actividades y cronograma de implementación de la solución.}

1. Optimización de los tiempos de respuesta del servicio de Primeros Auxilios Avanzados.

Para el proceso de optimización de los tiempos de respuesta del servicio de Atención de Primeros Auxilios Avanzados, la organización ha definido 3 fases que pondrán en práctica durante el inicio año 2019. Estas fases son las siguientes:

\section{Fase 1: Planificación y propuesta de solución}

- Análisis de incidentes, accidentes y tiempos de respuestas.

- Determinación de necesidades.

- Planteamiento de la solución optima

- Preparación de la presentación a la Gerencia General.

Fase 2: Aprobación

- Presentación de la propuesta a la Gerencia General.

Fase 3: Ejecución

- Reunión inicial con el proveedor, para la presentación de la propuesta de implementación.

- Revisión de documentos e instructivos operacionales

- Ejecución de marcha blanca.

- Recolección de datos, medición de desempeño.

El cronograma de implementación del servicio de Primeros Auxilios Avanzados se describe en la Tabla 5.6.

La duración de la implementación del proyecto se estima en 11 semanas. 
Tabla 5.6

Diagrama de Gantt optimización de los tiempos de respuesta del servicio de Primeros Auxilios Avanzados.

\begin{tabular}{|c|c|c|c|c|c|c|c|c|c|c|c|c|c|}
\hline $\begin{array}{c}\mathbf{N}^{\circ} \\
\text { Actividad }\end{array}$ & ACTIVIDADES & $\begin{array}{c}\mathbf{N}^{\circ} \text { de } \\
\text { Semanas }\end{array}$ & 1 & 2 & 3 & 4 & 5 & 6 & 7 & 8 & 9 & 10 & 11 \\
\hline & Fase 1: Planificación y propuesta de solución & 5 & & & & & & & & & & & \\
\hline 1 & Análisis de incidentes, accidentes y tiempos de respuestas. & 1 & & & & & & & & & & & \\
\hline 2 & Determinación de necesidades. & 1 & & & & & & & & & & & \\
\hline 3 & Planteamiento de la solución. & 2 & & & & & & & & & & & \\
\hline 4 & Preparación de la presentación a la Gerencia General. & 1 & & & & & & & & & & & \\
\hline & Fase 2: Aprobación & 1 & & & & & & & & & & & \\
\hline 5 & Presentación de la propuesta a la Gerencia General. & 1 & & & & & & & & & & & \\
\hline & Fase 3: Ejecución & 8 & & & & & & & & & & & \\
\hline 6 & Reunión inicial con el proveedor para la presentación de la propuesta de implementación & 1 & & & & & & & & & & & \\
\hline 7 & Revisión de documentos e instructivos operacionales & 1 & & & & & & & & & & & \\
\hline 8 & Ejecución de marcha blanca. & 2 & & & & & & & & & & & \\
\hline 9 & Recolección de datos, medición de desempeño. & 4 & & & & & & & & & & & \\
\hline & ${ }^{2}$ & 14 & & & & & & & & & & & \\
\hline
\end{tabular}

Elaboración Propia 
2. Implementación de un sistema de gestión de seguridad operacional basado en normas internacionales:

Para el proceso de implementación del SMS la organización ha definido 4 fases que pondrán en práctica durante el año 2019. Estas fases son las siguientes:

\section{Fase 1: Objetivos y Políticas de Seguridad (Planificación):}

- Definir la Política, Objetivos, Estructura y Responsabilidades y comunicarla al personal en el proceso de inducción.

- Definir los procesos del SMS y su interacción.

- Comunicar y promover el "Manual de Seguridad Operacional y Factores Humanos - SMS

- Desarrollar y aplicar el Procedimiento de diseño y elaboración de Documentos.

- Desarrollar y aplicar el Procedimiento de Comunicaciones del SMS.

- Desarrollar y aplicar el Procedimiento del Entrenamiento de Seguridad Operacional.

- Desarrollar y aplicar el Procedimiento de confidencialidad de la información de Seguridad Operacional.

- Desarrollar y aplicar el Plan de Contingencias aprobado por el Estado Peruano.

\section{Fase 2: Gestión de Riesgos (Procesos Reactivos):}

- Desarrollar y aplicar el procedimiento de Gestión de Riesgos de Seguridad Operacional.

- Desarrollar y aplicar el Instructivo de Investigación de Incidentes, Accidentes y Eventos de Seguridad Operacional.

\section{Fase 3: Gestión de Riesgos (Procesos Proactivos y Predictivos):}

- Desarrollar y aplicar el procedimiento de Gestión de Riesgos de Seguridad Operacional.

- Desarrollar y aplicar el procedimiento de Auditorias de Seguridad Operacional.

- Desarrollar y aplicar el procedimiento de Gestión del Cambio de Seguridad Operacional.

- Desarrollar y aplicar el procedimiento de Medición del Rendimiento, Efectividad, Resultados o una Situación Subestándar del SMS. 


\section{Fase 4: Garantía y Promoción de la Seguridad.}

- Desarrollar y aplicar el Procedimiento de Comunicaciones - SMS.

- Desarrollar y aplicar el Procedimiento de Entrenamiento de Seguridad Operacional.

- Desarrollar y aplicar el Procedimiento de Revisión Periódica de las Políticas y Objetivos de Seguridad Operacional.

- Desarrollar y aplicar el Procedimiento de Elaboración, Análisis y Uso de la Información Estadística de Seguridad Operacional.

- Desarrollar y aplicar el Instructivo de Encuesta de Seguridad Operacional.

- Reuniones GESO, CSO, SRB. (Aplicación del Instructivo de Elaboración de Informes (Aseguramiento de la Seguridad).

El cronograma de implementación del SMS se describe en la Tabla 5.7. La duración de la implementación del proyecto se estima en 28 semanas.

\subsection{Evaluación de la solución $\quad$ a análisis costo beneficio}

\subsubsection{Evaluación de la solución.}

1. Optimización de los tiempos de respuesta del servicio de Primeros Auxilios Avanzados.

Después de la implementación de la propuesta de solución y considerando el registro de datos al momento del inicio de la marcha blanca, se obtuvieron los siguientes tiempos de respuesta a emergencia del servicio de primero auxilios avanzados. Ver figura 5.2. 
Tabla 5.7

Diagrama de Gantt implementación del SMS en Línea 1

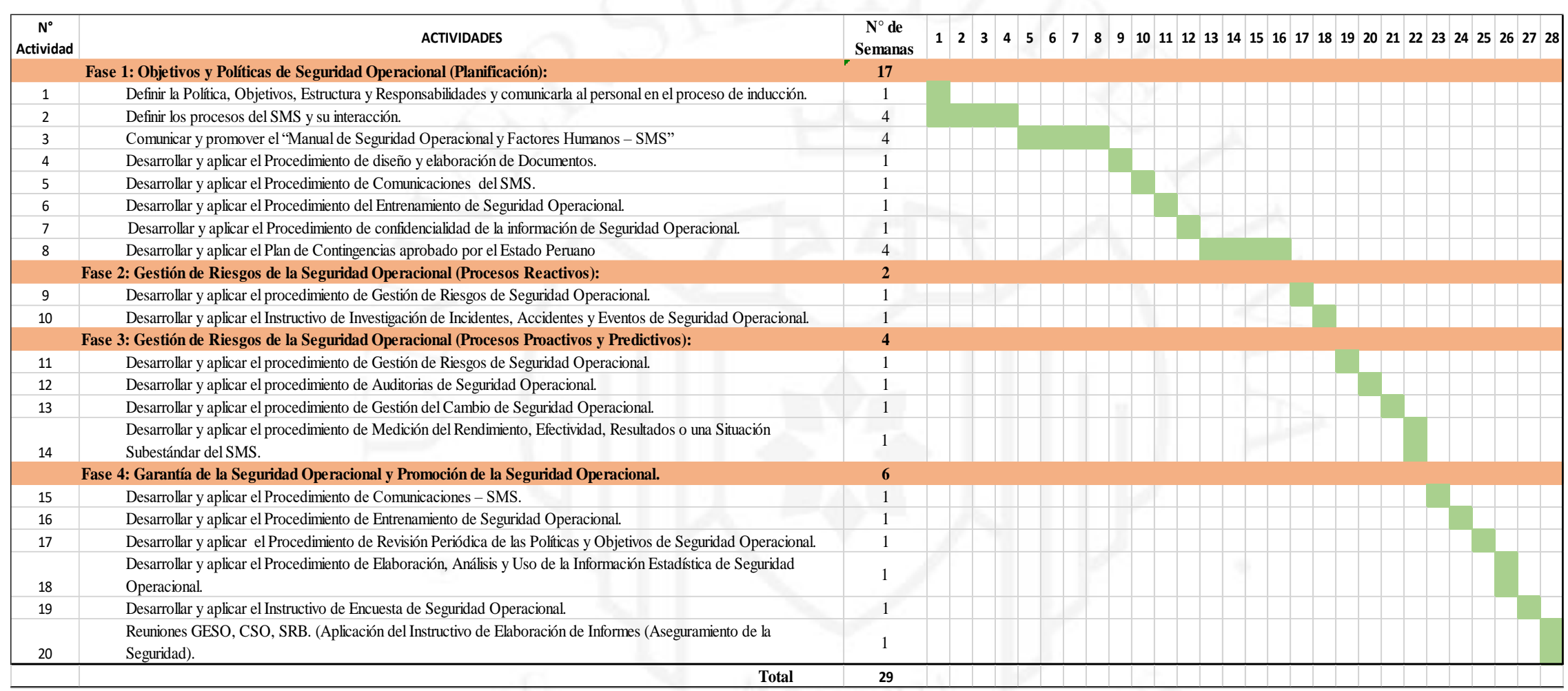

Elaboración Propia 
Figura 5.2.

Tiempo de respuesta promedio en minutos del SPAA

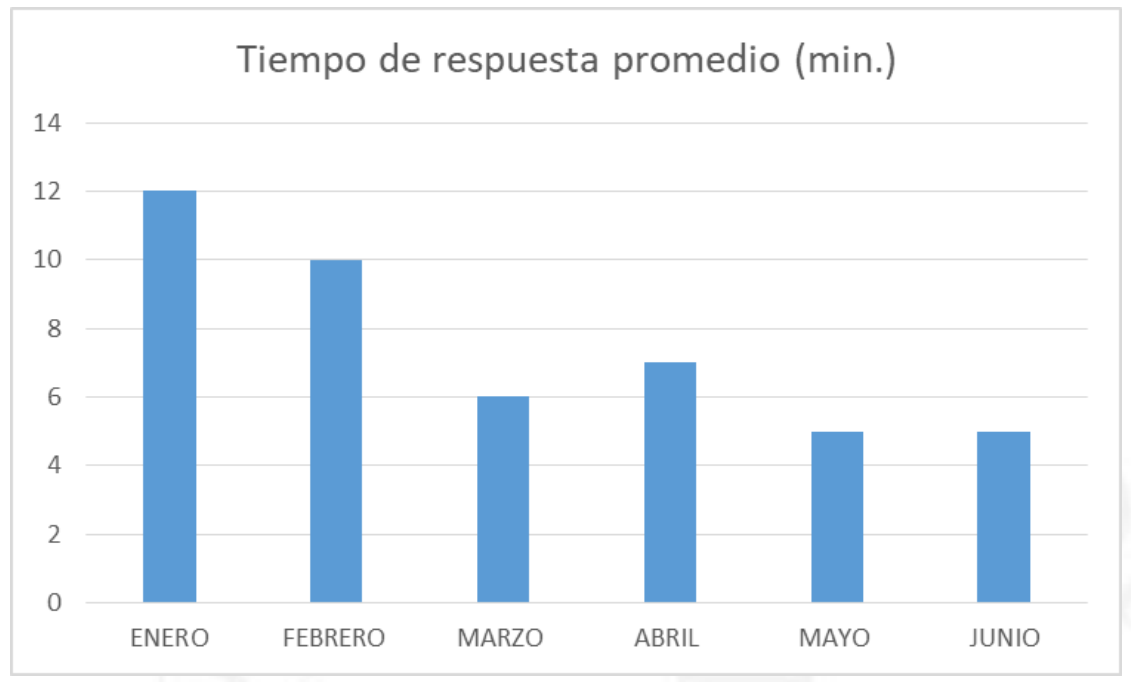

Elaboración propia

Como se observa en la figura 5.2 se registra una reducción de los tiempos de respuesta a partir de marzo (inicio de la marcha blanca) y se obtuvo un promedio de 5.8 minutos en los últimos 4 meses.

En el mismo periodo se solicitó al área de imagen institucional el valor de las noticias negativas producto de los accidentes ocurridos, brindando la siguiente información:

Tabla 5.8

Valor de noticias negativas por accidentes año 2019

\begin{tabular}{lr}
\hline \multicolumn{1}{c}{ Mes } & \multicolumn{1}{c}{$\begin{array}{l}\text { Valor de } \\
\text { noticias } \\
\text { negativas }\end{array}$} \\
\hline ENERO & 2,000 \\
FEBRERO & 4,500 \\
MARZO & 10,800 \\
ABRIL & 15,000 \\
MAYO & 2,000 \\
JUNIO & 7,000 \\
\hline \hline \multicolumn{2}{c}{ Total } \\
Elaboración propia
\end{tabular}


En la tabla 5.8 se observa que el valor de la noticias negativas del año 2019, producto de los accidentes, se encuentra muy por debajo del valor esperado y del valor registrado en los mismos meses durante el año 2018.

2. Implementación de un sistema de gestión de seguridad operacional basado en normas internacionales:

Luego de la implementación del SMS en Línea 1 se observó una reducción de los accidentes respecto a los mismos meses del año 2018 tal como se muestra en la tabla 5.9

Tabla 5.9

Estadística de incidentes con usuarios durante el año 2019.

\begin{tabular}{|c|c|c|c|c|c|c|c|}
\hline \multicolumn{8}{|c|}{$\mathbf{N}^{\circ}$ de eventos } \\
\hline Mes & $\begin{array}{r}\text { Pasajeros } \\
\text { transportados }\end{array}$ & $\begin{array}{c}\text { Ingresos a } \\
\text { la vía }\end{array}$ & $\begin{array}{l}\text { Caídas en } \\
\text { estación }\end{array}$ & $\begin{array}{c}\text { Impacto } \\
\text { físico } \\
\text { (golpes) }\end{array}$ & $\begin{array}{l}\text { Golpes en } \\
\text { el cierre } \\
\text { de puertas }\end{array}$ & $\begin{array}{c}\text { Atención x } \\
\text { Enfermedad }\end{array}$ & $\begin{array}{c}\text { Total } \\
\text { Accidentes }\end{array}$ \\
\hline ENE & $13,458,205$ & 5 & 14 & 0 & 15 & 125 & 29 \\
\hline FEB & $13,645,245$ & 3 & 12 & 0 & 12 & 180 & 24 \\
\hline MAR & $13,973,642$ & 5 & 13 & 0 & 4 & 190 & 17 \\
\hline ABR & $14,192,344$ & 3 & 10 & 0 & 13 & 180 & 23 \\
\hline MAY & $14,023,141$ & 3 & 11 & 0 & 12 & 220 & 23 \\
\hline Total & 69,292,577 & 19 & 60 & $\mathbf{0}$ & 56 & 895 & 116 \\
\hline
\end{tabular}

Fuente: GyM Ferrovías (2019)

\subsubsection{Análisis costo beneficio}

El valor monetario para la implementación de ambas propuestas ascendió a S/164,200.0 (ciento sesenta y dos mil doscientos soles) anuales. Ver tabla 5.10. 
Tabla 5.10

Implementación de Propuestas de solución

\begin{tabular}{|l|llllll|}
\hline Servicios Contratados & Valor Monetario & & Q & Valor Anual \\
\hline Optimización del tiempo de respuesta del & & & & & & \\
Servicios de Primeros Auxilios Avanzados & S/ & 31,200 & 1 & S/ & 31,200 \\
Asesoría en implementación del SMS & S/ & 49,000 & 1 & S/ & 49,000 \\
Coordinador del Sistema de Gestión & S/ & 7,000 & 12 & S/ & 84,000 \\
\hline \hline & & & & \multicolumn{2}{|c|}{ S/ $\mathbf{1 6 4 , 2 0 0}$} \\
\hline
\end{tabular}

Elaboración Propia

Para efectos del presente trabajo se considerarán como beneficio la reducción de las noticias negativas en los medios de comunicación, asimismo, se proyecta que a fines del año 2019 la reducción de noticias tenga un valor máximo de S/ 82,600 (ochenta y dos mil seiscientos soles), generando una reducción del valor de las noticias respecto al año 2018 de S/ 5, 917,400 (cinco millones novecientos diecisiete mil cuatrocientos soles).

\section{Tabla 5.11}

Tabla de Análisis Costo Beneficio

\begin{tabular}{|lcc|}
\hline Costo / Beneficios & \multicolumn{2}{c|}{ Valor } \\
\hline Reducción de Noticias Negativas & S/ & $5,917,400$ \\
Costo de Mejoras & S/ & 164,200 \\
\hline & & 36.03 \\
\hline
\end{tabular}

Elaboración Propia

Siendo la relación $\mathrm{B} / \mathrm{C}>1$, la implementación de las propuestas fueron viables pues los beneficios en la reducción de noticias negativas son mayores a los costos. Por cada sol de costos se obtiene más de 36 soles en beneficios. Ver tabla 5.11. 


\section{CONCLUSIONES}

Referente a las conclusiones:

A partir de la solución planteada se logró reducir los tiempos de respuesta a emergencia del servicio de primeros auxilios avanzados en más 30\%, pasando de 10 minutos a 6 minutos en promedio.

Con la implementación del sistema de gestión se redujo la cantidad de accidentes de pasajeros en más $10 \%$ respecto al año 2018.

La reducción de accidentes durante el año 2019 logró una reducción significativa en el valor de las noticias negativas respecto al año 2018.

Se logró identificar las casusas del incremento de los accidentes y su impacto en las noticias negativas, planteando soluciones viables. 


\section{RECOMENDACIONES}

Referente a las recomendaciones:

Plantear el problema de nivel de un software de simulación que permita tener información real del comportamiento estadístico de las incidencias de Líneal y recomiende a tiempo real, la distribución de los enfermeros en el sistema.

Mantener el sistema de gestión de seguridad operacional SMS realizando auditorias anuales revisadas por la alta dirección.

Incluir en el programa de inducción a personal propio y tercero los aspectos relacionados al sistema de gestión de seguridad operacional SMS. 


\section{REFERENCIAS}

Autoridad Autónoma del Tren Eléctrico. (2019). Recuperado de www.aate.gob.pe

Autoridad Autónoma del Tren Eléctrico. (2019). AATE. Recuperado de https://www.metrodelima.gob.pe/

Banco Central de Reserva. (2017). BCR. Recuperado de (http://www.bcrp.gob.pe/estadisticas/cuadros-anuales-historicos.html)

Banco Central de Reserva. (2019). Indicadores Económicos I Trimestre 2019. Recuperado de http://www.bcrp.gob.pe/docs/Estadisticas/indicadorestrimestrales.pdf

Barletta, F., Pereira, M., Robert, V., y Yoguel, G. (2013). Argentina: dinámica reciente del sector de software y servicios informáticos. Revista de la CEPAL(110), 137155. Recuperado de http://www.cepal.org/publicaciones/xml/1/50511/RVE110Yoqueletal.pdf

Choy, M., y Chang, G. (2014). Medidas macroprudenciales aplicadas en el Perú. Lima: Banco Central de Reserva del Perú. Recuperado de http://www.bcrp.gob.pe/docs/Publicaciones/Documentos-deTrabajo/2014/documento-de-trabajo-07-2014.pdf

Código de Conducta del Grupo Graña y Montero. (2018). Recuperado de http://www.granaymontero.com.pe/resources/files/Codigo_de_Conducta_v1.pdf

CONCAR . (2017). Procedimiento de Identificación de Peligros y Evaluación de Riesgos. Lima, Perú.

CONCAR. (2019). CONCAR. Recuperado de www.concar.com.pe

Concejo Nacional de Ciencia Tecnología e Innovación Tecnológica. (Julio de 2016). CONCYTEC. Recuperado de https://portal.concytec.gob.pe/index.php/publicaciones/politica-nacional-de-cti

CONCYTEC. (17 de 01 de 2016). CONCYTEC. Recuperado de http://portal.concytec.gob.pe/

Consejo Nacional de Ciencia, Tecnología e Innovación Tecnológica. (2016).

CONCYTEC. Recuperado de https://portal.concytec.gob.pe 
D’Alessio, F. (2015). El proceso estratégico. Un Enfoque de la gerencia. Lima: Pearson.

García Nieto, J. P. (2013). Consturye tu Web comercial: de la idea al negocio. Madrid: RA-MA.

GyM Ferrovías. (2018). Estadística de Incidentes con usuarios . Lima.

GyM Ferrovías. (2018). Plan de Seguridad Operacional. Lima.

GyM Ferrovías. (2019). Informe de Sostenibilidad 2018. Lima.

GyM Ferrovías;. (2019). Linea 1. Recuperado de https://www.lineauno.pe/estaciones/

Instituto Nacional de Estadística e Informática. (2017). INEI. Recuperado de (https://www.inei.gob.pe/estadisticas/indice-tematico/sociales/)

Instituto Nacional de Estadística e Informática. (2017). INEI. Recuperado de https://www.inei.gob.pe/estadisticas/indice-tematico/sociales/

Linea 1. (2019).

Mi Vivienda. (2017). Fondo Mi Vivienda. Recuperado de https://www.mivivienda.com.pe/PORTALWEB/inversionistas/pagina.aspx?idpa ge $=139$

Ministerio de Tansporte y Comunicaciones. (2015). Plan Nacional de Desarrollo Ferroviario. Lima.

Ministerio de Trabajo. (2010). MINTRA. Recuperado de http://www.mintra.gob.pe/archivos/file/estadisticas/peel/enaho/INFORME_AN UAL_EMPLEO_ENAHO_2010.pdf

Ministerio de Transportes y Comunicaciones. (2018). MTC. Recuperado de https://portal.mtc.gob.pe/transportes/aeronautica_civil/sistema_gestion/documen tos/SMS/9859_cons_es.pdf

Ministerio del Ambiente. (10 de Octubre de 2012). Ministerio del Ambiente. Recuperado de https://cdn.www.gob.pe/uploads/document/file/307801/EJESESTRATEGICOS-DE-LA-GESTION-AMBIENTAL.pdf

Ministerio del Ambiente. (24 de Agosto de 2019). MINAM. Recuperado de https://www.gob.pe/institucion/minam/noticias/50147-con-mas-de-150- 
acuerdos-culmina-proceso-emblematico-de-consulta-previa-de-la-propuesta-dereglamento-de-la-ley-marco-sobre-cambio-climatico

Organización Internacional de Normalización . (2018). ISO. Recuperado de https://www.iso.org/obp/ui\#iso:std:iso:31000:ed-2:v1:es

Porter, M. (2010). Ventaja competitiva: Creación y sostenibilidad de un rendimiento superior. Madrid: Ediciones Pirámide S.A.

Redación EC. (2 de Mayo de 2018). Metro de Lima: fue identificado el hombre que se lanzó sobre las vías del tren. El Comercio. Recuperado de https://elcomercio.pe/lima/sucesos/metro-lima-identifican-hombre-lanzo-viastren-noticia-516774

Teltronic. (2018). Recuperado de https://www.teltronic.es/productos/tetra/

Thorne, A. (02 de Noviembre de 2016). America Economía. Recuperado de https://www.americaeconomia.com/economia-mercados/finanzas/ministerio-definanzas-del-peru-medidas-fiscales-nos-permiten-acceder-fin 


\section{BIBLIOGRAFIA}

D’Alessio, F. (2015). El proceso estratégico. Un Enfoque de la gerencia. Lima: Pearson.

García Nieto, J. P. (2013). Consturye tu Web comercial: de la idea al negocio. Madrid: RA-MA. 
ANEXOS 
Anexo 1: Tiempo promedio en minutos de traslado entre estaciones

\begin{tabular}{|c|c|c|c|c|c|c|c|c|c|c|c|c|c|c|c|c|c|c|c|c|c|c|c|c|c|c|c|}
\hline \multirow{2}{*}{\multicolumn{2}{|c|}{$\begin{array}{l}\text { Tiempo } \\
\text { (min) }\end{array}$}} & \multirow[b]{2}{*}{ VES } & \multirow{3}{*}{$\frac{\text { PIN }}{2}$} & \multirow{3}{*}{$\frac{\text { PUM }}{4}$} & \multirow{3}{*}{$\begin{array}{l}\text { VMA } \\
6\end{array}$} & \multirow{3}{*}{$\frac{\text { MAU }}{8}$} & \multirow{3}{*}{$\frac{\text { SJU }}{10}$} & \multirow{3}{*}{$\frac{\text { ATO }}{12}$} & \multirow{3}{*}{$\frac{\mathrm{JCH}}{14}$} & \multirow{3}{*}{$\begin{array}{l}\text { AYA } \\
16\end{array}$} & \multirow{3}{*}{$\begin{array}{l}\text { CAB } \\
18\end{array}$} & \multirow{3}{*}{$\frac{\text { ANG }}{20}$} & \multirow{3}{*}{$\frac{\text { SBS }}{22}$} & \multicolumn{2}{|c|}{ DESTINO } & \multirow{3}{*}{$\frac{\text { GAM }}{28}$} & \multirow{3}{*}{$\frac{\mathrm{MIG}}{30}$} & \multirow{3}{*}{ ELA } & \multirow{3}{*}{$\frac{\text { PRE }}{34}$} & \multirow{3}{*}{$\frac{\text { CAA }}{36}$} & \multirow{3}{*}{$\frac{\text { PIR }}{38}$} & \multirow{3}{*}{$\begin{array}{l}\text { JAR } \\
40\end{array}$} & & & & & \\
\hline & & & & & & & & & & & & & & CUL & NAR & & & & & & & & & SCA & SMA & SRA & BAY \\
\hline & VES & 0 & & & & & & & & & & & & 24 & 26 & & & & & & & & 42 & 44 & 46 & 48 & 50 \\
\hline & PIN & 2 & 0 & 2 & 4 & 6 & 8 & 10 & 12 & 14 & 16 & 18 & 20 & 22 & 24 & 26 & 28 & 30 & 32 & 34 & 36 & 38 & 40 & 42 & 44 & 46 & 48 \\
\hline & PUM & 4 & 2 & 0 & 2 & 4 & 6 & 8 & 10 & 12 & 14 & 16 & 18 & 20 & 22 & 24 & 26 & 28 & 30 & 32 & 34 & 36 & 38 & 40 & 42 & 44 & 46 \\
\hline & VMA & 6 & 4 & 2 & 0 & 2 & 4 & 6 & 8 & 10 & 12 & 14 & 16 & 18 & 20 & 22 & 24 & 26 & 28 & 30 & 32 & 34 & 36 & 38 & 40 & 42 & 44 \\
\hline & MAU & 8 & 6 & 4 & 2 & 0 & 2 & 4 & 6 & 8 & 10 & 12 & 14 & 16 & 18 & 20 & 22 & 24 & 26 & 28 & 30 & 32 & 34 & 36 & 38 & 40 & 42 \\
\hline & SJU & 10 & 8 & 6 & 4 & 2 & 0 & 2 & 4 & 6 & 8 & 10 & 12 & 14 & 16 & 18 & 20 & 22 & 24 & 26 & 28 & 30 & 32 & 34 & 36 & 38 & 40 \\
\hline & ATO & 12 & 10 & 8 & 6 & 4 & 2 & 0 & 2 & 4 & 6 & 8 & 10 & 12 & 14 & 16 & 18 & 20 & 22 & 24 & 26 & 28 & 30 & 32 & 34 & 36 & 38 \\
\hline & $\mathrm{JCH}$ & 14 & 12 & 10 & 8 & 6 & 4 & 2 & 0 & 2 & 4 & 6 & 8 & 10 & 12 & 14 & 16 & 18 & 20 & 22 & 24 & 26 & 28 & 30 & 32 & 34 & 36 \\
\hline & AYA & 16 & 14 & 12 & 10 & 8 & 6 & 4 & 2 & 0 & 2 & 4 & 6 & 8 & 10 & 12 & 14 & 16 & 18 & 20 & 22 & 24 & 26 & 28 & 30 & 32 & 34 \\
\hline & CAB & 18 & 16 & 14 & 12 & 10 & 8 & 6 & 4 & 2 & 0 & 2 & 4 & 6 & 8 & 10 & 12 & 14 & 16 & 18 & 20 & 22 & 24 & 26 & 28 & 30 & 32 \\
\hline & ANG & 20 & 18 & 16 & 14 & 12 & 10 & 8 & 6 & 4 & 2 & 0 & 2 & 4 & 6 & 8 & 10 & 12 & 14 & 16 & 18 & 20 & 22 & 24 & 26 & 28 & 30 \\
\hline $\mathbf{Z}$ & SBS & 22 & 20 & 18 & 16 & 14 & 12 & 10 & 8 & 6 & 4 & 2 & 0 & 2 & 4 & 6 & 8 & 10 & 12 & 14 & 16 & 18 & 20 & 22 & 24 & 26 & 28 \\
\hline 뎁 & CUL & 24 & 22 & 20 & 18 & 16 & 14 & 12 & 10 & 8 & 6 & 4 & 2 & 0 & 2 & 4 & 6 & 8 & 10 & 12 & 14 & 16 & 18 & 20 & 22 & 24 & 26 \\
\hline$\underline{z}$ & NAR & 26 & 24 & 22 & 20 & 18 & 16 & 14 & 12 & 10 & 8 & 6 & 4 & 2 & 0 & 2 & 4 & 6 & 8 & 10 & 12 & 14 & 16 & 18 & 20 & 22 & 24 \\
\hline 0 & GAM & 28 & 26 & 24 & 22 & 20 & 18 & 16 & 14 & 12 & 10 & 8 & 6 & 4 & 2 & 0 & 2 & 4 & 6 & 8 & 10 & 12 & 14 & 16 & 18 & 20 & 22 \\
\hline & MIG & 30 & 28 & 26 & 24 & 22 & 20 & 18 & 16 & 14 & 12 & 10 & 8 & 6 & 4 & 2 & 0 & 2 & 4 & 6 & 8 & 10 & 12 & 14 & 16 & 18 & 20 \\
\hline & ELA & 32 & 30 & 28 & 26 & 24 & 22 & 20 & 18 & 16 & 14 & 12 & 10 & 8 & 6 & 4 & 2 & 0 & 2 & 4 & 6 & 8 & 10 & 12 & 14 & 16 & 18 \\
\hline & PRE & 34 & 32 & 30 & 28 & 26 & 24 & 22 & 20 & 18 & 16 & 14 & 12 & 10 & 8 & 6 & 4 & 2 & 0 & 2 & 4 & 6 & 8 & 10 & 12 & 14 & 16 \\
\hline & CAA & 36 & 34 & 32 & 30 & 28 & 26 & 24 & 22 & 20 & 18 & 16 & 14 & 12 & 10 & 8 & 6 & 4 & 2 & 0 & 2 & 4 & 6 & 8 & 10 & 12 & 14 \\
\hline & PIR & 38 & 36 & 34 & 32 & 30 & 28 & 26 & 24 & 22 & 20 & 18 & 16 & 14 & 12 & 10 & 8 & 6 & 4 & 2 & 0 & 2 & 4 & 6 & 8 & 10 & 12 \\
\hline & JAR & 40 & 38 & 36 & 34 & 32 & 30 & 28 & 26 & 24 & 22 & 20 & 18 & 16 & 14 & 12 & 10 & 8 & 6 & 4 & 2 & 0 & 2 & 4 & 6 & 8 & 10 \\
\hline & POS & 42 & 40 & 38 & 36 & 34 & 32 & 30 & 28 & 26 & 24 & 22 & 20 & 18 & 16 & 14 & 12 & 10 & 8 & 6 & 4 & 2 & 0 & 2 & 4 & 6 & 8 \\
\hline & SCA & 44 & 42 & 40 & 38 & 36 & 34 & 32 & 30 & 28 & 26 & 24 & 22 & 20 & 18 & 16 & 14 & 12 & 10 & 8 & 6 & 4 & 2 & 0 & 2 & 4 & 6 \\
\hline & SMA & 46 & 44 & 42 & 40 & 38 & 36 & 34 & 32 & 30 & 28 & 26 & 24 & 22 & 20 & 18 & 16 & 14 & 12 & 10 & 8 & 6 & 4 & 2 & 0 & 2 & 4 \\
\hline & SRA & 48 & 46 & 44 & 42 & 40 & 38 & 36 & 34 & 32 & 30 & 28 & 26 & 24 & 22 & 20 & 18 & 16 & 14 & 12 & 10 & 8 & 6 & 4 & 2 & 0 & 2 \\
\hline & BAY & 50 & 48 & 46 & 44 & 42 & 40 & 38 & 36 & 34 & 32 & 30 & 28 & 26 & 24 & 22 & 20 & 18 & 16 & 14 & 12 & 10 & 8 & 6 & 4 & 2 & 0 \\
\hline
\end{tabular}

Elaboración Propia 


\section{Anexo 2: Tablas de optimización de tiempos según franja horaria}

Tabla de optimización de tiempos entre estaciones en minutos L-V Hora Punta Mañana

\begin{tabular}{|c|c|c|c|c|c|c|c|c|c|c|c|c|c|c|c|c|c|c|c|c|c|c|c|c|c|c|c|c|}
\hline \multirow{3}{*}{\multicolumn{2}{|c|}{$\begin{array}{l}\text { L-V hora } \\
\text { punta } \\
\text { mañana }\end{array}$}} & \multirow{2}{*}{\multicolumn{26}{|c|}{ DESTINO }} & \multirow[t]{3}{*}{ Minimizar } \\
\hline & & \multirow{2}{*}{$\begin{array}{l}3 \\
\text { VES }\end{array}$} & \multirow{2}{*}{$\begin{array}{l}2 \\
\text { PIN }\end{array}$} & \multirow{2}{*}{$\begin{array}{l}0 \\
\text { PUM }\end{array}$} & \multirow{2}{*}{$\begin{array}{l}3 \\
\text { VMA }\end{array}$} & \multirow{2}{*}{$\frac{2}{M A U}$} & \multirow{2}{*}{$\begin{array}{l}1 \\
\text { SJU }\end{array}$} & \multirow{2}{*}{$\frac{10}{\text { ATO }}$} & \multirow{2}{*}{$\begin{array}{l}6 \\
\mathrm{JCH}\end{array}$} & \multirow{2}{*}{$\begin{array}{l}5 \\
\text { AYA }\end{array}$} & \multirow{2}{*}{$\begin{array}{l}1 \\
\mathrm{CAB}\end{array}$} & \multirow{2}{*}{$\begin{array}{l}10 \\
\text { ANC }\end{array}$} & \multirow{2}{*}{$\begin{array}{l}8 \\
\text { SBS }\end{array}$} & \multirow{2}{*}{$\begin{array}{l}13 \\
\mathrm{CUL}\end{array}$} & \multirow{2}{*}{$\begin{array}{l}3 \\
\mathrm{NA}\end{array}$} & \multirow{2}{*}{$\begin{array}{l}6 \\
\text { GAM }\end{array}$} & \multirow{2}{*}{$\begin{array}{l}15 \\
\mathrm{MIG}\end{array}$} & \multirow{2}{*}{$\begin{array}{l}5 \\
\text { ELA }\end{array}$} & & 18 & 0 & 10 & & & & & & \\
\hline & & & & & & & & & & & & & & & & & & & PRE & $\mathrm{CAA}$ & PIR & JAR & POS & $\mathrm{SCA}$ & SMA & SRA & BAY & \\
\hline & VES & 0 & 4 & 0 & 18 & 16 & 0 & 0 & 0 & 0 & 0 & 0 & 0 & 0 & 0 & 0 & 0 & 0 & 0 & 0 & 0 & 0 & 0 & 0 & 0 & 0 & 0 & 38 \\
\hline & PIN & 6 & 0 & 0 & 12 & 12 & 0 & 0 & 0 & 0 & 0 & 0 & 0 & 0 & 0 & 0 & 0 & 0 & 0 & 0 & 0 & 0 & 0 & 0 & 0 & 0 & 0 & 30 \\
\hline & PUM & 12 & 4 & 0 & 6 & 8 & 0 & 0 & 0 & 0 & 0 & 0 & 0 & 0 & 0 & 0 & 0 & 0 & 0 & 0 & 0 & 0 & 0 & 0 & 0 & 0 & 0 & 30 \\
\hline & VMA & 18 & 8 & 0 & 0 & 4 & 0 & 0 & 0 & 0 & 0 & 0 & 0 & 0 & 0 & 0 & 0 & 0 & 0 & 0 & 0 & 0 & 0 & 0 & 0 & 0 & 0 & 30 \\
\hline & MAU & 24 & 12 & 0 & 6 & 0 & 0 & 0 & 0 & 0 & 0 & 0 & 0 & 0 & 0 & 0 & 0 & 0 & 0 & 0 & 0 & 0 & 0 & 0 & 0 & 0 & 0 & 42 \\
\hline & SJU & 0 & 0 & 0 & 0 & 0 & 0 & 20 & 24 & 30 & 8 & 0 & 0 & 0 & 0 & 0 & 0 & 0 & 0 & 0 & 0 & 0 & 0 & 0 & 0 & 0 & 0 & 82 \\
\hline & ATO & 0 & 0 & 0 & 0 & 0 & 2 & 0 & 12 & 20 & 6 & 0 & 0 & 0 & 0 & 0 & 0 & 0 & 0 & 0 & 0 & 0 & 0 & 0 & 0 & 0 & 0 & 40 \\
\hline & $\mathrm{JCH}$ & 0 & 0 & 0 & 0 & 0 & 4 & 20 & 0 & 10 & 4 & 0 & 0 & 0 & 0 & 0 & 0 & 0 & 0 & 0 & 0 & 0 & 0 & 0 & 0 & 0 & 0 & 38 \\
\hline & AYA & 0 & 0 & 0 & 0 & 0 & 6 & 40 & 12 & 0 & 2 & 0 & 0 & 0 & 0 & 0 & 0 & 0 & 0 & 0 & 0 & 0 & 0 & 0 & 0 & 0 & 0 & 60 \\
\hline & $\mathrm{CAB}$ & 0 & 0 & 0 & 0 & 0 & 8 & 60 & 24 & 10 & 0 & 0 & 0 & 0 & 0 & 0 & 0 & 0 & 0 & 0 & 0 & 0 & 0 & 0 & 0 & 0 & 0 & 102 \\
\hline & ANG & 0 & 0 & 0 & 0 & 0 & 0 & 0 & 0 & 0 & 0 & 0 & 16 & 52 & 18 & 48 & 0 & 0 & 0 & 0 & 0 & 0 & 0 & 0 & 0 & 0 & 0 & 134 \\
\hline & SBS & 0 & 0 & 0 & 0 & 0 & 0 & 0 & 0 & 0 & 0 & 20 & 0 & 26 & 12 & 36 & 0 & 0 & 0 & 0 & 0 & 0 & 0 & 0 & 0 & 0 & 0 & 94 \\
\hline & CUL & 0 & 0 & 0 & 0 & 0 & 0 & 0 & 0 & 0 & 0 & 40 & 16 & 0 & 6 & 24 & 0 & 0 & 0 & 0 & 0 & 0 & 0 & 0 & 0 & 0 & 0 & 86 \\
\hline & NAR & 0 & 0 & 0 & 0 & 0 & 0 & 0 & 0 & 0 & 0 & 60 & 32 & 26 & 0 & 12 & 0 & 0 & 0 & 0 & 0 & 0 & 0 & 0 & 0 & 0 & 0 & 130 \\
\hline & GAM & 0 & 0 & 0 & 0 & 0 & 0 & 0 & 0 & 0 & 0 & 80 & 48 & 52 & 6 & 0 & 0 & 0 & 0 & 0 & 0 & 0 & 0 & 0 & 0 & 0 & 0 & 186 \\
\hline & MIG & 0 & 0 & 0 & 0 & 0 & 0 & 0 & 0 & 0 & 0 & 0 & 0 & 0 & 0 & 0 & 0 & 10 & 24 & 108 & 0 & 0 & 0 & 0 & 0 & 0 & 0 & 142 \\
\hline & ELA & 0 & 0 & 0 & 0 & 0 & 0 & 0 & 0 & 0 & 0 & 0 & 0 & 0 & 0 & 0 & 30 & 0 & 12 & 72 & 0 & 0 & 0 & 0 & 0 & 0 & 0 & 114 \\
\hline & PRE & 0 & 0 & 0 & 0 & 0 & 0 & 0 & 0 & 0 & 0 & 0 & 0 & 0 & 0 & 0 & 60 & 10 & 0 & 36 & 0 & 0 & 0 & 0 & 0 & 0 & 0 & 106 \\
\hline & CAA & 0 & 0 & 0 & 0 & 0 & 0 & 0 & 0 & 0 & 0 & 0 & 0 & 0 & 0 & 0 & 90 & 20 & 12 & 0 & 0 & 0 & 0 & 0 & 0 & 0 & 0 & 122 \\
\hline & PIR & 0 & 0 & 0 & 0 & 0 & 0 & 0 & 0 & 0 & 0 & 0 & 0 & 0 & 0 & 0 & 120 & 30 & 24 & 36 & 0 & 0 & 0 & 0 & 0 & 0 & 0 & 210 \\
\hline & JAR & 0 & 0 & 0 & 0 & 0 & 0 & 0 & 0 & 0 & 0 & 0 & 0 & 0 & 0 & 0 & 0 & 0 & 0 & 0 & 0 & 0 & 0 & 12 & 12 & 8 & 70 & 102 \\
\hline & POS & 0 & 0 & 0 & 0 & 0 & 0 & 0 & 0 & 0 & 0 & 0 & 0 & 0 & 0 & 0 & 0 & 0 & 0 & 0 & 0 & 0 & 0 & 6 & 8 & 6 & 56 & 76 \\
\hline & SCA & 0 & 0 & 0 & 0 & 0 & 0 & 0 & 0 & 0 & 0 & 0 & 0 & 0 & 0 & 0 & 0 & 0 & 0 & 0 & 0 & 0 & 0 & 0 & 4 & 4 & 42 & 50 \\
\hline ZI & SMA & 0 & 0 & 0 & 0 & 0 & 0 & 0 & 0 & 0 & 0 & 0 & 0 & 0 & 0 & 0 & 0 & 0 & 0 & 0 & 0 & 0 & 0 & 6 & 0 & 2 & 28 & 36 \\
\hline 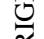 & SRA & 0 & 0 & 0 & 0 & 0 & 0 & 0 & 0 & 0 & 0 & 0 & 0 & 0 & 0 & 0 & 0 & 0 & 0 & 0 & 0 & 0 & 0 & 12 & 4 & 0 & 14 & 30 \\
\hline 용 & BAY & 0 & 0 & 0 & 0 & 0 & 0 & 0 & 0 & 0 & 0 & 0 & 0 & 0 & 0 & 0 & 0 & 0 & 0 & 0 & 0 & 0 & 0 & 18 & 8 & 2 & 0 & 28 \\
\hline
\end{tabular}

Elaboración Propia 
Tabla de optimización de tiempo entre estaciones en minutos L-V Hora Valle

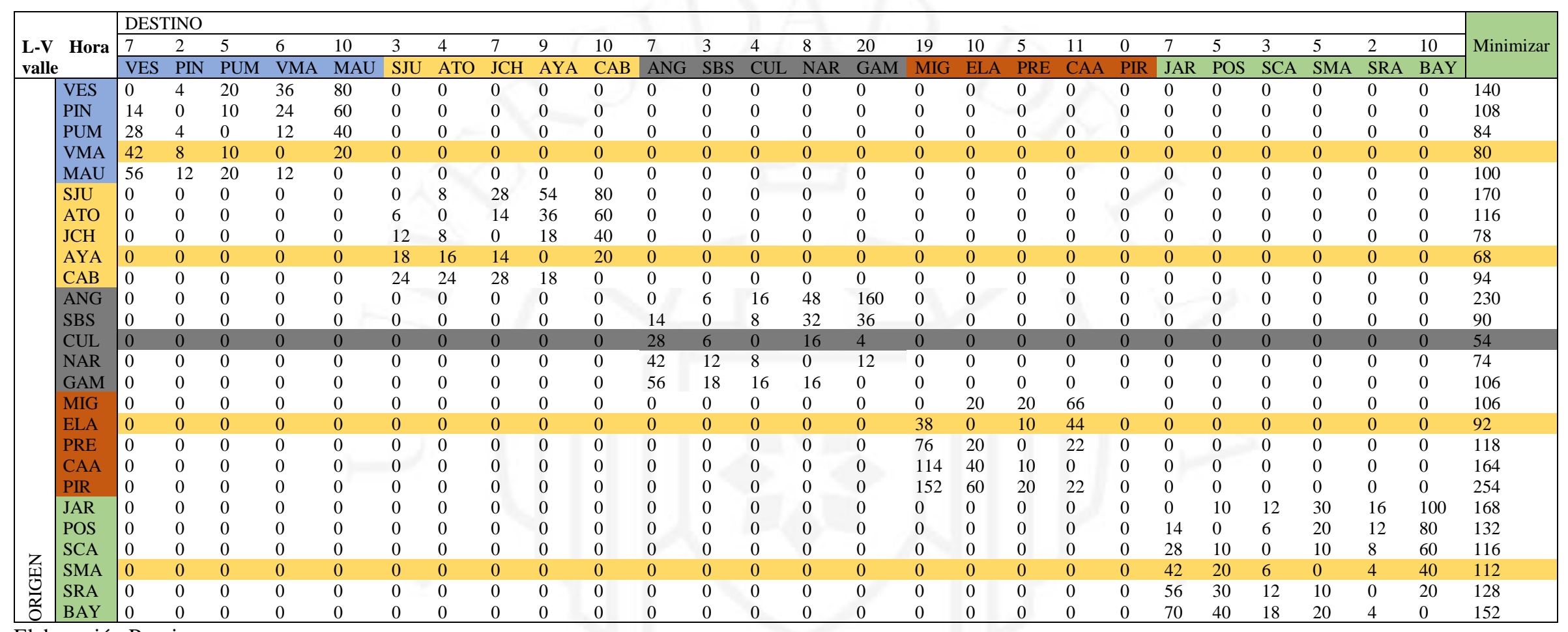

Elaboración Propia 
Tabla de optimización de tiempos entre estaciones en minutos L-V Hora Punta Noche

\begin{tabular}{|c|c|c|c|c|c|c|c|c|c|c|c|c|c|c|c|c|c|c|c|c|c|c|c|c|c|c|c|c|}
\hline \multirow{3}{*}{\multicolumn{2}{|c|}{$\begin{array}{l}\text { L-V Hora } \\
\text { punta noche }\end{array}$}} & \multicolumn{26}{|c|}{ DESTINO } & \multirow[t]{3}{*}{ Minimizar } \\
\hline & & \multirow{2}{*}{\begin{tabular}{|l|}
2 \\
VES \\
\end{tabular}} & \multirow{2}{*}{\begin{tabular}{|l|}
0 \\
PIN \\
\end{tabular}} & \multirow{2}{*}{\begin{tabular}{|l|}
2 \\
PUM \\
\end{tabular}} & \multirow{2}{*}{\begin{tabular}{|l|}
1 \\
VMA \\
\end{tabular}} & \multirow{2}{*}{\begin{tabular}{|l|}
4 \\
$\mathrm{MAU}$ \\
\end{tabular}} & \multirow{2}{*}{\begin{tabular}{|l|}
4 \\
SJU \\
\end{tabular}} & \multirow{2}{*}{$\begin{array}{ll}1 \\
\text { ATO }\end{array}$} & \multirow{2}{*}{\begin{tabular}{|l|}
9 \\
$\mathrm{JCH}$ \\
\end{tabular}} & \multirow{2}{*}{\begin{tabular}{|l|}
2 \\
AYA \\
\end{tabular}} & \multirow{2}{*}{$\begin{array}{l}2 \\
\mathrm{CAB} \\
\end{array}$} & \multirow{2}{*}{\begin{tabular}{|l|}
15 \\
ANG \\
\end{tabular}} & \multirow{2}{*}{\begin{tabular}{|l|}
5 \\
SBS \\
\end{tabular}} & \multirow{2}{*}{\begin{tabular}{|l|}
10 \\
CUL \\
\end{tabular}} & \multirow{2}{*}{$\begin{array}{l}9 \\
\text { NAR } \\
\end{array}$} & \multirow{2}{*}{$\begin{array}{l}10 \\
\text { GAM }\end{array}$} & \multirow{2}{*}{$\begin{array}{l}7 \\
\mathrm{MIG} \\
\end{array}$} & & 4 & 11 & 0 & 13 & 2 & 4 & 2 & 1 & 1 & \\
\hline & & & & & & & & & & & & & & & & & & & PRE & CAA & PIR & JAR & POS & SCA & SMA & SRA & BAY & \\
\hline & VES & 0 & 0 & \begin{tabular}{|l|}
8 \\
\end{tabular} & 6 & 32 & 0 & 0 & \begin{tabular}{|l|}
0 \\
\end{tabular} & \begin{tabular}{|l|}
0 \\
\end{tabular} & 0 & \begin{tabular}{|l|l|}
0 \\
\end{tabular} & \begin{tabular}{|l|}
0 \\
\end{tabular} & \begin{tabular}{|l|}
0 \\
\end{tabular} & 0 & \begin{tabular}{|l|l}
0 \\
\end{tabular} & \begin{tabular}{|l|}
0 \\
\end{tabular} & 0 & 0 & \begin{tabular}{|l|}
0 \\
\end{tabular} & 0 & 0 & 0 & 0 & \begin{tabular}{|l|l|}
0 \\
\end{tabular} & $\begin{array}{ll}0 \\
\end{array}$ & $\begin{array}{l}0 \\
\end{array}$ & 46 \\
\hline & PIN & 4 & 0 & 4 & 4 & 24 & 0 & 0 & 0 & 0 & 0 & 0 & 0 & 0 & 0 & 0 & 0 & 0 & 0 & 0 & 0 & 0 & 0 & 0 & 0 & 0 & 0 & 36 \\
\hline & PUM & 8 & 0 & 0 & 2 & 16 & 0 & 0 & 0 & 0 & 0 & 0 & 0 & 0 & 0 & 0 & 0 & 0 & 0 & 0 & 0 & 0 & 0 & 0 & 0 & 0 & 0 & 26 \\
\hline & VMA & 12 & 0 & 4 & 0 & 8 & 0 & 0 & 0 & 0 & 0 & 0 & 0 & 0 & 0 & 0 & 0 & 0 & 0 & 0 & 0 & 0 & 0 & 0 & 0 & 0 & 0 & 24 \\
\hline & MAU & 16 & 0 & 8 & 2 & 0 & 0 & 0 & 0 & 0 & 0 & 0 & 0 & 0 & 0 & 0 & 0 & 0 & 0 & 0 & 0 & 0 & 0 & 0 & 0 & 0 & 0 & 26 \\
\hline & SJU & 0 & 0 & 0 & 0 & 0 & 0 & 2 & 36 & 12 & 16 & 0 & 0 & 0 & 0 & 0 & 0 & 0 & 0 & 0 & 0 & 0 & 0 & 0 & 0 & 0 & 0 & 66 \\
\hline & ATO & 0 & 0 & 0 & 0 & 0 & 8 & 0 & 18 & 8 & 12 & 0 & 0 & 0 & 0 & 0 & 0 & 0 & 0 & 0 & 0 & 0 & 0 & 0 & 0 & 0 & 0 & 46 \\
\hline & \begin{tabular}{|l|}
$\mathrm{JCH}$ \\
\end{tabular} & 0 & 0 & 0 & 0 & 0 & 16 & 2 & 0 & 4 & 8 & 0 & 0 & 0 & 0 & 0 & 0 & 0 & 0 & 0 & 0 & 0 & 0 & 0 & 0 & 0 & 0 & 30 \\
\hline & \begin{tabular}{|l|l} 
AYA \\
\end{tabular} & 0 & 0 & 0 & 0 & 0 & 24 & 4 & 18 & 0 & 4 & 0 & 0 & 0 & 0 & 0 & 0 & 0 & 0 & 0 & 0 & 0 & 0 & 0 & 0 & 0 & 0 & 50 \\
\hline & CAB & 0 & 0 & 0 & 0 & 0 & 32 & 6 & 36 & 4 & 0 & 0 & 16 & 52 & 18 & 48 & 0 & 0 & 0 & 0 & 0 & 0 & 0 & 0 & 0 & 0 & 0 & 212 \\
\hline & ANG & 0 & 0 & 0 & 0 & 0 & \begin{tabular}{|l|}
0 \\
\end{tabular} & 0 & \begin{tabular}{|l|}
0 \\
\end{tabular} & 0 & 0 & \begin{tabular}{|l|}
0 \\
\end{tabular} & 10 & 40 & 54 & 80 & 0 & 0 & 0 & 0 & 0 & 0 & 0 & 0 & 0 & 0 & 0 & 184 \\
\hline & SBS & 0 & 0 & 0 & 0 & 0 & 0 & 0 & 0 & 0 & 0 & 30 & 0 & 20 & 36 & 60 & 0 & 0 & 0 & 0 & 0 & 0 & 0 & 0 & 0 & 0 & 0 & 146 \\
\hline & CUL & 0 & 0 & 0 & 0 & 0 & 0 & 0 & 0 & 0 & 0 & 60 & 10 & 0 & 18 & 40 & 0 & 0 & 0 & 0 & 0 & 0 & 0 & 0 & 0 & 0 & 0 & 128 \\
\hline & $\begin{array}{l}\text { NAR } \\
\end{array}$ & 0 & 0 & 0 & 0 & 0 & 0 & 0 & 0 & 0 & 0 & 90 & 20 & 20 & 0 & 20 & 0 & 0 & 0 & 0 & 0 & 0 & 0 & 0 & 0 & 0 & 0 & 150 \\
\hline & GAM & 0 & 0 & 0 & 0 & 0 & 0 & 0 & 0 & 0 & 0 & 120 & 30 & 40 & 18 & 0 & 0 & \begin{tabular}{|l|}
10 \\
\end{tabular} & 24 & 108 & 0 & 0 & 0 & 0 & 0 & 0 & 0 & 350 \\
\hline & MIG & 0 & 0 & 0 & 0 & 0 & 0 & 0 & 0 & 0 & 0 & $\begin{array}{l}0 \\
\end{array}$ & \begin{tabular}{ll|}
0 \\
\end{tabular} & $\begin{array}{l}0 \\
\end{array}$ & $\begin{array}{ll}0 \\
\end{array}$ & 0 & 0 & 8 & 16 & 66 & 0 & 0 & 0 & 0 & 0 & 0 & 0 & 90 \\
\hline & ELA & 0 & 0 & 0 & 0 & 0 & 0 & 0 & 0 & 0 & 0 & 0 & 0 & 0 & 0 & 0 & 14 & 0 & 8 & 44 & 0 & 0 & 0 & 0 & 0 & 0 & 0 & 66 \\
\hline & PRE & 0 & 0 & 0 & 0 & 0 & 0 & 0 & 0 & 0 & 0 & 0 & 0 & 0 & 0 & 0 & 28 & 8 & 0 & 22 & 0 & 0 & 0 & 0 & 0 & 0 & 0 & 58 \\
\hline & CAA & 0 & 0 & 0 & 0 & 0 & 0 & 0 & 0 & 0 & 0 & 0 & 0 & 0 & 0 & 0 & 42 & 16 & 8 & 0 & 0 & 0 & 0 & 0 & 0 & 0 & 0 & 66 \\
\hline & PIR & 0 & 0 & 0 & 0 & 0 & 0 & 0 & 0 & 0 & 0 & 0 & 0 & 0 & 0 & 0 & 56 & 24 & 16 & 22 & 0 & 0 & 0 & 0 & 0 & 0 & 0 & 118 \\
\hline & \begin{tabular}{|l|} 
JAR \\
\end{tabular} & 0 & 0 & 0 & 0 & 0 & 0 & 0 & 0 & 0 & 0 & 0 & 0 & 0 & 0 & 0 & 0 & \begin{tabular}{|l|}
0 \\
\end{tabular} & 0 & \begin{tabular}{|l|}
0 \\
\end{tabular} & 0 & 0 & 4 & 16 & 12 & 8 & 10 & 50 \\
\hline & \begin{tabular}{|l|} 
POS \\
\end{tabular} & 0 & 0 & 0 & 0 & 0 & 0 & 0 & 0 & 0 & 0 & 0 & 0 & 0 & 0 & 0 & 0 & 0 & 0 & 0 & 0 & 26 & 0 & 8 & 8 & 6 & 8 & 56 \\
\hline & SCA & 0 & 0 & 0 & 0 & 0 & 0 & 0 & 0 & 0 & 0 & 0 & 0 & 0 & 0 & 0 & 0 & 0 & 0 & 0 & 0 & 52 & 4 & 0 & 4 & 4 & 6 & 70 \\
\hline ZI工 & SMA & 0 & 0 & 0 & 0 & 0 & 0 & 0 & 0 & 0 & 0 & 0 & 0 & 0 & 0 & 0 & 0 & 0 & 0 & 0 & 0 & 6 & 4 & 2 & 0 & 2 & 4 & 18 \\
\hline$\widetilde{O}$ & \begin{tabular}{|l|} 
SRA \\
\end{tabular} & 0 & 0 & 0 & 0 & 0 & \begin{tabular}{|l|}
0 \\
\end{tabular} & 0 & 0 & 0 & 0 & 0 & 0 & 0 & 0 & 0 & \begin{tabular}{|l|}
0 \\
\end{tabular} & 0 & 0 & 0 & 0 & \begin{tabular}{|l|}
104 \\
\end{tabular} & 12 & 16 & 4 & 0 & 2 & 138 \\
\hline है & BAY & 0 & 0 & 0 & 0 & 0 & $\begin{array}{ll}0 \\
\end{array}$ & 0 & 0 & 0 & 0 & 0 & 0 & 0 & 0 & 0 & 0 & 0 & 0 & 0 & 0 & 130 & 16 & 24 & 8 & 2 & 0 & 180 \\
\hline
\end{tabular}

Elaboración Propia 
Tabla de optimización de tiempos entre estaciones en minutos sábados todo el día

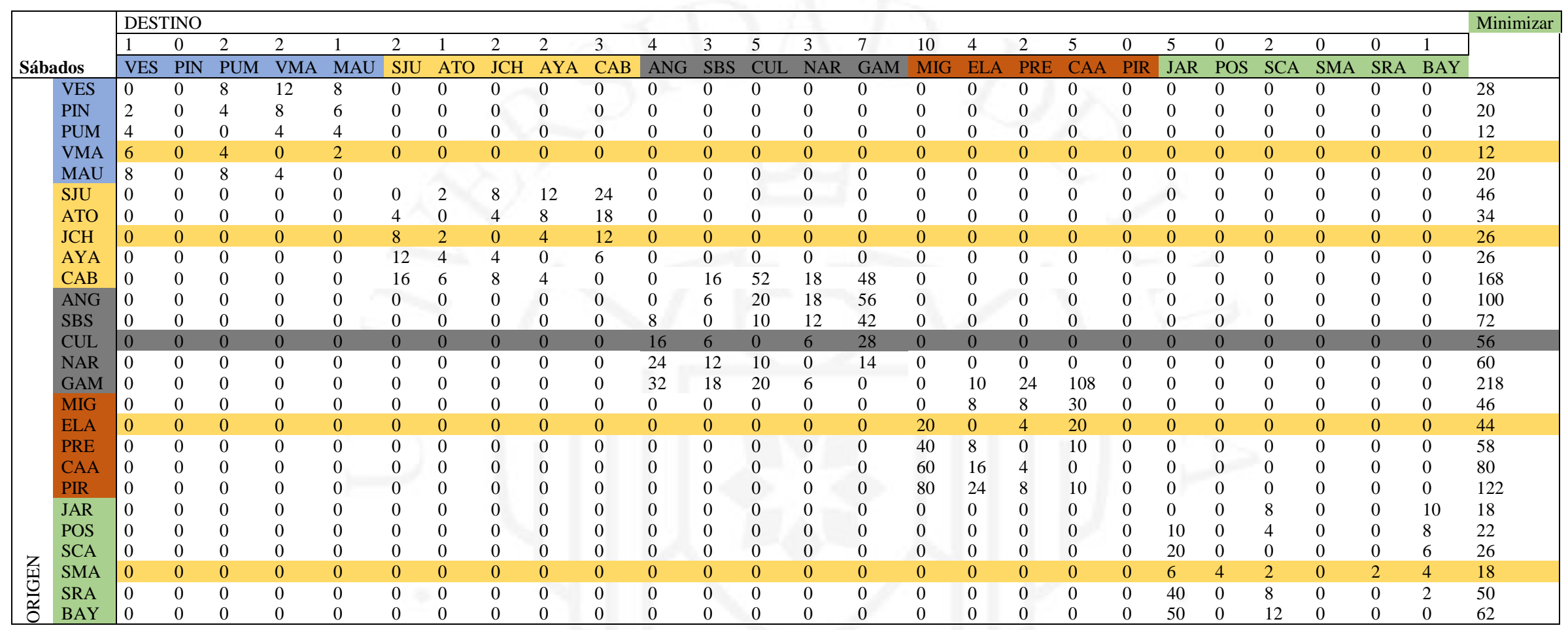

Elaboración Propia 
Tabla de optimización de tiempos entre estaciones en minutos domingo todo el día

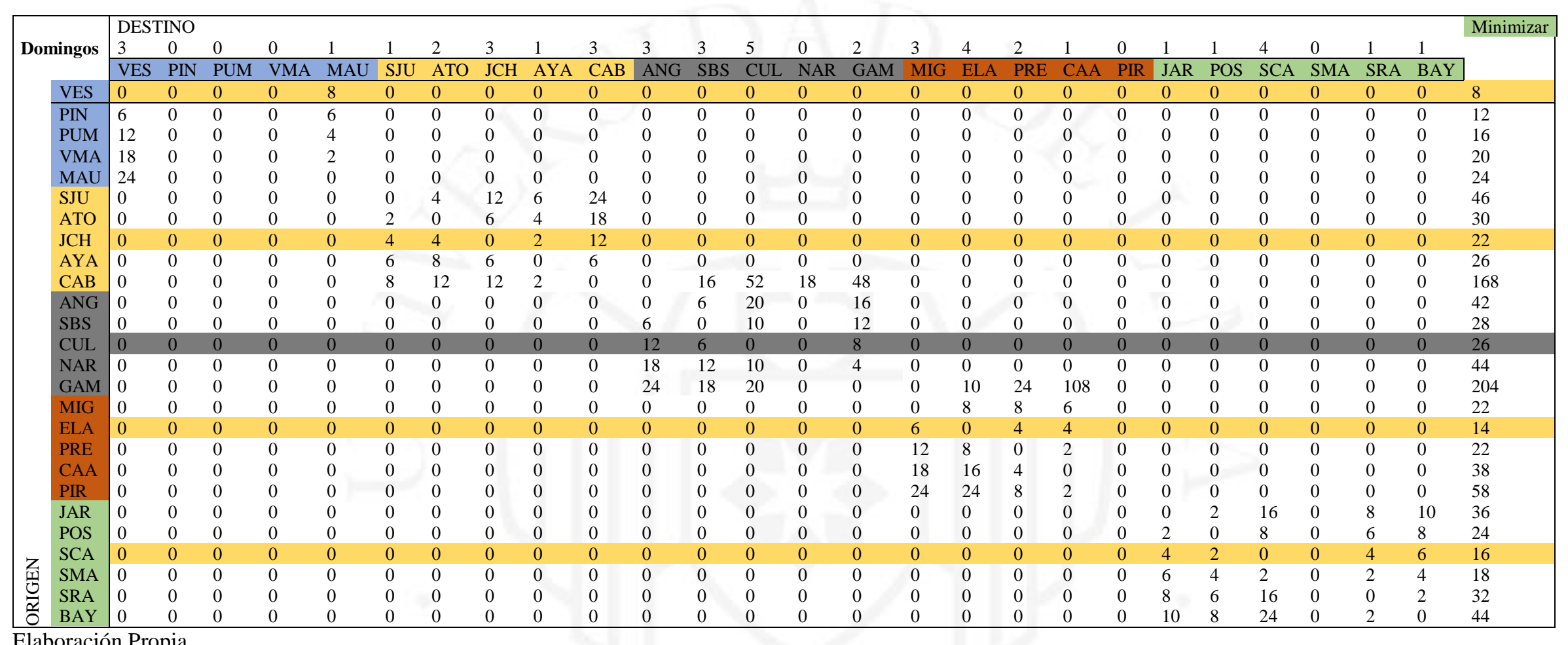

Elaboración Propia 